University of Massachusetts Amherst

ScholarWorks@UMass Amherst

Doctoral Dissertations 1896 - February 2014

$1-1-2008$

\title{
A defense of a particularist research program.
}

Uri D. Leibowitz

University of Massachusetts Amherst

Follow this and additional works at: https://scholarworks.umass.edu/dissertations_1

\section{Recommended Citation}

Leibowitz, Uri D., "A defense of a particularist research program." (2008). Doctoral Dissertations 1896 February 2014. 2433.

https://doi.org/10.7275/062f-8g53 https://scholarworks.umass.edu/dissertations_1/2433

This Open Access Dissertation is brought to you for free and open access by ScholarWorks@UMass Amherst. It has been accepted for inclusion in Doctoral Dissertations 1896 - February 2014 by an authorized administrator of ScholarWorks@UMass Amherst. For more information, please contact scholarworks@library.umass.edu. 


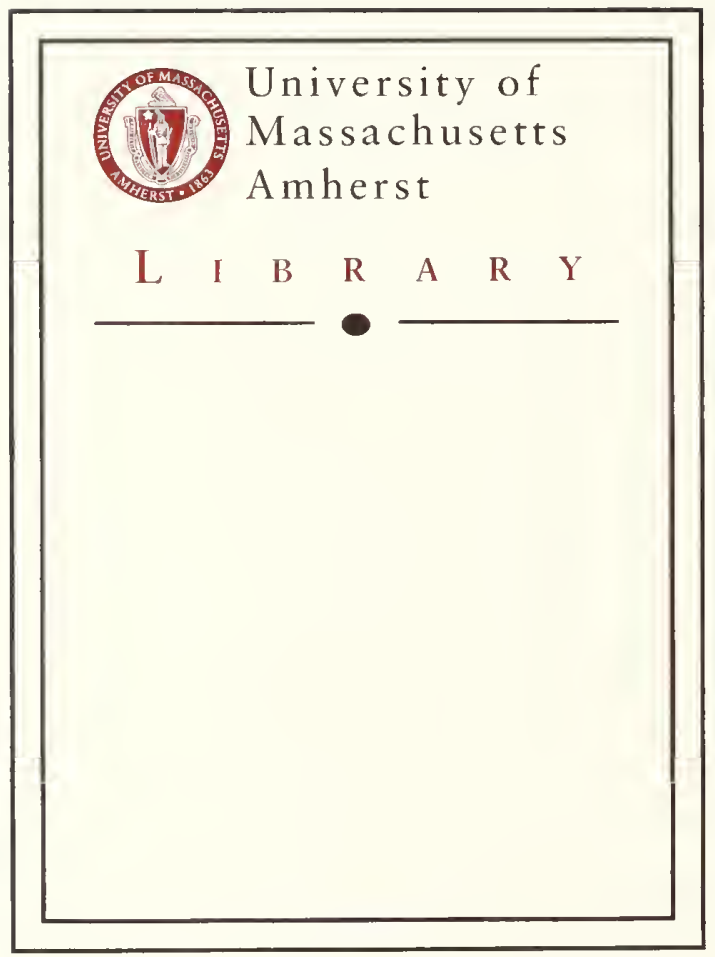


Digitized by the Internet Archive in 2015 



This is an authorized facsimile, made from the microfilm master copy of the original dissertation or master thesis published by UMI.

The bibliographic information for this thesis is contained in UMI's Dissertation Abstracts database, the only central source for accessing almost every doctoral dissertation accepted in North America since 1861.

\section{UMI
Dissertation
Services}

\section{From:Pro Guest}

300 North Zeeb Road

P O. Box 1346

Ann Arbor. Michıgan 48106-1346 USA

$8005210600 \quad 7347614700$

web unw il proquest com 



\title{
A DEFENSE OF A PARTICULARIST RESEARCH PROGRAM
}

\author{
A Dissertation Presented \\ by \\ URI D. LEIBOWITZ
}

\begin{abstract}
Submitted to the Graduate School of the University of Massachusetts Amherst in partial fulfillment of the requirements for the degree of

DOCTOR OF PHILOSOPHY
\end{abstract}

September 2008

Department of Philosophy 
UMI Number: 3336984

\title{
INFORMATION TO USERS
}

The quality of this reproduction is dependent upon the quality of the copy submitted. Broken or indistinct print, colored or poor quality illustrations and photographs, print bleed-through, substandard margins, and improper alignment can adversely affect reproduction.

In the unlikely event that the author did not send a complete manuscript and there are missing pages, these will be noted. Also, if unauthorized copyright material had to be removed, a note will indicate the deletion.

\section{UMI}

UMI Microform 3336984

Copyright 2009 by ProQuest LLC

All rights reserved. This microform edition is protected against unauthorized copying under Title 17, United States Code.

\author{
ProQuest LLC \\ 789 East Eisenhower Parkway \\ P.O. Box 1346 \\ Ann Arbor, MI 48106-1346
}


(1) Copyright by Uri D. Leibowitz 2008

All Rights Reserved 


\title{
A DEFENSE OF A PARTICUIARIST RESEARCH PROGRAM
}

\author{
A Dissertation Presented \\ by \\ URI D. LEIBOWITZ
}

Approved as to style and content by:

Gatreth B. Matthews, Chair

Fred Feldman. Member

Hilary Kornblith, Member

Lyn Frazier, Member

Phillip Bricker, Department Head

Department of Philosophy 


\section{A DEFENSE OF A PARTICULARIST RESEARCH PROGRAM}

A Dissertation Presented

by

URI D. LEIBOWITZ

Approved as to style and content by:

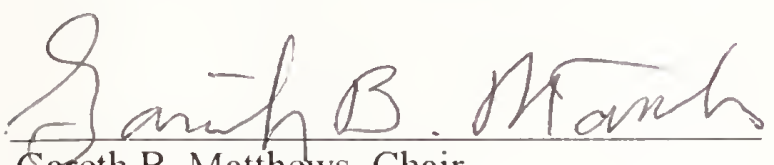

Gareth B. Matthews, Chair

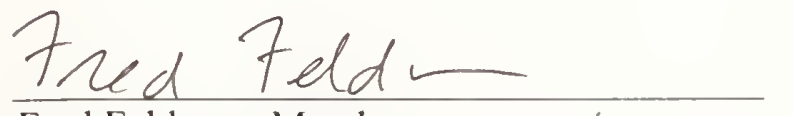

Fred Feldman, Member
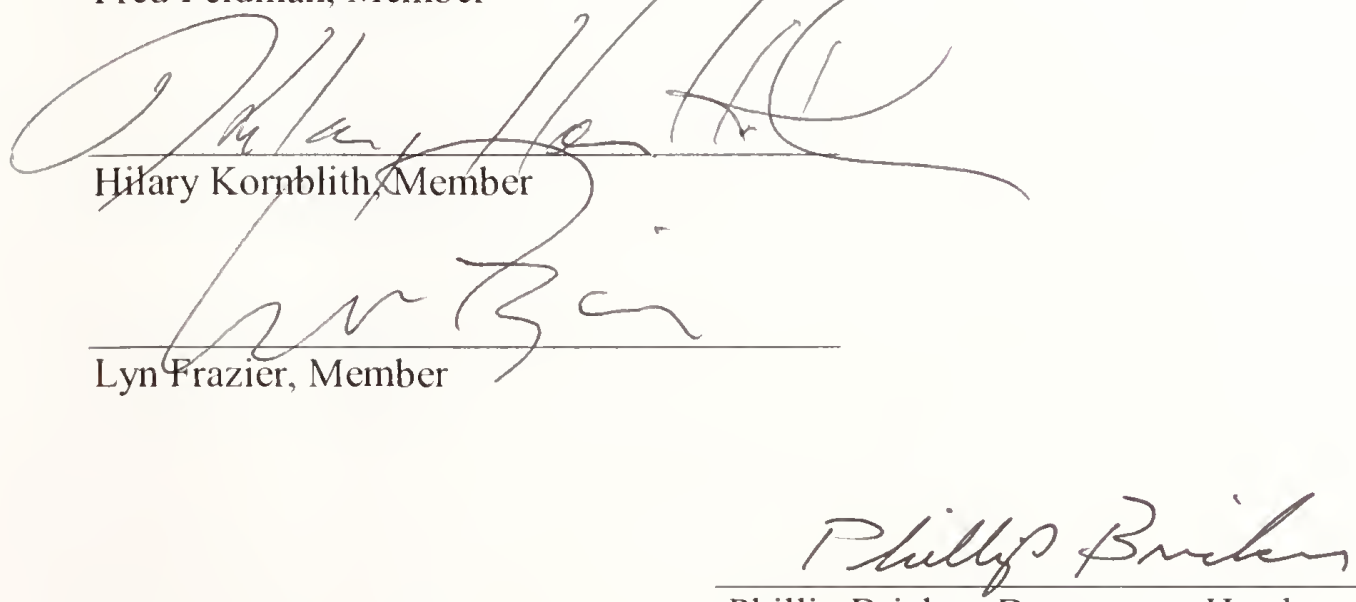

Phillip Bricker, Department Head

Department of Philosophy 



\section{I)EIC $\triangle$ TION}

To my moral and intellectual role models, my grandparents, Leal and Simon Giller and my parents, Danicla and Elia Leibowitz 


\section{ACKNOWLEIOGMENS}

I am extremely fortunate to have had the opportunity to write my dissertation under the guidance of Gareth Matthews. It is impossible to express in words my gratitude to Gary lor his invaluable guidance, encouragement, and support ever sinec my very lïst semester in graduate school. Indeed, it was Gary’s seminar on Aristolle’s Niconachean Ethics in the fall of 2002 that sparked my interest in Aristotle's virtue theory, and subsequently, in particularism. Not only has Gary been a teacher, a mentor, and a friend to me, but also a philosophical role model. While writing my dissertation, I have often found mysell thinking how Gary would address the questions I was thinking about, what questions he would ask me, and how he would have expressed these ideas had he been writing my dissertation instead of me. Moreover. Gary has tremendously influeneed my approach to teaching philosophy. In teaching, as in writing, I often ask mysell what Gary would do-how Gary would present the relevant subject matter and how he would handle various situations in the classroom.

In the Nicomachean Ethic's IX.1 Aristotle observes that a student's debt to his philosophy teacher is unique. "For" money is not the standard by which the worth of" at Iphilosophyl teacher can be measured, and no honor could match what he has given." Surely, no amount of money and no honor could match what I received liom Gary over the past six years. Yet Aristotle goes on to saly that we must "make what return we can. just as we do in the case of the gods and our parents." The only return I can currently offer is to humbly express my gratitude to, and my immense admiration and respect for my teacher. Thank you, Gary! 
I am also tremendously fortunate to have had Fred Feldman and Hilary

Kornblith serve on my dissertation committee. Both Fred and Hilary played a crucial role in my philosophical development. Fred and Hilary have very dillerent philosophical worldviews and they approach phitosophical problems in radically dillerent ways. I have greatly benelited from having the opportunity to study with both of them. Despite their many dilferences. Fred and Hilary have at least one thing in common: they are both extraordinary teachers. Both Fred and Hilary were always willing to make themselves available to discuss philosophical issues with me. Over the years I've received remarkable amounts of invaluable leedback from them. They each read many drafts of my work, and on each and every occasion I received prompt. delailed, and signilicant comments. I would not have been able to complete my dissertation when I did had it not been for the exceptionally speely response time from each of them. and the quality of my work increased substantially as a result of their constructive criticisms. I cannot imagine a better dissertation committee than the committee I had, and I am forever gratefut to Gary, Fred, and Hilary for all that they have taught me.

In addition to my eommittee members, I would like to thank all the faculty members at UMass for the wonderlul philosophical education and guidance they have provided me. I am enormously appreciative of the philosophical training l received at UMass. In particular. I would like to thank Lynne Rudder Baker and Pete Graham. I am also grateful to Lyn Frazier from the linguistics depatment at UMass lor serving on my dissertation eommittee and for her kind and friendly support, and to Nishi Shah from Amherst College. 
Throughout the years in graduate school I have learned a lot not only from my official teachers, but also from my friends and colleagues. First and foremost, I am indebted to my good friend Daniel Doviak. Dinn and I shared an office for several years and we spent a ridiculous amount of time conversing about philosophy. l've learned a Iot from these conversations with Dan. Furthermore, Dan was kind enough to read many drafts of my papers and he always made friendly suggestions that helped me to improve my work - in fact, Dan is probably the most charitable reader I have met. 1 would also like to thank all my friends without whom graduate school would not have been the wonderful intellectual and social experience it has been. I am happy to say that there are too many friends to list here, but 1 cannot fail to mention my good friends Jessica Butler, Ori Herstein. Kristen Hine, Meghan Masto, Josh Patchak, Creighton Rosental, Stephan Torre, and Brandt Van der Gaast who made my graduate school experienee enjoyable, stimulating, and rewarding.

I presented earlier versions of Chapter One at the 7th annual NYU/Columbiat graduate conference, the 8th annual Rutgers/Prineeton graduate conferenee, and the first annual conference of the Society for Ethical Theory and Political Philosophy. 1 am grateful to my commentators-Tushar Irani, Felix Koch, and Andrew Sepielli. I have also greatly benefited from comments 1 received on earlier versions of this chapter from Tad Brennan, Jonathan Dancy, Stephen Darwall, Chris Heathwood, Kris McDaniel. Sean McKeever, Michael Ridge, and two anonymous referees for Ethical Theory and Moral Practice.

Earlier versions of Chapter Two were presented at the Florida State University graduate conference, and at the Yale/UConn graduate conferenee. I would like to thank 
my commentators Brian Coffey and Gwen Bradford. I am also grateful to Michacl

Zimmerman and an anonymous referee for Philosophical Studies for their helpful criticisms and suggestions.

Finally, I would like to thank all my lamily for their lifelong encouragement and support. 


\section{ABSTRACT \\ A DEFENSE OF A PARTICULARIST RESEARCH PROGRAM SEPTEMBER 2008 \\ URI D. LEIBOWITZ, B.A., TEL-AVIV UNIVERSITY, ISRAEL Ph.D., UNIVERSITY OF MASSACHUSETTS AMHERST \\ Directed by: Professor Gareth B. Malthews}

Particularism is one of the most interesting and controversial doctrines in moral philosophy today. Yel despite the considerable attention it has received in recent years, there is still extensive disagreement about its precise content, and whether it is a viable alternative to traditional moral theories. In this dissertation I develop, motivate, and defend a novel formulation of particularism.

In Chapter One, I present my formulation of particularism. I claim that particularism is not a single thesis but a resectrch program. Research programs are collections of theories and methodological rules that can be characterized by their "hard core"- the set of commitments that eannot be abandoned without abandoning the research program altogether. The particularism-generalism debate. I suggest, is a debate over which research program we ought to pursue. Generalism is a research program characterized by the core hypothesis that in order to explain morality, and especially the rightness and wrongness of actions, we must appeal to exceptionless moral principles. Particularism is an alternative research program chatracterized by the core hypothesis that morality-including the rightness and wrongness of actions-can be explained without appealing to exceptionless principles. I go on to show that my formulation is not vulnerable to the most common objections to particularism. 
Chapter Two argues that particularist aceounts of morality have a certain advantage over many of their more eonventional competitors. Consider the following moral advice: (RD) Perform action $A$ only il after rellecting on and deliberating about the normative status of $A$, you do not believe that $A$ is morally wrong. I argue that if (RD) is good moral adviee, then we should be able to explain how it is that the features that one considers while reflecting on and deliberalting about the normative status of actions reliably track the real right-making features of actions. I claim that generalists cannot explain this lact, whereas particularists cann. Finally. I submit that there is strong intuitive support for the claim that (RD) is good moral aldviee, and consequently, that we have reason to favor particularist accounts of morality over generalist accounts.

Chapter Three examines the nature of particularist explantations of the rightness (or wrongness) of alctions. First, I discuss some reasons for thinking that explanations must be grounded in exeeptionless prineiples. and I claim that a deductive approach to explanation is unmotivated. Next, I atrgue that we have good reasons for thinking that not all explanations are deductive, and I explore severil non-deductive models of explanation, some that are based on the availability of ceteris paribus laws. and others that do not require laws all all. Finally, I argue that when we apply insights about the nature of explanation from the philosophy of seience to ethies, we have good reason to believe that explanation in ethies need not be deductive.

In Chapter Four, I propose a particularist interpretation of Aristotle's Niconacheen Ethics. First, by foeusing on Aristotle's proclaimed goals and methods in the Nicomachean Ethics, I show that we have ample evidene for thinking that Aristotle was not a generalist. Next, I argue that we can read Aristotle as offering an explanation 
of morality without appealing to exceptionless moral principles. More specifically, I maintain that Aristotle is not trying to help us identify which of the range of actions available to us is morally right: instead his theory is meant to teach us how to explain why those acts that we know are right have the normative status they do. I claim that Aristotle's doctrine of the mean is not intended to serve as a deeision procedure, but as an explanatory schema that we should apply in order to explain why right acts are right. Finally, I explain how my proposed interpretation is compatible with Aristotle's claim that the study of ethics should help us to become good. 


\section{CHAPTER}

1. PARTICULARISM AS A RESEARCH PROGRAM

1.1 Introduction.

1.2 The Standard Debate over Particularism ................................................... 2

1.3 What is a Reseatch Program? .............................................................. 11

1.4 Pallicularism ats a Rescalch Program............................................ 14

1.5 The Positive Henristic of a Particulatist Research Program....................... 21

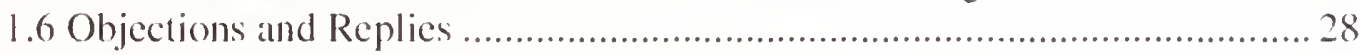

1.7 Conclusion .................................................................................. 41

1.8 Appendix: Dancy's (2004) Formulation of Patrticularism ......................... 43

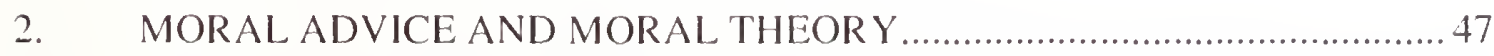

2.I Introduction................................................................................ 47

2.2 The Two Roles of Moral Theorizing ................................................... 47

2.3 Monism, Pluralism, and Particularism ..................................................... 55

2.4 The Argument from Good Moral Advice .................................................57

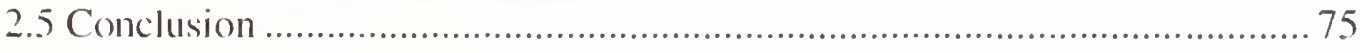

3. EXPLANATION IN ETHICS ......................................................... 76

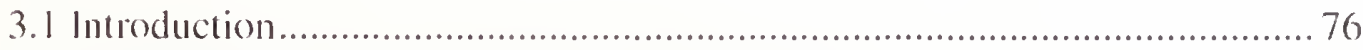

3.2 Explanation and Exceptionless Gencralizations .................................... 77

3.3 Are All Explanations Deductive? ........................................................ 85

3.4 Ceteris Paribus Explanation .............................................................. 96

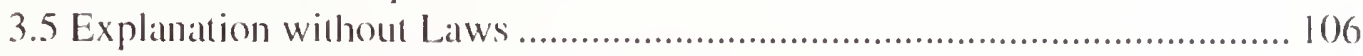

3.6 Explanation as a Pragmatic Phenomenon .......................................... 11.5

3.7 Explanation in Ethics .................................................................. 119

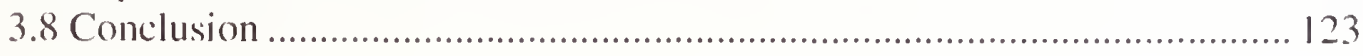

4. PARTICULARISM IN ARISTOTLE'S ETHICS ................................... 126

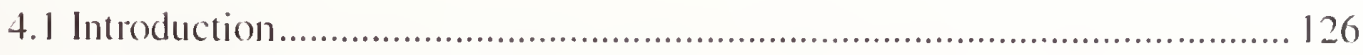


4.2 A Prima Facie Calse for a Particularist Interpretation

4.3 The Starting Point for Moral Theorizing....

4.4 The Practical Goal of Aristotle"s Niconacheren Ethicis

4.5 Aristolle and Moral Explanation. 165

4.6 Conclusion 168

BIBLIOGRAPHY 170 


\section{CHAP'TER I}

\section{PAR'TICUL $\triangle R I S M \Lambda S \Lambda$ RESE $\Lambda R C H$ PROGR $\Lambda M$}

What makes some acts morally right and others morally wrong? Traditionally, philosophers have thought that in order to answer this question we must find and formulate exceptionless morel principles-principles that capture all and only morally right actions. Utilitarianism and Kantianism are paradigmatic examples of such attempts. In recent years, however, there hats been a growing interest in a novel approach-Partichlarism-although its precise content is still a maller of controversy. In this chapter I develop and motivate a new formulation of particularism as a researd progetam and I show that my formulation is not vulnerable to the most common objections to particularism. Moreover, I argue that the particularist research program shows enough promise to warrant further exploration.

\subsection{Introduction}

Particularism is one of the most interesting and controversial doctrines in moral philosophy today. Yet despite the considerable attention it has received in recent years, there is still extensive disagreement about its precise content, and whether it is a viable alternative to traditional moral theories. The most prevalent objections to particularism are that particularism is demonstrably false and that particularism is unmotivated. 'I believe that these negative assessments of particularism result from a misconception of

\footnotetext{
'See, for example, Sinnotl-Armstrong (1999), Irwin (2000), Hooker (2000), Crisp (2000), McKeever \& Ridge (2005a, 2005b, 2006), and Raz (2006).
} 
the nature of particularism. I hope to show that particularism, properly understood, is a well-motivated project that should not be dismissed out of hand.

1 proceed as follows: first, l outline onc recent version of a standalld argument against particularism and explain why it is based on a misconception of particularism (section I.2). Then, I offer a new formulation of pallicularism as a resectreh program, and 1 show that my formulation is not vulnerable to the most common objections to particularism (sections 1.3 \& I.4). Next. 1 argue that particularism is a promising rescarch program that warrants further exploration (section I.5). Latst, I respond to three possible objections to my proposed formulation of particularism (section 1.6).

\subsection{The Standard Debate over Particularism}

Recent interest in particularism has given rise to a plurality of distinct views that go under this heading. Pauticularism has been identified as a claim about moral psychology, a statement about the nature of reasons, a view about the relationship between descriptive and evaluative predicaltes, a thesis about the normative priority of particular moral judgments, a denial of the existence of exceptionless moral principles, ${ }^{6}$ the theory that morality cannot be codified by any finite set of principles, and as the claim that the possibility of moral thought and judgment does not depend on the provision of a suitable supply of moral principles.

\footnotetext{
${ }^{2}$ Dancy ( I 983), McNatughton (1988), Dworkin ( 1995$)$.

3 Hooker (2000), Little (2000), Richaldson (2003), Kirchin (2007).

t Jackson, Pctlit \& Smith (2000).

5 Irwin $(2000)$.

"Shafer-Landau ( I997). McNaughton \& Rawling (2000), Dancy (1983), Raz (2006).

${ }^{7}$ Holion (2002).

${ }^{8}$ Dancy (2004).
} 
The common leature of all particularist theses is often identilied as the deniat of (some feature of) prineiple-based moral theories. For example, MeKeever \& Ridge elaim that: "Different forms of pattieularism are delined by the different negative elaims they make about moral principles." And that "The dilferent species of particularism] are united in that they all assert what intuitively is a negative thesis about moral principles." They go on to propose a classification of particularist theories based on the negative thesis each version advocates, and they add that "each form of particularism which falls out of our taxonomy corresponds neatly to a form of generalism which is the negation of that particularist thesis." (5) Similarly. Lance and Little $(2006)$ claim that particularism "hangs its hat on" rejecting classical primciples. They identify classical principles as "exceptionless, explanatory interrelated moral generalization that are capable of serving key epistemic functions," (571) and they individuate each version of partieularism according to the component of the classical principles framework it rejects. Joseph Raz (2006), in a recent critique of particularism. considers (and rejects) several possible particularist theses. In each case he characterizes the particularist thesis by identifying a generalist thesis it denies. " Particularism, then, is often construed as a negative thesis, and the dialectic between particularists and their generalist opponents is often eharacterized as follows: generalists propose moral principles or principle-based aecounts of morality, and particularists object to these principles/accounts.

\footnotetext{
${ }^{9}$ McKeever \& Ridge [heneeforth M\&R] (2006) P. 14.

${ }^{10}$ See Raz (2006) esp. pp. 113-117.
} 
After identifying the common feature of all particularist theses, M\&R go on to argue that all particularist theses are false. In Chapter Six of their recent book, M\&R present what I take to be their main argument against particularism:

|O|ur judgments about all things considered moral verdicts, insofar as those judgments constitute knowledge, suffice to ensure the availability of a suitable moral principle, namely a default principle. So moral judgment, insofar as it constitutes knowledge. does presuppose the availability of a suitable stock of moral principles. [Particularism] about hedged principles is thus false. (120) 121)

I propose the following two-step reconstruction of their argument: ${ }^{1}$

\section{The Knowledge to Principles (KP) Argument:}

1. There are instances of moral knowledge.

2. If there are instances of moral knowledge, then there are exeeptionless moral principles.

3. Therefore, there are exceptionless moral principles.

11 The argument in Chapter Six is meant to show that particularism about hedged moral principles is lalse; in Chapter Seven M\&R argue that we can "trim the hedges"-that we have reason to be confident that there ate non-hedged moral principles that can codify the entire moral landscape. A hedged principle, aceording to $M \& R$, is a principle that doesn't specify all the possible defeaters and countervailing reasons, but instead it quantifies over them. For example, the following principle is a hedged principle: For any action, A. if A involves torturing babies for fun and no other reasons are present, then $\mathrm{A}$ is morally wrong. This principle is a hedged principle because of the qualificattion "and no other reasons are present." This "hedge" doesn t specify which features may outweigh the fact that the act involves torturing bahies for fun. Instead, this principle states that as long as such feature are not present-whatever they might be-an act that involves torturing babies for fun is wrong. To the best of my knowledge no one defends what M\&R call "particularism about hedged moral principles." M\&R discuss this version of particularism as a step in their argument against particularism about non-hedged principles. However, M\&R's argument against particularism about hedged moral principles-indeed, the fact that their taxonomy allows for particularism about hedged principles and generalism about hedged principles-illustrates a standard misconeeption concerning the debate over particularism. I will argue that the issue is not whether there are hedged or non-hedged moral principles, but rather whether there are principles that are both explanatory and exceptionless. For simplicity of exposition. then, I reconstruet M\&R's argument in the main text as an argument for the eonclusion that particularism is false. 
The Principles to Generalism (PG) Argument: ${ }^{12}$

3. There are exceptionless moral principles.

4. Il there are any exceptionless moral principles, then particularism is false.

5. Therefore, Panticularism is false.

M\&R spend most of chapter six defending premise (2). They claim that premise (2) is demonstrably true, and indeed, they argue for its truth by constructing a method for generating exeptionless moral principles. ${ }^{1.3}$ According to M\&R, moral knowledge is based on the identification of purely descriptive faets that are moral reasons for and against performing a certain action: "|l|n a standard calse knowledge that a given action is wrong is based on a recognition of the relevant moral reasons, where these reasons are themselves simply descriptive facts which lavor not performing the action." ( I I5) Given the limitations of our pereptual faculties, cases of moral knowledge must be cases in which the number of morally relevant features is limited-otherwise, we will not be able to register all the morally relevant facts, and our knowledge claim will be deleated. So in casses in which we have moral knowledge we can, all least in principle, list all the morally relevant lacts.

Il one aceepts Atomism in the theory of reasons-that a feature that is a (primary) reason ${ }^{1+}$ in one case must remain a reason, and retain the same polarity, in

\footnotetext{
${ }^{12}$ In the introduction I have said that I will consider one standard argument against particularism. The standard argument is the (PG) argument. The (KP) argument is, to the best of my knowledge, an original contribution by M\&R.

${ }^{13}$ Since M\&R assume that all participants in the particularism-generalism debate accept premise (1), they do not argue lor it.

${ }^{14}$ Some proponents of atomism differentiate primary (or ultimate) realsons from other (non-ultimate) reasons. These atomists allow that some reasons can sometimes count in favor of an action, and sometimes count against an action, but they insist that primary (or ultimate) reasons always make the same contribution. For example, they grant that the fact that my claim will be a lie may be a reason against making it on some occasion
} 
any case ${ }^{15}$ - blen one has a recipe for generating exeeptionless moral principles: (1) consider any particular morally right action; (2) list all the relevant moral reasons; call the conjunction of all these reasons (RC). The following principle, then, is an exceptionless moral principle:

(K) For any action, $A$, if $A$ instantiates (RC) and no other reasons are present, then $A$ is morally right.

However, particularists reject atomism; instead, they favor holism in the theory of reasons-a feature that is a reason in one case may be no reason at all, or an opposite reason, in another. ${ }^{16}$ For example, that a job applicant really wants the job maly be a reatson to hire her in one context-saly, in a context of hiring a new faculty member to a philosophy department, and a reason not to hire her in another context-say, in al context of hiring a new guard for Abu Ghraib prison. ${ }^{17}$ Thus if holism is true, then even if an action instantiates (RC) and no other reasons are present, the action mat be morally wrong because (RC) can change its polarity in different contexts in which it is instintiated. But sine the polarity of (RC), even aceording to holism, is determined by feattures of the context, then there are some leatures of the context that explain why (RC) changes its polarity when it does. Consequently, even if holism is true, the following is an exceptionless moral principle:

and no reason all all on another occasion (e.g., when playing 'Countraband"). Nevertheless, they maintain that a claim's being dishonest always counts against making il. Sec, for example, Crisp $(2000)$.

15 See, for example, Dancy (2004) p. 7. See also Shafer-Landau's discussion of The Delimiting Thesis in Shafer-Landau (1997) esp. pp. 591-597.

${ }^{16}$ See, for example, Dancy (2004) pp. 73-78.

${ }^{17}$ For more examples see Dancy (1993) pp. 60-64. 
(K') For any action, $A$, if (a) $A$ instantiates (RC), and (b) No feallure of the situation explains why (RC) would fail to be at reatson to perform $A$, and (c) No other (moral) reatsons are present, then $A$ is morally right. 18

Therefore, even if holism is true, the possibility of moral knowledge, aceording to M\&R, guarantecs that there are exceptionless moral principles. Therefore, premise (2) of the (KP) algument is llue.

But is $\left(K^{\prime}\right)$ really a moral principle? Moral principles are supposed 10 identify an exeptionless relation between non-moral properties and moral properties. ${ }^{19}$ Yet arguably, not an! relation of this sort qualifies as a moral principle. For example, consider the following claim:

(GR) For any aclion, $A$, if (and only if) $A$ is a member of (Gromp- $R$, then $A$ is morally right.

Let (iromp- $R$ be the set of all (and only) morally right actions. If moral properties supervene on non-moral properties, then all members of Gromp-R can, in principle, be described in purely non-moral terms. ${ }^{20}$ Consequently, (GR) identifies an exceptionless relation between non-moral properties and moral properties. But it may seem odd to call (GR) a moral principle. (GR), though true and exceptionless, is

\footnotetext{
${ }^{18}$ M\&R statement of this principle is slightly different (See pp. 117-8). My version of $\left(K^{\prime}\right)$ is a simple generalization of their statement.

${ }^{19}$ One might be satisfied with moral principles that identify exceptionless relations between thick moral properties and thin moral properties. Sec, for example, McNaughton \& Rawling (2000). However, since ( $\mathrm{K}^{\circ}$ ) is supposed to identily an exceptionless relation hetween non-moral propertics and moral properties, the possibility of principles from thick to thin will not concern us here.

${ }^{20}$ For ease of exposition I use properties and predicates interchangeably throughout this paper.
} 
uninteresting-it identilies the wrong kind of relattion between non-moral and moral properties. The worry is that $\left(K^{\prime}\right)$ also identilies the wrong kind of relation between non-moral and moral propertics, so it may not qualify ats a genuine moral principle. I do not offer here an account of the kind of relation between non-moral and moral properties that is required in order to qualily as a genuine moral principle. My point is only that not any such relation will do. Consequently, we have reason to doubt whether $\left(\mathrm{K}^{\prime}\right)$ is a genuine moral principle.

Moreover, (K') seems to amount to the claim that there must be some non-moral difference between any two actions that differ in moral status: that is, that moral properties supervene on non-moral properties. But particularists admit that the moral supervenes on the non-moral. For example, although Dancy says that he does not "insist in advance that all moral properties exist in virtuc of, or result from, non-moral properties" ( $1999: 25)$ he does insist that particularism is compatible with the supervenience of moral properties on non-moral properties. ${ }^{21}$ In addition, particularists acknowledge that the supervenience relation entails that there are true exceptionless statements of the form:

$$
\text { (SP) } \forall x(G x \rightarrow M x)
$$

Ix ranges over actions, $G$ is a non-moral property, and $M$ is a moral property (SP) is true and exceptionless when $G$ describes a complete world state. Yet particularists deny that (SP) is incompatible with particularism, 22 and M\&R said nothing to counter this claim. If this is right, then ( $\left.K^{\prime}\right)$ hats no dialectical foree in an argument against particularism.

21 See Dancy $(2004)$ p. 85.

22 See Dancy $(2004)$ pp. 85-93. 
Opponents of particularism have typically focused their efforts on trying to establish that there are exceptionless moral principles. So latr, l hatve elaimed that it is debaltable whether M\&R"s (KP) argument establishes that there alre any such principles. But suppose that it does-lhat is, suppose that ( $\mathrm{K}^{\prime}$ ) is a genuine moral principle. Or alternatively, suppose that we can just see that there are some exceptionless moral principles. For example, one might think that no one should object to the following principle:

(TBF) For any action, $A$, if $\Lambda$ involves torturing babies for fun and no other reasons are present, then $A$ is morally wrong.

If $\left(\mathrm{K}^{*}\right)$ and/or (TBF) are genuine exeeptionless moral principles, is this a problem for patticularists?

It has often been taken for granted that if there are any exeeptionless moral principles, then particularism must be false. In other words, premise (4) of the (PG) argument has been thought to require no support. I suspect that this premise has been acepted as a result of the interpretation of particularism as the denial of all principlebased moral theories. The thought, perhaps, is that if there atre any exceptionless moral principles, there is no reason to oppose a principle-batsed approalch. Particularists, on this interpretation, are committed to the claim thatl all moral principles are objectionable.

Particularists, I submit, should resist this construal of their thesis for several reasons. First, if particularism is understond ats the denial of the existence of any exeptionless statement of the form $\forall x\left(G x \rightarrow M_{x}\right)$ then patricularism is clearly false. As we have seen, (GR) and (SP) are obvious counterexamples to this elaim. So 
particularists will have to specify which statements of this form cualily as genuine principles. ${ }^{23}$ But the philosophical import of marking this distinction, independent of the particularism-generalism dehate, is far from obvious; it would be a mistake to reduce this exciting debate to a debate over the proper application of the term moral principle.

Second, it is hard to imagine how particularists could sueceed in showing that there are no unobjectionable principles. Prools of non-existence are notoriously difficult, and in the absence of a proof for the non-existence of exceptionless moral principles, the particularist conclusion would always be tentative-perhaps the correct moral principles have not yet been discovered or formulated. Thus, identifying particularism as a negative thesis- hat is, as the claim that all moral principles are objectionable-places the particularist at a dialectical disadvantage. Particularism could be refuted, on this construal, by one example of an unobjectionable exceptionless moral principle.

Finally, even if particularists could establish that all conceivable principle-based moral theories are problemaltic, it might still be rational to retain a principle-based approach to morality. Theory choice is a comparative task-we adopt the theory that has the best overall balanee of advantages over disadvantages. So if particularists want to argue that the principle-based approach to morality should be abandoned, they must offer a plausible positive non-principle-based account of morality; pointing out that a

\footnotetext{
${ }^{23}$ It is noteworthy that the question "What statements of the form $\forall x(c i x \rightarrow M x)$ qualify as genuine principles?' is equally pressing for the generalist, since no one thinks (and M\&R do not claim) that principles like (GR), (SP), (K') and (TBF) are the kind of principles that will partake in a generalist account of morality. It should. therefore, seem surprising that statements like (SP) and (TBF) can refute particularism despite being entirely unhelplul in constructing a generalist account of morality.
} 
principle-based approach is problematic is not enough. Understood as a negative thesis. then, particularism is essentially only a partial story.

But if particularism is not a megative thesis, if it is not the denial of (some form of) principle-based moral theories, then what is it?

\subsection{What is a Rescarch Program?}

1 propose to undersiand particularism ats a research progranr. Rescalleh programs, according to Imre Lakatos, consist of theories and methodological rules that specify which paths of rescarch to avoid (negative hemristic), and which paths to pursue (positive henristic). ${ }^{24}$ Research programs are individuated by their "hatd eore"-lhe set of eommitments that cannot be abandoned without abandoning the research program altogether. Lakallos writes:

All scientilic rescalch programmes may be chatracterized by their "hard core'. The negative heuristic of the programme forbids us to direct the modus tollens at this "hard core". Instead we must use our ingenuity to articulate or even invent "auxiliary hypotheses", which form a protective belt around this core, and we must redirect the molus tollens to these... The | core' is 'irrefulable' by the methodological decision of |the proponents of a rescarch programl: anomalies must lead to changes only in the "protective' belt of atuxiliary... hypotheses." (1970:48)

The following example should help us gel a sense of whall a reseanch program is. In 1781 William Herschel discovered planet Uranus. By the carly 1800 ’s it became clear that the planel's observed location did not match the path predicted by Newton's laws. Despite the discrepancies between theory and observation, very few astronomers doubted the truth of the Newtonian theory. They believed that this anomaly could be resolved without relinguishing Newton's laws. Some astronomers, for example,

\footnotetext{
${ }^{24}$ See Lakaltos (1970).
} 
suggested that observations that were incompatible with the predicted path should be discarded. Others-most notably, Le Verrier-suggested that the discrepancy in Uranus" motion wass due to the existence of an unknown planet, and that once the gravitational fore on Uranus due to this planet is taken into account. Uranus" motion will comply with Newton's inverse-square law. We can say that these astronomers were pursuing a Newtonian rescarch program. The hard core of the program-the set of protected commitments, as it were-included Newton`s laws, and the negative heuristic of the program forbade directing a modus tollens against this hard core.

Nevertheless, some astronomers were willing to question the accuracy of the Newtonian framework; they suggested that the discrepancies in Uranus' orbit lie with Newton's law of gravitation. These astronomers, we can say, were pursuing an alternative researeh program. The hard core of their research program included all available observations of Uranus, and perhaps the rule that one should not posit the existence of unseen entities. Proponents of this research program had to explain the motion of Uranus without Newton's law of gravitation. For example, some proposed that Newton's laws become different at a great distance from the sun.

In 1846 the planet Neptune was observed at the location predicted by Le Verrier. Le Verrier assumed that Newton's law of gravitation was true, and calculated an orbit of the yet-unknown planet that together with Newton's theory would account for the motion of Uranus. And indeed, when the gravitational pull of Neptune on Uramus wats taken into consideration, Uranus"s observed motion harmonized with its predicted orbit. The discovery of Neptune was a great triumph not only for the Newtonian research 
program, but also for Le Verrier himself; he was deemed by his eontemporaries as "a sage" and "a genius" for" having "discovered a stal" with the tip of his pen." 25

It is not surprising, then, that Le Verrier was a passionate devotee of to the Newtonian research program, and that upon considering the anomalous motion of The Planet Mercury in 1849 he proclaimed: "If the lables /of Mereury"s positionl do not strietly agree with the group of observations, we will never again be tempted into charging the law of universal gravitation with inadequacy." 20 In 1859 Le Verrier published his report on the anomalous motion of Mereury, and offered the hypothesis that the anomaly is due 10 a yet-unobserved mass orbiting between Mereury and the Sur.

Here, again, we can distinguish between those pursuing a Newtonian research program, and those who were willing to question the adequacy of Newton's laws. Proponents of the former research program began looking for the missing mass. Sure enough, various sightings of Vulcan-the intra-Mercurial planel-were reported, but all predictions of Vulcan"s location based on these observations were disconfirmed.

Nonetheless, Le Verrier"s belief in the existence of an intra-Mereurial mass never wavered. In 1874 he wrote: "There is, without a doubt, in the neighborhood of Mereury, and between that planet and the Sun, matter hitherto unknown. Does it eonsist of one. or of several small planets, or of asteroids, or even cosmic dust? Theory alone camnot decide this point. $" 27$

\footnotetext{
25 Sec Baum and Sheehan (1997) esp. p. 118.

${ }^{26}$ Quoted from Baum and Shechan (1997), p. 133.

${ }^{27}$ Quoted from Baum and Shechan ( 1997) pp. 173-4.
} 
In contrast. we can characterize a competing, non-Newtonian research proglam by its hard core-that the motion of Mereury can be explained without appeal to a yetto-be-found intra-Mercurial mass. For example, in 1894 one astronomer suggested a modification to the law of gravitation in order to explain Mercury"s motion; instead of inverse-square, he proposed that the exponent ought to be $2.00000016 .^{28}$

The puzzle of the motion of Mercury was resolved in 1915, when Einstein showed that his General Theory of Relativity explains the observed motion of Mercury. Conseguently, the Newtonian reseatch program was abandoned.

\subsection{Particularism as a Research Program}

Surely there are numerous dissimilarities between science and moral philosophy (methods, goals, language, etc.) Nevertheless, there is at least one thing they have in common. Moral philosophy, like science, is in the business of explaining certain features of the world.

Suppose we observe that actions A 1,A2... An alle morally right. ${ }^{29}$ We may want to explain these observations. We may ask, for example, (Q1) What is it that makes these actions morally right? We can think of various ways of approaching this question-or alternative research programs. According to one rescarch programgeneralism-at satisfactory answer to (Q1) must be in the form of an exeeptionless principle that identifies features that $\mathrm{Al}, \mathrm{A} 2 \ldots \mathrm{A} n$ have in common. The generalist rescarch program appeals to a familiar notion of explanation-explanation as

28 Sec Hall (1894).

29 1 do not intend to commit to any particular account of moral epistemology or any specific theory about the nature of moral properties when I say that we obserere that Al ... An are morally right. One could replace this "observation statement" with whatever one thinks is the source of the relevant data for moral theorizing. 
subsumption under exeeptionless principles. So one advantage of the generalist research program is that if we find an exeeptionless principle that gives the right verdict about A1,A2...A A we will thereby have a satisfactory answer to (Q1). ${ }^{30}$

Aecording to an alternative research program-particularism-we can answer (Q1) without presupposing that there are exeeptionless principles that will give the right verdict about A1,A2...An. Proponents of this research program do not seareh for features that all and only these actions have in common. Instead, they try to come up with an explanation of the rightness of each of these actions without appealing to exeeptionless principles. Proponents of this research program can point out that in some

${ }^{30}$ Both monists and pluralists are generialists because they both believe that an explanation of the rightness of an action is inadequate unless it is grounded in an exeptionless moral prineiple. Nevertheless, monists and pluralists disagree about the number of intrinsically morally relevant properties (heneelorth IMR-properties). Let us saly that a property, $P$, is intrinsically morally relevant if and only if $P$ is morally relevant for its own sake, or non-derivatively morally relevant. A property is extrinsieally morally relevant if and only if it is non-intrinsically morally relevant; that is, if it is only derivatively morally relevant, or morally relevant only in virtue of its relation to some IMR-property. Monists claim that there is only one IMR-propertycall it P-and that every action that exemplifies $\mathrm{P}$ is morally right. Pluralists maintain that there are several IMR-properties-call these properties PI...Pn-and that for each IMR-property, Pi, there will be a presumptive, or pro linto, principle: for any action, A, if A exemplifies Pi then A is presumptively morally right (or wrong). See, for example, Ross (1930) Ch. 2, and Schaller-Landau (1997). For instimce, consider the following version of act-utilitarianism: (AU) An act. A, is morally right if and only it A maximizes utility. (AU) is a monist theory. According to (AU) there is only one IMRproperty-namely, utility-maximization. If an atcion exemplilies this property, it is morally right: otherwise, it is morally wrong. Justiec. for instance, can only be extrinsically morally relevant according to (AU); if justice is morally relevant, it is only in virtue of its relation to utility-maximization. Pluralists, in contrast, hold that there atre several morally relevant properties. So pluralists may claim that being just, being truthful, and being beneficent are all IMR-properties. Nevertheless, pluralists are generalists becaltse they think that in order to explain the rightness of $\mathrm{A}$, it is not enough to recognize that A exemplifies benefiecnee, and that benefieence is rightmaking here; pluralists believe that we must identify an exceptionless principle that states that for any action, if it exemplifies benefieenee, then it is presumptively morally right. 
areats of incuiry we are used to, and comfortable with, explanations that do not appeal to exeeptionless principles. For example, when we explain the alesthetic status of an artwork we do so without mentioning exceptionless aesthetic principles. ${ }^{31}$ Similarly. explanations in the special sciences-e.g.. psychology, economics, and history-seem to conform to a different model of explanation than the model of subsumption under exceptionless principle. ${ }^{32}$

The particularism-generalism debate, I propose, is best understood as a debate over which research program we ought to pursue. Generalism is a research program characterized by the core hypothesis that in order to explain morality, and especially the rightness and wrongness of actions, we must appeal to exceptionless moral principles. Utilitarians and Kantians, for example, are generalists: despite their disagreement about the content of the correct moral theory. they both strive to identify exceptionless moral principles in order to explain the moral status of actions. Particularism, in contrast, is an alternative research program chatracterized by the core hypothesis that moralityincluding the rightness and wrongness of actions-can be explained without appealing to exceptionless principles.

We are now in a position to see why particularists need not argue that all moral principles are objectionable, or why premise (4) of the (PG) argument is false. Strictly speaking, research programs are not true or false. Research programs consist of theories

\footnotetext{
${ }^{31}$ For example, one cannot fail to mention symmetry as a relevant feature to the aesthetic merits of the Taj Mahal. Yet, it seems absurd to think that symmetry is always aesthetically relevant; the contribution of symmetry to the overall aesthetic status of an object can change its polarity - it may contribute positively, negatively, or make no contribution alt all. See Little (2000), and Dancy (2004) p. 76.

${ }^{32}$ For instance, economists may appeal to the law of supply and demand in order to explain the change in price of certain products, even though this law is not exceptionless.
} 
and methodological rules. Theories may be true or false, but methodological rules require a different mode of evaluation. Lakatos suggests that insteat of truth and falsehood we should evaluate research programs for their success. In order to explain what makes for a successlul research program, Lakatos introduces the lollowing terminology:

Let us saly that... a series of theories is theoretically progressive (or "constitutes a theoretically progressive problemshift") if each new theory has some excess empirical content over its predecessor... Let us saly that a theoretically progressive series of theories is also empirically progressive (or 'constitutes an empirically progressive problemshifi') if some of this excess empirical content is also corroborated... Finally, let us call a problemshilt progressive if it is both theoretically and empirically progressive, and degencrating if it is not. (33-4)

With the notions of progressive problemshift and degenerating problemshift, Lakatos states the criterion for suceess of rescarch programs as follows: "A research programme is successlul if lit leads to a progressive problemshift; unsuccessful if it leads to a degenerating problemshift." (48)

Clearly, some modilications are required in order to import these definitions to our discussion in moral philosophy. ${ }^{33}$ The key point, though, should be cleal enough: a research program provides a strategy for modifying theories in the face of anomalies; if by employing this strategy we generate better theories-that is, theories with greater explanatory power-then the research program is suceessful. So perhaps instead of premise (4) we should eonsider the following premise:

\footnotetext{
33 It should be interesting to work out whether, and il so, how Lakatos's terminology can be "translated" into terms that are appropriate for moral philosophy. For example, it would be interesting to figure out what (il anything) in the moral realm corresponds to "excess empirical content" and how (or whether) this "empirical content" can be "corroboralted." However, I will not pursuc this route here.
} 
(4') If there are any exceptionless moral principles, then particularism is unsuccessful.

But premise (4') is clearly false. Even if there were exceptionless moral principles, it would not entail that the particularist research program is unsuccessful, since it is surely possible that several research proglams would lead to progressive problemshilts. Even if there were no counterexamples to the principle of utility, for instance, it would not follow that the particularist research program is unsuccessful.

Perhaps the availability of exeeptionless moral principles undermines the motivation to pursuc the paticularist research program. The thought is that if we had a sattisfactory principle-based account of morality, then there might well be no reason to pursue the particularist research program, sinee there would be no need for alternative explanations. This seems right to me. Yet, not amy exceptionless principle would undermine the motivation to pursue the particularist research program, but only an exceptionless moral principle that provides an adegune areomm of morality. So, I think that the following premise is true:

(4") If there are exeeptionless moral principles that provide an adequalte aceount of morality, then patticularism is ummotivated.

But principles like $\left(\mathrm{K}^{*}\right),(\mathrm{GR}),(\mathrm{SP})$ or $(\mathrm{TBF})$ clearly do not provide an adecuate account of morality. Indeed, no one has ever claimed that they do.

I take this to show that the standard debate concerning the availability of amy exceptionless moral principles is misguided. For example, Sinnott-Armstrong (1999) claims that generalists have the dialectical upper hand in the particularism-generalism debate. He writes: 
Consider the dialectical situation: A generalist holds a theory with a long list of defeaters shaped into groups. A particularist eomes up and claims, "This example shows you need another item on your list." A generalist can always respond, "No. it doesn’t. Your moral judgment about the example is incorreet." Alternatively, a generalist ean respond, "OK, l’ll add another item to my list." A particularist can then come up with more examples, but a generalist again has these two possible responses-and so on... [it seems possible in principle for generalists to keep alding qualifications and defeaters until no more are needed. (7-8)

Generalists, according to Simnott-Armstrong, can always accommodate counterexamples offered by particularists by adding these counterexamples to the list of defeaters to a proposed principle. Eventually, one might hope, the particularist will run out of counterexamples, and so the generalist should be able to formulate the following exceptionless principle:

(AH) $\forall x \mid\left(G x \& \neg C_{1} x \& \neg C_{2} x \ldots \& \neg C_{n} x\right) \rightarrow M x$

Ix ranges over actions, $G$ is a non-moral property, $M$ is a moral property, and $\mathrm{Cl}$... $\mathrm{C} n$ are the known defealers to the principle $\forall x(G x \rightarrow M x)$

But even if (AH) is exceptionless-that is, if it were possible to list all defealters ${ }^{3+4}$ - it is hardly an explanarory principle. since it is manifestly ad-hor. And since (AH), like ( $\left.\mathrm{K}^{\prime}\right)$, (GR), (SP), and (TBF) plays no role in a generalist account of morality, the question of whether $(\mathrm{AH})$ is exceptionless is tangential to the debate over particularism.

To the best of my knowledge, no one has yet presented an argument against particularism based on the availability of exceptionless explanatory prineiples. I suspect that the reason no such argument has been offered is that all exceptionless explanatory

\footnotetext{
${ }^{3+}$ See Robinson $(2006)$ for some worries coneerning the possibility of listing all defeaters (esp. pp. 349-50).
} 
principles that have been formulated thus far are, al best, controversial and an a result they have no dialectical foree in the context of the particularism-generalism debate. Consider, for example, the following argument:

6. If there are exceptionless moral principles that provide an adequate account of morality, then particularism is unmotivated.

7. The principle of utility is an exceptionless moral principle that provides an adequate account of morality.

8. Therefore, particularism is unmotivated.

In order to defend this argument one would have to argue for the claim that the principle of utility provides an adequate account of morality. And likewise, il one replaces the principle of utility in line (7) with any other comprehensive moral theoryc.g., Kantianism, Rule Utilitarianism or Rossianism ${ }^{35}$ - one would have to defend that particular theory in order to demonstrate that particularism is unmotivated. But debates over the adequacy of such theories have occupied center stage in moral philosophy for many years, and the prospects for a conclusive argument for the adequacy of any one of these comprehensive moral theories, at least at present. look grim.

It is not surprising, then, that opponents of particularism have tried to argue against particularism without arguing for the truth of any specilic principle-based moral theory. For example, M\&R describe the project of their book as follows: "This book is a defense of moral principles, yet it is not a defense of any specific moral principle.

Although we are as interested as anyone in determining the specific content of morality, we here address the prior question of whether morality is principled at all." (3) M\&R,

${ }^{35} \operatorname{Ross}(1930)$. 
like all other opponents of particularism, try to undermine particularism without defending any specifie comprehensive principle-based moral theory. But once we understand particularism as a research program, we can see thal without defending at specific comprehensive principle-based account of morality, the prospects for a demonstrative argument against particularism are extremely bleak.

\subsection{The Positive Heuristic of a Particularist Rescarch Program}

So far. I have claimed that my formulation is not vulnerable to the most common objections to particularism. Still, in order to molivate particularism it is not enough to show that the standard objections are ineffective; particularists must also indicate what a particularist account of morality could look like. That is, particularists must answer the following question: if one wants to pursue the particularist research program. what should one do? Or in other words, what is the positive heuristic of the particularist research program? The positive heuristic of the generalist research proglam is well known-try to formulate a principle that is not susceptible to counterexamples. and when faced with a counterexample, adjust the principle (in some aceeptable way) so that it yiclds the correct verdict about the proposed counterexample. Can particularists recommend any comparable positive heuristic?

In this section I will outline two rescarch paths particularists could pursuc. These paths by no means exhaust the research possibilities open to particularist. Nevertheless, identifying these alternatives should suffice to demonstrate that particularism offers a positive heuristic and that there are promising research paths for particularists to explore. 
Jonathan Dancy - the philosopher most associated with particularism-initially thought that holism in the theory of reasons simply entails particularism. " Accordingly, a large portion of his work on particularism has centered on developing and defending holism in the theory of reasons. ${ }^{37}$ However. M\&R have shown that holism is compatible with the existence of exceptionless moral principles. ${ }^{38}$ They presented the following principle:

(U) The fact that an action would promote pleasure is a reason to perform the action if and only if the pleasure is nonsadistic. The fact that an action would promote pain is a reason not to perform the action. An action is morally right just in case it promotes at least as greal a balanee of reason-giving pleasures over pain as any of the available alternatives; otherwise it is wrong. ${ }^{39}$

Recall that holism in the theory of reasons is the thesis that a feature that is a reason in one case may be no reason at all, or an opposite reason, in another ease. Prineiple (U) is compatible with holism sinee it allows that a certain feature-namely, that an action would promote pleasure-is a reason in favor of performing an action in some situations (i.e., in situations in which the pleasure is nonsadistic), and it is no reason al all, or an opposite reason, in other situations (i.c., in situations in which the pleasure is sadistic). We should note that $M \& R$ do not argue that (U) is an exeeptionless moral principle, but only that one could formulate principles that are compatible with holism. and that for all we know some such principle may be exeeptionless.

\footnotetext{
${ }^{36}$ For example, in his (2000), Dancy elaimed that particularism is "merely one expression" of holism in the theory of reasons.

${ }^{37}$ Sce, for example, Dancy (1993), (2000), (2003), and (2004).

${ }^{38}$ See M\&R (2005b) and (2006).

${ }^{39}$ See M\&R (2006) p. 29.
} 
As a result, Dancy now acknowledges that "onc camnot argue from holism directly to the conclusion that moral principles are impossible." (2004:82) His current view is that if holism were true then "it would be a sort of eosmic alecident il it were to turn out that a morality could be calptured in a set of holistic contributory principles." $(82)^{4()}$

Recently, several philosophers have argued that holism provides no support for particularism. Joseph Raz (2006), for example, questions Dancy"s "cosmic accident" thesis. He argues that since "claims |about principles] are conceptual or perhaps metaphysical, if principles are possible and have a role then it would seem that there are principles. After all conceptual or metaphysical truths are not a domain in which accidents are possible." (1 17) Moreover, according to Rav, even if the "cosmic accident" thesis were true, it would not help Dancy"s case for particularism because "lo succeed Dancy must show that principles are impossible; not even a universal accident can bring them about." (117) But since holism is compatible with the existence of exceptionless principles, Raz concludes that "Dancy's /holism/ tends no support for particularism. because it cannot show (and Dancy himself does not claim) that true lexeeptionless] principles are impossible." (1 17) Similarly, M\&R (2006) reject Dancy"s "cosmic accident" thesis: "holism about reasons does nothing to support the thought that the finite and useful codilication of morality would be metaphysically mysterious." (35) And since we have no reason to acept the "cosmic accident" thesis, they conclude: "Holism about reasons provides no positive support for particularism. Holism neither

\footnotetext{
${ }^{40}$ For similat theses see Little $(2000)$ and Stratton-Lake (2000) pp. 128-130.
} 
implies that there are no lexceptionless/ principles nor that any principles there might be would be "cosmic accidents." (45)

Nevertheless, once we undersland particularism as a research program, we can see that the question of whether holism is compatible with the existence of principles. or whether holism entails that the availability of exeeptionless moral principles is extremely unlikely- hat is, that given holism a principled morality would be a "cosmic accident" or a "world historical chance"tl -is tangential to the particularism-generalism debate. The relevatt question, I claim, is whether holism contributes to a particulatist account of morality.

To see this, consider again the case of The Planet Vulcan. Suppose that the theory of relativity is compatible with the existence of a mass orbiting between Mercury and The Sun. Suppose, further, that the theory of relativity doesn 't entail that it is mmlikely that some iutra-Mereurial mass exists. Nonetheless, it would be odd to argue that since the theory of relativity doesn't imply that Vulcan does not exist, or doesn't entail that its existence is unlikely, it offers no support for the non-Newtonian reseatleh program. The theory of relativity provides a good explanation of the motion of Mereury without assuming that there is a yet-to-be-found intrat-Mercurial mass. Therefore, the theory of relativity undermines the motivation to search for Vulcan, since it solves the puzzle that wats the impetus for positing the existence of Vulcan in the first place.

Analogously, even though holism is compatible with the existence of exceptionless principles, and even if holism doesn`t make the existence of such principles unlikely, it can provide support for the particularist research program. If

${ }^{4}$ Stratlon-L̇ake $(2000)$ p. 128. 
holism makes possible a plausible non-principle-based alecount of morality, it

undermines the motivation to seareh for exeeptionless principles in much the same way that the theory of relativity undermines the motivation to search for Vulcan. So far,

philosophers have failed to formulate exceptionless explanatory principles. It seems that the quest for such principles is motivated by the thought that such principles are necessary for an adecuate account of morality. However, if an adequalte non-principlebased aceount of morality were available, then we would no longer have reason to assume that such principles exist, and thereby we might no longer have reason to try to find and formulate exceptionless principles. Therefore, if holism in the theory of reasons contributes to the development of a suceessful particularist aceount of morality. then pace Ray and M\&R, holism does provide positive support for the particularist research program regardless of whether it is compatible with the existence of exceptionless principles, and regardless of whether the "cosmic alecident thesis is true.

I suspect that holism in the theory of reasons will play an important role in a particularist account of morality. Dancy's pionecring work on this topic is commendable. Nevertheless, holism is still in its eally stages and the specifics of the theory need to be worked out in much more detail before we caln determine whether at particularist account of morality based on holism in the theory of reasons is superior to its generalist eompetitors. ${ }^{42}$ So a positive hemristic of the particularist reseanch program is to develop and defend a comprehensive aceount of holism.

Another-perhaps complementary-path particularists could pursue is to develop a particularist-friendly virtue ethics. It is noteworthy that in the Nicomachean

${ }^{42}$ For a recent criticism of Dancy"s holism, sec Raz (2006). 
Ehhicr, Aristotle makes no reference to exceptionless moral principles. ${ }^{43}$ Since generalists insist that one must appeal to exceptionless moral principles in order to explain the rightness/wrongness of actions, there seem to be three interpretative strategies available to generalists who attempt to understand Aristotle's project in the Nicomacherm Elhics: they can try to identify an exeeptionless principle to attribute to Aristotle; or they call argue that Aristotle wasn't interested in explaining the normative status of actions; or alternatively, they can claim that Aristotle was just hopelessly confused and that his whole project was misguided.

To the best of my knowledge no one pursues the third option. However, the two former interpretative strategies can be easily identified in the work of some neoAristotelians and contemporary virtue ethicists. For example, some philosophers propose a virtue-based criterion of moral rightness of the following form:

(VE) An act is right il and only if a fully virtuous agent would perform it in the circumstinces. $^{4+}$

Others elaim that Aristotle was not interested in solving moral quandaries or in identilying a criterion for the rightness/wrongness of actions; instead he was interested in providing a regimen for a good life or in questions concerning the nature of good moral character. ${ }^{45}$

\footnotetext{
4.3 Irwin $(2000)$ claims that Aristotle asserts several exceptionless generalizations such as "one ought always to be willing to face great danger if some important cause is all stake, and one ought never to be willing to face it for some trivial reason." (111) However, I doubt that terms like "great danger", "important cause" and "trivial reason" can be cashed out without appealing to the judgment of the man of practical wisdom. th See, for example, Oakley (1996), Hursthouse (1999), and Swanton (2001).

45 See, for example, Pincolifs (1971) and Taylor (1988). One interesting examples of the second interpretative strategy is Irwin $(2000)$ who claims that Aristotle did not try
} 
With the particularist research program in mind, though, a new interpretative

strategy becomes available: we can try to interpere Aristotle as oflering a particularist account of morality-lhat is, we ean interpret him as giving an explanation of the normative status of actions which is not based on the availability of exceptionless moral principles. ${ }^{46}$ Indeed, several passages in the Nicomadhecm Ethics are as close to an explicit endorsement of the particularist rescarch program as one may hope to find in a two-thousand-year-old text. For example. Aristotle writes:

In a discussion of | what is noble, just of gooll ... we must be satislied to indicate the truth with a rough and general sketch: when the subject and the basis of a discussion consist of matters that hold good only ats at general rule, but not always, the conclusions reached must be of the same order... For the well-schooled math is one who searches for that degree of precision in each kind of study which the mature of the subject at hand admits. ( 1094 b 19-26, Ostwald trans.)

|A |ll law is universal but about some things it is not possible to make a universal statement which shall be correct. In those cases, then, in which it is necessary to speak universally, but not possible to do so correcily, the law takes the usual case, though it is not ignorant of the possibility of crror. And it is nonetheless correct; for the error is not in the law nor in the legislattor but in the nature of the thing. since the matter of practical atlaits is of this kind from the statt. (1 1.37b 12-21 Ross trans.)

So another positive hemristic of the particularist research program is to develop and defend a particularist reading ol Aristotle, or to try to construct at neo-Aristotelian

formulate exceptionless moral principles because he believed that ethical theory essentially has a practical aim, and lormulating exceptionless principles-lhough possible-will not serve this aim. I classify Irwin with the second interpretative strategy because he attributes to Aristotle at goal other than explaining the rightness/wrongness of actions, and thus excuses Aristotle from the requirement to formulate exeeptionless principles.

46. Although several particularists find inspiration and support in Aristolle-c.g., McDowell (1979)-no one has yet offered a detailed particularist reading of Aristotle's ellics. 
particularist-friendly virtue ethics, including, among other things, an account of moral education and moral development that is compatible with particularism. ${ }^{47}$

\subsection{Objections and Replies}

Objection: Particnlarist explanations of morality are defertive. This objection can be spelled out in various ways. For example: (a) Particularist explanations can, al best, provide a partial explanation of morality but not a full explanation, because a full or a complete explanation must be grounded in an exceptionless moral principle. To pursue the particularist research program is simply to announce that we cannot provide an adequate answer to the question "what makes some acts right and others wrong?" To endorse particularism, then, is simply to "admit defeat." (b) If there are any exceptionless moral principles, then these principles provide a hetter explanation of morality than any non-principle-based account. But if the best possible result of pursuing the particularist research program is not as good as the best possible result of pursuing the generalist rescarch program-that is, if we know in advance that exceptionless principles provide the best explanation of morality-then why should we pursue the particularist research program in the first place? What's more, if we pursue the generalist research program and all explanatory principles we come up will turn out to have exeeptions, we can simply aceept whatever aceount we end up with as a particularist account of morality. So there is no reason to "admit defeall" right at the outset-i.c., there is no reason to pursue the particularist research program. ${ }^{\text {ts }}$

\footnotetext{
${ }^{47}$ For an account of moral development friendly to particularism see Dreyfus and Dreyfus (1990).

48 |omitted for blind review|.
} 
Reply: The statement that an adequate explanation must be grounded in an exeeptionless moral principle, or that an explanation that is grounded in an exeeptionless principle is superior to an explanation that is not, is precisely the claim that particularists deny. As we have seen, the core of the particularist reseanch program is the claim that morality, including the rightness and wrongness of actions, can be explained-that is. fully, or adequately, explained-without appealing to exceptionless prineiples. Opponents of particularism cannot simply cite their eommitment to the generalist reseatrch program as an objection to particularism. In the context of the particularism-gencralism debate. a generalist who simply asserts that we cannot fully explain morality without exeeptionless moral principles is comparable to an advocate of the Newtonian research program who declates that we cannot explain the motion of Mercury without Newton's law of gravitation.

Perhaps the thought is that there are independent arguments for the conclusion that an adequate explanation must be grounded in an exeeptionless principle. The proposal, perhatps, is that we can use results from the philosophical literature on the nature of explanation in order to settle the particularism-generalism debate. To explain a phenomenon, the objector might argue, is to subsume it under a general statement. John Ladd, for example, claims that an explanation "is an ordering of phenomena under general law...To the guestion "Why?", explanations answer by a subsumption under a general statement." ${ }^{+9}$ So if we are to explain anything in morality we must find exeeptionless moral principles. Without exceptionless moral principles subsumption of

4) See Ladd (1952) p. 499 
a paticular moral phenomenon under general statement is impossible, and consequently no moral explanation can be had.

Although the covering law model of explanation was-and still is-extremely influential in the literature on explanation, it is eertainly not the only available theory of explanation. And several alternative theories of explanation are compatible with the particularist project. For example, dispositionalism-the view that dispositions, rather than laws are the fundamental units of explanation-is one possible alternative to the covering law model. ${ }^{50}$ According to this view, we should understand the elaim that "lying is wrong", for example, as the claim that acts of lying have the disposition to be wrong: under "suitable" conditions acts of lying manifest this disposition, but they need not do so under all cireumstances. On this view, then, explanations may appeal to generalizations, but these generalizations need not be exceptionless. And sinec particularists, as I argue in this paper, want 10 explain morality without appealing 10 exceptionless moral principles, they may appeal to some version of dispositionalism.

But since dispositionalism is a controversial thesis, it is worth pointing out that there are other avenues open to particularists. In the 40`s, $50^{\circ} \mathrm{s}$, and $60^{\circ} \mathrm{s}$ there has been a lively debate conceming the nature of historical explanaltion. Several philosophers were unsatisfied with the covering law approach to explanation in history as championed by Hempel. William Dray, for example, argued that the dominance of the covering law theory of explanation is an instance of what we may call "physics chatuvinism.' Even if the covering law model provides an accurate account of

\footnotetext{
50) See Robinson (2006). Note, however, that my understanding of the disagrement between particularists and generalists is very different from Robinson"s.
} 
explanation in physics, says Dray, it is unaceptable as an account of explanation in history:

There is, in fact, some reason for thinking that what the covering law theory gives us is the criterion of a technical sense of "explanation" found only in narrowly scientific discourse, perhaps only among certain philosophers of science... Hempel's formulation begins by laying down the logical structure of explanation as he helieves he finds it in physics: he then goes on to show that historical cases approximate to this in varying degrees. There is no apology for the direction of the analysis from physies, where the logical outline is boldly displatyed, 10 other fields, where traces of the model have to be found by dint of eareful reconstruction... 'Explanation', als covering law theorists use it, is al technical term... But if scientists, for their own legitimate purposes. redefine explain' so that it means roughly what covering law theorists saly it does, then we are quite justified in aldvertising our awareness of what has been done by saying that, in fact, seientists do not seem to be much interested in explanation; they care only for "explanation" (als technically defined). (1957:76-78)

Dray argues that many historical explanations ats found in some history books are perfectly adequate. For Draly, then, the fact that most, if not all, historical explanations offered by historians fail to satisfy Hempel's aceount of explanation does not demonstrate that historical explanations are inalequate. of that historians typically present only explanation sketches, but rather it is an indication that Hempel's account is defective. Since we currently cannot formulate strict historical laws, and since some historical explanations ane adequate, then it must be the catse that att leatst some kind of explanation need not appeal to laws, or to exeeptionless generalizations. Woodward $(2002)$ reaches a similat conclusion by focusing on the special sciences. Woodward notes that explanations in the special sciences often appeal to ceteris paribus law statements. But since, according to Woodward, there are no ceteris paribus laws, we must conclude that explanation need not appeal to laws or to exceptionless generalizations. 
Dray and Woodward propose radically different accounts of explanation that do not appeal to exceptionless generalizations offered by. Dray opts for a narrative account of explanation. "An historical explanation," he writes, "may thus amount to telling the story of what actually happened, and telling it in such a way that the various transitions... raise no cycbrows. The story is told in such a way that presumptions of the form. 'But surely that couldn't have happened!', are rebutted in alvance. Answers to likely objections are built into the narrative, which may thus have explanatory force" (1954:27) Woodward, in contrast. asserts that "the core idea in explanation is that an explanans should cite vartiables or faetors that make a difference for the explanandum... for this condition to be saltisfied it is neither necessary nor sufficient that the explanans provide at nomically sufficient condition for the explanandum." (2002:320) It is beyond the scope of this paper to present and discuss the details of these proposals. Sulfice it to saly that these proposals represent alternative models of explanation that are not based on the availability of exceptionless generalizations and thus are friendly to particularism. 51

The question whether an adequate explanation must terminate in an exceptionless principle is, at least at present, an open question. And sinee the literature on the nature of explanation does not provide us with a non-eontroversial account of explanation, we cannot appeal to results in the theory of explanation in order to resolve

\footnotetext{
${ }^{51}$ Several philosophers developed accounts of truth conditions for ceteris paribus generalizations (e.g., Fodor (1991) and Pietrosky \& Rey (1995)) II. pace Woodward. there are ceteris paribus laws, then, again, we have available to us a model of explanation that is not based on the availability of exceptionless generalizations. Also, van Fralassen's pragmatic theory of explanation (van Fraassen (1980)) seems to be compatible with particukarism. Sec, also, Scriven (1959). For a detailed discussion of various models of explanation that are friendly to particularism see my 'Explanation in Ethics" |MS|.
} 
the particularism/generalism controversy. Moreover, it is important to keep in mind that particularists and gencralists anc likely to disagree about the standards of adequacy for an account of morality. A comparison to the competing scientific rescanch programs discussed above is instructive. For scientists pursuing the Newtonian research program an adequale explanation of the motion of Mercury requires that we show how the motion of Mereury can be deduced from Newton's laws (and a sel of initial conditions). But for scientists pursuing the non-Newtonian rescarch program an adequate explanation of the motion of Mereury need not mention Newton's laws all all. Similarly, I expect that generalists would think that in order to explain the normative status of an action we must subsume this action under an exceptionless moral principle.

Particularists, in contrast, would endorse a different model of explanation.

Consequently, given the current status of the debate regarding the nature of explanation, arguments against particularism based on appeal to a particular theory of explanation have no dialectical forec.

Moreover, 'explanation' is a semantically flexible word, and an Dray points out there are surely contexts in which we give and receive adequate explanations that do not appeal to exeeptionless gencralizations. So even if opponents of particularism wish to draw on results fiom the theory of explanation, it would not suffice to show that there is some sense of "explanation" that demands exceptionless moral principles; generalists will also have to argue that this is the only admissible sense of "explanation" relevant to moral theorizing. We should note that if this could be established, then if, as I claim, we do not yet have exceptionless moral principles available to us, then it follows that we have never given nor received-and indeed, we have never even consciously grasped- 
a full, or an addeguate explanation of the rightness/wrongness of any action. And this seems like an implausible consequence for any account of moratity.

I do not meanl to suggest that al detailed particularist-friendly theory of explanation is currently available, even though Dancy and Lance \& Little have made a few interesting advancements in this direction alleady. ${ }^{52}$ Nevertheless, the lack of at full-fledged particularist theory of explanation does not favor the generalist research program since there are well known difficulties for the aecounts of explanation generalists make use of ${ }^{53}$ Moreover, particularists can provide an explanation of morality without first developing an appropriate theory of explanation. If I am right in claiming that we can interpret Aristolle's Ethics as a particularist account of morality, then this is precisely what Aristotle does. Once a particularist aceount of morality is offered, we eall evaluate its strength and weaknesses and eompare it to competing principle-based explanations. We shoutd keep in mind, though, that the standards of adequacy we ought to employ are not independent of the research program we are pursuing.

Finally, It is important to keep in mind that a particularist account of morality is not simply a failed generalist account. A generalist, who admits that the best explanatory principles she is able to come up with all have exceptions, has not thereby provided a particularist explanation of morality. A particularist account must explain.

\footnotetext{
${ }^{52}$ See, for example, Dancy (2004) esp. pp. 45-49, and Lance \& Little (20)4) \& (2007) ${ }^{53}$ Philosophers pursuing the generalist researeh program do not explicitly state which theory of explanation they endorse. However, the model of explanation they seem to employ is some version of Hempel's covering law model. For a diseussion of some famous counterexamples to Hempel's model see Salmon (1989). For other difficulties in employing Hempel's model in moral explanations see my "Explanation in Ethics" |MS|.
} 
anong other things, why all attempts to come up with exceptionless principles have failed. Holism in the theory of reasons and the "cosmic accident' thesis may prove to be useful for this task.

I suspect that some readers may still find the "admitting defiall" charge compelling. I believe that the reason it seems so compelling is that we have grown accustomed to thinking about the goal of moral theorizing in terms of identifying and formulating exceptionless principles. But if, as I suggest, Aristolle's Nicomachean Enhics can be read as a particularist-friendly aceount of morality, then we have a more direct way to debunk the "admitting defeat" chatrge. There are few, if any, moral theories that ate more ambitious and more instructive than Aristotle's moral philosophy. Therefore, if we ean sensibly count Aristolle as a particularist. we can show that far from admitting defeat, the particularist research program is a flourishing line of ethical inquiry will an unimpeachable pedigree.

\section{Objection: The very conception of particularism as a research program is} incoherent. If particularism is a rescarch program, it should lead to the development of new theories. In order to evaluate those theories we need to be able to make sense of the notion of explanctory power of theories. For generalists the explanatory power of a specific theory is a function of the range of phenomena covered by the principles this theory advocates-the more phenomenal these principles cover, the greater the explanatory power of the theory. But particularists cannot give any companable informative account of what the explanatory power of at theory consists in. As a result 
the formulation of particularism as a rescarch program proposed in this paper is at best underdeveloped, and perhaps even incoherent. ${ }^{54}$

Reply: the notion of explanatory ponter of theories is a difficult concept to analyze, and there are obvious dilliculties for the proposed account of the explanatory power of gencralist theories presented above. For instance, compare the following version of act-utilitarianism: (AU) An act, $A$, is morally right if and only if $A$ maximizes utility, and the principle (TBF) discussed about: (TBF) For any action, $A$, if $\Lambda$ involves torturing babies for fun and no other reasons are present, then $A$ is morally wrong. Intuitively, (AU) has more explanatory power than (TBF). But both principles range over all actual and possible actions, and to the extent they "cover" the same amount of phenomena. So perhaps the explanatory power of a generalist theory is not a function of the number phenomena it eovers, but instead it is a function of the range of normative judgments it implies. While (TBF) implies only the normative status of actions that involve torturing babies for fun, (AU) implies the normative status of all actions. But barring obvious difficulties in specifying what the range of normative judgments a theory implies amounts to, we should note that a principle alone does not imply the normative status on any action. In order to deduce the normative status of a particular action from a principle, we must also recognize that this action sattisfies the antecedent of the principle. Surely a principle according to which an aet is morally right if and only if it is morally right does not explain the normative status of any aetion.

All this is to say that there is no simple account of the explanatory power of theories available to generalists. Nevertheless, even though we eannot provide a strict

${ }^{54}$ Thanks to an anonymous referee for pressing me on this issue. 
analysis of this concept. I believe that we can apply it intelligibly. Moral theories provide us with eertain theoretical machinery and explanatory standards, or palladigms, that we can employ in our attempts to explain moral phenomena. For example, consider a particular wrongful act of stealing. Can a generalist theory explain the wrongness of this action? Presumably, if the specific generalist theory under consideration identifies an exceptionless principle according to which any ation that manifests a certain property is wrong, and one could justifiably claim that this particulat at manifests this property, then this generalist theory could explain the normative status of this ation based on the standards of explanation generalists typically endorse.

Can a particularist theory explain the wrongness of this action? Surely, the answer depends on the specific theory under consideration. But in this respeet particularism is no different from generalism. However. different particularist theories may endorse different standards of explanation: some theories matequire that we identify disposition, other theories maty focus on exeeption-full principles that might be applicable to this case, and yet other theories may look for the right kind of story we can tell about the relevant action. Panticularists reject a deductive model of explanation, but this does not mean that "anything goes," or that these theories do not impose any constraints on good explanation. We have no formula for determining the explanatory power of theories-this is true of particularist theories as well als generallist theoriesbut there is no reason to think that particularists cannot make sufficiently good sense of this notion based on the theory of explanation they end up endorsing.

Objection: The defense of a particularist research program proposed in this paper defends too much. Everything argued for in this paper in defense of a particularist 
reseatrch program can be used. mmatis mmandis, to delend other research programs, including research programs that no one should take seriously. For example, consider the "ch-ist' researeh program. Ch-ism is a research program chatraterized hy the core hypothesis that morality, including the rightness and wrongness of actions, can be explained by using only sentences that start with the letters 'ch'. Since $c h-i s m$ is a researeh program, it is neither true nor lalse, and it should be evaluated for its suceess. Moreover, the motivation to pursue ch-ism eannot be undermined simply by eiting one unobjectionable principle that does not start with the letters "ch"; in order to undermine (ch-ism one would have to present a non- "ch'starting-principle-based moral theory that provides an adequate aceount of morality. But sinee no such theories are currently available, ch-ism remains unseathed. Moreover, $c h$-ists can offer the following positive heuristic: try to formulate explanations of morality that hegin with the letters "ch". Obviously, no one should seriously consider pursuing the ch-ist research program. Yet the arguments put forward in this paper lead to the conclusion that $c / h$-ism should be laken seriously. Therefore, there must be something wrong with the arguments presented in this paper-il they prove anything they prove too mueh. ${ }^{55}$

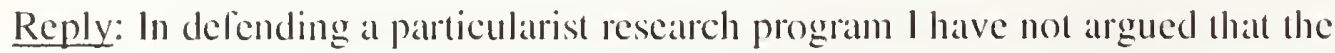
generalist research program should be abandoned. Indeed, I have presented no arguments against pursuing a generalist research program, or any other conceivable researeh program for that matter. The main goal of this paper is to fend off a familian and prominent line of objections to partieularism that purports to show that the particularist project is founded on a simple mistake-that particularist are committed to

${ }^{55}$ Thanks to Kelby Mason for pressing me on this issue. 
a thesis which is demonstrably false and/or entirely unmotivated. I think that these objections fail for reasons discussed in the previous sections. Moreover, I think that these objections are equally ineffective as objections to ch-isml; the fad that we can formulate one or a few unobjectionable moral principles such as (SP) or (TBF) is elearly not the reason why we should not pursue ch-ism. The reason we shouldn't pursue ch-ism is that it is an uninteresting project and we have no reatson to believe that it will produce any worthwhile results. The fact that the aforementioned objections fail to undermine ch-ism does not demonstrate that my defense of paticularism defends too much, but instead it indicates that these objections are completely misguided.

Someone might, perhalps, think that panticulanism, like (h-ism, is uninteresting and that we have no reason to think that it will lead to any worthwhile results. However, to the best of my knowledge no one has yet allgued that particularism is uninteresting, and it seems to me that the particularist rescarch program hats alleady generated worthwhile results-namely, holism in the theory of reasons; even those who reject holism admit that it is an interesting and worthwhile contribution to the study of the mature of reasons. Yet more, if it is reasonable to suspect that we can sensibly interpret Aristotle as offering a particularist account of morality. then we maly have good reason to think that particularism will lead to further interesting and important philosophical results. Surely there are many important differences hetween particularism and ch-ism and it should be clear that particularists, like generalists, have the resources to explain why-unlike particularism and generalism-ch-ism is not worthy of pursuit.

Objection: The main thesis of this chapter is just trivial. This chapter defends the thesis that the particularist rescarch program is worthy of pursuit-lhat is, that we 
should try to develop an explanation of morality that is not based on the availability of yet-to-be-found exeeptionless moral principles, and that it may turn out that a particularist account of morality will be superior to compeling principle-based accounts. But why would anyone think otherwise? Why would anyone think that any explanation must be grounded in exceptionless principles? Clearly, in the soft sciences we explain phenomena without exceptionless principles. No one has ever claimed-or at least, no one should ever have elaimed-that a full explanation of a historical event, for example, must be grounded in an exceptionless principle. Moreover, the objector might saly, even in physics our explanations are not exception-free since our fundamental physical theories are notoriously inconsistent. So why spend all these words arguing for a trivial point?

Reply: When an objection to the effeet that a thesis is trivially true is juxtaposed with an objection to the effect that this thesis is obviousty false, one might think that the prefixes "trivially" and "obviously" cancel each other out-the thesis is cither true of false, but it is probably neither mivially true nor obvious/y false. But perhaps those who are moved by the triviality objection think that the objection to the effect that the main thesis is obviously false need not have been mentioned at all. I am happy to endorse this part of the criticism. However, it should be clear thatl, all least sinec Kant, many outstanding philosophers have tried to find and formulate exceptionless moral prineiples, and many outstanding philosophers still do so today. So even if the point is trivial, I believe it is worth mentioning.

In fact, however, I do not think that this is a trivial matter. In this chapter I have only mentioned what I take to be the most prevalent objections to particularism. But 
there are other worries that I have not discussed. For example. it has been claimed that a particularist aceount of morality entails one or more of the following undesirable consequenees: (i) moral knowledge is impossible: ${ }^{56}$ (ii) other peoples (moral) behavior is entirely unpredictable: ${ }^{57}$ (iii) moral disagreements camnot be resolved: ${ }^{58}$ and (iv) moral education is impossible. ${ }^{59}$ I will not try to respond to these worries here. Suffice it to saly that even though I believe that these worries are not insurmoumtable. circumventing these problems is eertainly not a trivial matter.

\subsection{Conclusion}

Moral philosophy in the past few hundeed years hats been dominated by generalism. Philosophers have assumed-without argument-hall a suecessful explanation of morality must be grounded in exeeptionless principles. Perhaps the commitment to gencralism was influenced by the remarkable progress in the sciences spawned by the scientific revolution. Perhaps the thought was that a successiul explanation of morality should be modeled on explanations in the sciences, and that moral phitosophers should seck exceptionless moral principles that would platy a similar explanatory role to the role played by laws of nature in the seiences. Yet despite the fact that many outstanding philosophers have spent their eareers trying to find and formulate exceptionless explanatory moral principles, such principles have not yet been found.

It would be a mistake to argue from the persistent failure to formulate satisfactory prineiples, to their non-existence. After all, it was Le Verrier's unwavering

\footnotetext{
${ }^{56}$ Sec Täinnsjö (1995) and M\&R (2006).

57 Sec Hooker (2000).

${ }^{58}$ See Simnoll-Armstrong (1999).

59 See Hooker $(2000)$ and Hare (1952).
} 
commitment to the Newtonian research program in the face of persistent failures that led to his celebrated discovery of The Planet Neptune. However, it wals his unwavering commitment to the Newtonian research proglam that led him on a wild goose chase in search of The Planet Vulcan.

Despite the surge of interest in particularism in recent years. we must not forget that particularism is a budding research program-it promises an account of morality. but it has not yet delivered a full-fledged theory. At present, then, it would be rash to endorse particularism. However, we should also keep in mind that generalism is only a promise of a theory as well. A full-fledged generalist theory will consist of a principle. or a set of principles, that provides an adequate account of morality. At present, no such principle has been found. So it is equally rash to endorse generalism for the very same reasons it is rash to endorse particularism, and consequently, the claim that particularism is only a promise of a theory has no dialectical foree in the context of the particularism-gencralism debatc.

Even though it may be rash to endorse particularism, it may well be rational to explore its strengths and weaknesses. As Laudan observes, onc can pmrste a research program without endorsing it. He writes:

|There are| many historical cases where scientists have investigated and pursued theories or research traditions which were pattently less aceeptable, less worthy of belief, than their rivals. Indeed. the emergenee of virtually every new reseatreh tradition oceurs under just such circumstances...it would be...mistaken to refuse to pursue /a budding reseatrch program if it has exhibited a capacity to solve some problems (empirical or conceptual) which its older, and generally more acceptable rivals have failed to solve. (1977:110-1) 
We cannot yet determine whether the particularist research program will produce a better aceount of morality than eompeling principle-based theories.

Nevertheless, the persistent failure to formulate exceptiontess explanatory principles should motivate us to explore new routes and particularism shows enough promise to warrant further exploration. Particularism, I submit. is worthy of pursuit.

\subsection{Appendix: Dancy's (2004) Formulation of Particularism}

Jonathan Dancy is the philosopher most associated with patricularism; the current interest in particularism is latgely due to his extensive work on the topic. In his recent book. Ethic Without Principles (2004), Dancy offers a suecinct statement of the particularist thesis. Given Dancy's singular contribution to the atvancement of the particularist project in the past twenty years, and given that Dancy deseribes his recent book as "the culmination of twenty-five years" work" on this topic, his own recent formulation of the particularist thesis undoubtedly deserves special attention. Dancy's identifies particularism as lollows: "Particnlarism: the possibility of moral thought and judgment does not depend on the provision of a suitable supply of moral principles." (7)

Several philosophers have recently examined Dancy"s statement. Joseph Raz (2006), in his recent critique of Dancy"s book, struggles with Dancy"s formulation of particularism. He claims that this formulation is open to several interpretations, but only one of these interpretations, he thinks, can be properly attributed to Dancy, since the others appear to be empirical theses. So Raz proposes that the best literal interpretation of Dancy"s particularism is the clenial of the following claim: "Conditions of thonght generalism (CTG): no one would be capable of having moral thought and judgments unless there were suitable moral principles." (114) 
But the denial of CTG, Raz claims, is clearly false: "The problem is that it is a necessary truth that general moral thoughts are possible only if there are general moral propositions which express them, propositions being the content of a possible truth-apt thought. And it maly be a necessary truth that all particular propositions have corresponding general propositions." (1 14-5). So, he concludes, we must interpred Dancy non-literally.

Perhaps, he suggests, particularism is the denial of the following claim: "JG: Justilicatory generalism is the thesis that the justification of any moral view involves a true, or justified moral principle." (115) However, Raz thinks that we cannot properly interpret Dancy's patticularism as the denial of JG. Raz cites the following passage from Dancy:

|T there can be forms of holism that do not go so far as particularism. That is, we can aceept the context-sensitivity, the variability, of reasons, but still suppose that there are the sorts of general truths about how reasons behave that might be expressed by moral principles (Dancy (2004) pp. 7-8)

He then comments that "This |passage|, in showing |Dancy| to believe that particularism denies that there are true or valid moral principles, shows that my interpretation of his definition |as the denial of JG| does not eapture his intentions." (115) Having ruled out this interpretation of Dancy's particularism, Raz goes on to attributes to Dancy the following view "there are true moral propositions but no true moral principles" (115) and concludes that this view is untenable.

M\&R also have difliculties with Dancy's formulation since il does not fit nicely into their proposed systematic laxonomy of particularist theses. They name Dancy's form of particularism Anti-Transcendental Particularism (henceforth ATP), and they 
view it as one of several negative elaims that palticularists make about moral principles. ${ }^{60}$ They interpred ATP as "at thesis about what is presupposed by our ability to make moral judgment sucessfully or correctly, where this includes the ahility to have moral knowledge" (19) and they observe that "Anti-Transeendental Particularism seems ill-suited to provide the radical challenge to the possibility of moral theory particularists sometime envisage... ATP| poses a challenge not to principled morality as such, but merely to transcendental arguments for it." (19-20)

The problems Ray and M\&R encounter with interpreting Dancy"s formulation indicate that Dancy”s formulation is probably not as clear ats we maly have wanted it to be. Nevertheless, it seems to me that both of their proposed final interpretations atre unaceptable. In the very lïst paragraph of his book Dancy writes: "A particularist conception fof moralityl is one which sees little if any role for moral principles.

Patticularists think that moral judgment can get along perfectly well without any appeal to principles, indeed that there is no essential link between being a full moral agent and having principles." Dancy is not saying. pare Rat,, that there are no true moral principles. Moreover, these two sentences indicate that Dancy's project, pare M\&R. does pose a "radical challenge" to traditional moral philosophy sinec it undermines the foundational assumptions of some of the most widely discussed ethical theories-viz.. Utilitarianism and Kantianism.

\footnotetext{
6) See M\&R (2006) p. 14. Other "negative claims" include: eliminativism-that there are no true moral principles, skepticism-that there is no reason to think that there are any moral principles, abstinence-that we ought not rely on principles, and principled particularism-that any finite set of moral principles will be insulficient to capture all moral truths.
} 
It seems to me that the best way to understand Dancy's book is to interpret his formulation of particularism as a statement of the particularist research proglanm. Understond as such, we can view his account of holism in the theory of reasons as fleshing out a schema for non-principle-based explanations of moral facts/judgments, rather than as an angument against the existence of moral principles. I do not mean to suggest that Dancy thought of his project in these terms, or that there are no textual difficulties for interpreting Dancy"s project in the way I suggest here. Nevertheless, it seems 10 me that this interpreation allows for the most plausible, and perhaps also the most interesting, construal of Dancy"s project.

"In personal correspondence. Dancy acknowledged that this interpretation is close to how he sees the matler. 


\section{CHAP'TER 2}

\section{MORAL ADVICE AND MORAL 'THEORY}

\subsection{Introduction}

Monists, pluralists, and particularists disagree about the structure of the best explanation of the rightness (wrongness) of actions. In this chapter I algue that the availability of good moral advice gives us reason to prefer particularist theories and pluralist theories to monist theories. First, I identify two distinct roles of moral theorizing-explaining the rightness (wrongness) of actions, and providing moral adviee-and l explain how these two roles are related. Nex1, I explain what monists, pluralists, and particularists disagree about. Finally. I argue that particularists and pluralists are better situated than monists to explatin why it is a good idea to think before we act, and that this gives us reason to favor particularism and pluralism over monism.

\subsection{The Two Roles of Moral Theorizing}

It is eommon to distinguish between two different roles of moral theorizing: a theoretical role and a practical role. The theoretical role of moral theorizing is to provide an account of the rightness/wrongness of actions. Smith. for example, asserts that the theoretical role of moral principles is 10 "specify the chatrateristics in virtue of which acts possess their moral status."2 Similarly, Bales stattes that one thing an ethical theory is supposed to do is "to provide an account of that characteristic, or perhaps that

\footnotetext{
${ }^{1}$ This terminology is due to Smith (1988). Similar distinctions can be found, for' example, in Bales (1971), Reed and Brown (1984), Railton (1984), Frazier (1994), Crisp (2000), and Väyrynen (2006).

${ }^{2}$ Smith (1988) p. 89.
} 
very complex set of characteristies, which all and only right acts have by virtue of which they are right.. ${ }^{3.4}$ Let us saly that at theory fulfils the theoretical role if it explains the rightness/wrongness of actions, or if it identifies the feature (or the set of features) that makes right acts right.

The practical role of moral theorizing is to guide judgment or action. Smith, for example, salys that the practical role of moral principles is to serve as "a standard by reference to which a person can guide his or her own behavior: a standard to help the person choose which acts to perform and which not." And Bales suggests that in addition to identifying a criterion of moral rightness, we may want moral theories to provide us with "a procedure which would help us single out, in the particular case and meder an inmediately hetpfinl description, which alternative would in fact the morally rightl." In order to fulfill the practical role, a theory must provide some advice regarding which action to perform. ${ }^{7}$ General moral advice is at statement of the following form: perform action $A$ if and/or only if $\psi{ }^{8}{ }^{8}$

\footnotetext{
${ }^{3}$ Bales (1971) p. 260.

${ }^{4}$ Smith and Bales seem to think that in order to provide an aceount of the rightness/wrongness of actions, we must find and formulate exceptionless moral principles of the form: For any action, $A$, if $A$ exemplifies property $P$. then $A$ is morally right (wrong). However, we need not presuppose that the only way to explain the rightness/wrongness of actions is to identify exceptionless moral principles-there may be other ways to do so. See Chapter I and section 2.3 below.

${ }^{5}$ Simith (1988) pp. 89-90.

"Bales (1971) p. 261.

${ }^{7}$ For simplicity of exposition, I focus on guiding action alone, rather than guiding action or judgment. However, everything 1 say about guiding action applies, mutatis murandis, to the guidance of judgment ats well.

${ }^{8}$ In particular situations moral advice could take a simpler form: perform action $A$ (without the 'if and/or only if $\psi$ ' clause). I will focus on moral advice that is meant to apply generally, and not only to an individual case. Nevertheless, we sometimes give/receive advice in different forms; e.g., "think about the consequences", or "if I were
} 
The theoretical role and the practical role of moral theories are distinct. A theory can futfill one of these roles without fulfilling the other. For example, many ateconsequentialists betieve that although act-consequentialism provides the best account of what makes right acts right, it offers no moral guidanee." Several nonconsequentialists also endorse this distinction. C. D. Broad, for example, writes: "We can no more learn to act rightly by appealing to the ethical theory of right action than we can play golf well by appealing to the mathematical theory of the flight of the golfball." ${ }^{10}$ In a similar vein, one can offer moral advice without commilling oneself to any particular aecount of what makes right acts right; indeed, this is quite common in the applied ethics literature. "Simply put, then, the point is this: an explanation of what makes right acts right need not help us determine which act to perform, and a statement of moral advice need not explain what makes right acts right. Let us reserve the term moral theory for accounts that explain the rightness/wrongness of actions, and the term moral adive for accounts that purport to guide judgment or action.

In principle, we can supplement any moral theory with any moral advice.

Consider, for example, the following version of act-utilitarianism:

you, I would do $A^{*}$. But strictly speaking these forms of advice do not help us decide which action to perform: they could be helpful if they are understood as shorthand for something like the following: "think about the consecuences, and perform the action that you believe would lead to the best possible eonsequences"; and "Perform action $A$ if you want to perform that action that I would have performed if I were you". So even if moral advice does not explicitly take the form: perform action $A$ if and/or only if $\psi$, we should be able to restate it in this form.

"Sec, for example, Bales (1971), and Feldman (2006).

${ }^{10}$ Broad (1930) p. 285. It is interesting to compare Broad’s view to Aristotle's view. Aristolle motivates his project in the Nicomachean Ethic's by suggesting that the study of ethics is likely to help us hit upon what is right (1094al8-25). For more on this, see Chapter Four.

$"$ See, for example, Hébert (1996), and Strong (1988). 
( $\mathrm{UU})$ An ace, $A$, is morally right il and only il $A$ maximizes utility.

(AU) tells us that an act is right if and only il it exemplifies the property of utility maximization. We eould supplement (AU) with the following advice: Perform action $A$ if and only if $A$ exemplilies the property of utility maximization. But we could, instead, supplement (AU) with diflerent advice. For example: Perform atetion $A$ onty if you believe that your mother would not disapprove of it.

One could insist that the theoretical role and the practical role of moral theorizing ate not distinct. Consider (AU) again. One could ctaim that (AU) both explains what makes right acts right and tells us which action to perform; to saly that an act is morally right is simply to saly that it is permissible to perform that act. So (AU) call be stated as follows:

( $\Lambda \mathbf{U}^{\prime}$ ) It is permissible to perlorm act $A$ il and only if $A$ maximizes utility. We can restate (AU") in the imperative mood as follows:

$\left(\Lambda U^{\prime \prime}\right)$ Perform action $A$ il and only if $A$ maximizes utility.

But (AU”) is a statlement of moral advice. So a eriterion of moral rightness does tell us which action to pertorm, and as a result, the objection goes, there is no distinction to be made between moral theory and moral advice.

(AU') satlisfies the one constraint on moral advice that we have discussed so lar-that is, it hats the proper form for moral advice (perform action $A$ if and/or only il $\psi$ ). But surely there is more to good moral advice than having this lorm. I propose the following two additional constraints on good moral advice:

1. Good moral advice is advice that agents con use. Let us saly that agents can use moral advice $S$ just in case the condition $\psi$ mentioned in $S$ is specified under a 
helplul description. Roughly speaking, a description of $\psi$ is helpful if (normal) agents can usually tell whether this eondition (as described) is satisfied. This requirement on good moral advice is an epistemic requirement-if we usually cannot determine whether $\psi$ is satisfied, then $S$ is not good moral advice. One reason to think that the theoretical and the practical roles of moral theorizing are distinet, then, is that the metaphysies of morality need not be constrained by epistemic requirements. In other words, a criterion of moral rightness could be true even if we usually cannot tell whether any action exemplifies the property this criterion identilies as the right making property. So, for example, even if we cannot use (AU"), the lact that we eannot use (AU") does not give us reason to believe that (AU) is lalse. ${ }^{12}$ And consequently, if we believe that (AU) is true. but also that we eannot use (AU“"), we must lind alternative moral advice in order to satisly the practical role of moral theorizing.

2. Good moral advice is advice that agents should follow. Let us saly that an agent should follow $S$, if she is more likely to do the right thing if she follows $S$ than if she fails to follow $S^{13}$. $1 \mathrm{is}$ important to note that it does not follow firom the fate that an agent is more likely to choose a morally right action if she follows S than

\footnotetext{
12 This is the main point of Bales"s paper (1971). He writes: "The...argument|s| I am challenging may be telling eritiques of the decision-making procedure most frecpuently associated with act-utilitarianism, as a decision-making procedure for act-utilitarianism. but I cannot see that they are even relevant to the question of whether act-utilitarianism, as it is usually formulated, is true. For ectainly it eould be the ease both that all and only right acts are those which eontribute no less than would any alternative towards intrinsically good states of affairs, and that the procedure of estimating and comparing the probable eonsequences of alternative acts is an impracticable or self-deleating procedure for singling out, under immediately helpful descriptions, right acts so challacterized." (263)

${ }^{1.3}$ The "should" here is the prudential should; if one wants to aet rightly, then one has reason to use good moral advice.
} 
il she fails to follow $S$, that all, or even most, agents who follow $S$ would agree about which action is morally right in any particular situation. Indeed, it does not even imply that those agents who follow S are more likely to chose a morally right action rather than a morally wrong action. The best waly to understand this elaim is as follows: Consider a large number of agents, each of which is required to make a moral decision. Divide these agents into two groups. All agents in one group-Group $A$ - lollow $S$, while all agents in the other group-Group B-Cail to follow S. Let us saly that the rightness-to-wrongness ratio of each group is the number of morally right acts chosen by members of the group divided by the number of morally wrong acts chosen by members of that group. We should understand the claim that agents are more likely to choose a morally right action if they follow $S$ than if they fail to follow $S$ as follows: it is likely that the rightness-to-wrongness ratio of Group) $A$ is greater than the rightness-to-wrongness ratio of (Gromp) B. Surely there are many possible ways to fail to follow $\mathrm{S}$, and the rightness-to-wrongness ratio of Group $B$ will depend on the procedure the members of this group adopt. If there is a known proecdure, $T$, which is distinct from $S^{1+}$ such that if agents in Group $B$ were to follow $T$ the

\footnotetext{
${ }^{14}$ Adviee $T$ is distinct from advice $S$ just in case agents who follow $T$ do not, ipso facto. also follow $S$. For example, if advice $S$ is perform action $A$ only if $\psi$, and advice $T$ is perform action $A$ only if $\mid \psi$ and (o) then agents who follow $T$ also follow $\mathrm{S}$. In other words, since $T$ is a precisification of $S$, agents who follow $T$ do not fail to follow $S$. This means that it is possible that agents should follow $S$ even if we know that there is some other moral adviee, $O$, that yields a greater rightness-to-wrongness ratio, as long as agents who follow $O$, ipso facto, also follow $S$.
} 
rightness-to-wrongness rattio of (iromp $B$ would be greater than the rightness-towrongness ratio of Gromp $A$, then agents should follow Trather than $S .{ }^{1.5}$

To illustrate these constraints on good moral advice, consider the following advice:

(M $\Lambda$ l) Perform action $\Lambda$ il and only if $A$ is morally right.

Surely an agent is more likely to do the right thing if she follows this advice than if she fails to follow it. However, the condition $\psi$ is not speeified under a helplul deseription-we often do not know whether an action satisfies the description "is morally right'. So although agents should follow (MAl), they cannot use it.

Now consider this advice:

(MA2) Perform action $A$ only if you believe that $A$ will bring you pleasure in the immediate future.

Here the condition $\psi$ is specilied under a helplul description-we call usually tell whether we believe that an action would bring us pleasure in the immediate luturebut it is not true that an agent is more likely to do the right thing if she follows this advice than if she lails to do so. (MA2), like (MA1), is not good moral advice. Even though agents con use (MA2), it is not the case that they should use it.

Much more needs to be said about these constraints on good moral advice. For instance. we must explain what it is for an agent to use moral advice. ${ }^{16}$ We must also specify more accurately which descriptions of $\psi$ are helpful descriptions. However, for

\footnotetext{
15 Thanks to an anonymous referee for pressing me on this issue.

${ }^{16}$ Smith (1988) suggests the following: "an agent uses a principle as a guide for making a decision just in case the agent chooses an act out of a desire to conform to the principle, and a belief that the act does conform." (91) She goes on to make several qualifications to this statement on p. 92, and p. 105 n. 18.
} 
the purpose of this chapter our intuitive grasp of what it is to use advice, and which descriptions are helpful descriptions, will do. Instead, I want to focus on a certain constraint that good moral advice imposes on moral theories, a comstraint that has been largely overlooked: If $S$ is good moral advice, our moral theory should be able to explain this fact. That is, our moral theory must explain how it is that agents who follow $S$ are more likely to choose a morally right action than those who fail to follow $S$.

Recall that moral advice $S$ is a statement of the following lorm: perform action $A$ if and/or only if $\psi$. Recall, also, that to saly that agents should use $S$ is to say that agents who follow $S$ are more likely to do a right action than agents who fail to follow $S$. This means that an agent is more likely to perform a right action if she is sensitive to whether condition $\psi$ is satisfied than il she is not so sensitive. So in order to explain the fact that $S$ is good moral advice, we have to explain how being sensitive to the features mentioned in condition $\psi$ can help agents to identify morally right actions. But in order for $\psi$ to help agents to identify morally right actions, $\psi$ must somehow track morally relevant features of actions-otherwise it would be utterly mysterious how using $S$ could possibly increase an agent's likelihood of performing a right action.

Consider, for example, the following moral theory:

(TT) An act, $A$, is morally right if and only if $\varphi$.

Presumably $\varphi$ explain what makes right acts right- $\varphi$ is the feature in virtue of which right acts are right. Now, if the condition $\psi$ mentioned in $S$ is completely unrelated to the condition $\varphi$ mentioned in (TT), then the lact that sensitivity to whether $\psi$ is satisfied increases one's likelihood of doing a right action is inexplicable. So although the theoretical role and the practical role of moral theorizing are distinct, they 
are related in (at least) the following way: there should be some explanation for the fact that sensitivity to the faetors mentioned in $y$ helps agents to track features that our moral theory identifies as morally relevant.

\subsection{Monism, Pluralism, and Particularism}

The particularism-generalism debate, as I understand it, is a debatte about the structure of the best explanation of morality. ${ }^{17}$ Generalists believe that in order to explain the fact that an aet, $A$, is morally right, we must identify some property, $P$, that A exemplifics, and an exeeptionless principle according to which any action that exemplifies $P$ is morally right. Particularists, on the other hand, clatim that we can explain the rightness of $A$ without appealing to an exceptionless principle. That is, the best explanation of the fact that $A$ is morally right is that $A$ exemplifies a property, $P$. and that in this patticular casc $P$ is right-making. 18

Monists and pluralists are generalists becatuse they believe that an explanation of a normative status of an action is inadequate unless it is grounded in an exceptionless moral principle. However, monists and pluralists disagree about the number of intrinsically morally rele'tmu properties (henceforth IMR-properties). Let us saly that at property, $P$, is intrinsically morally relevant if and only if $P$ is morally relevant for its own sake, or non-derivatively morally relevant. A property is extrinsically morally relerant if and only if it is nom-intrinsically morally relevant; that is, if it is only

\footnotetext{
${ }^{17}$ See Chapter 1.

${ }^{18}$ Parlieularist may be able 10 saly more about why $P$ is right-making in this case. See, for example, Lanee and Litle (2004) \& (2007). Nevertheless, the key point is that particularists insist that an explanation of the rightness of an aetion need not be grounded in an exeeptionless moral prineiple.
} 
derivatively morally relevant, or morally relevant only in virtue of its relation to some IMR-property.

Monists claim that there is only one IMR-property-call it $P$-and that any action that exemplifies $P$ is morally right. Pluralists maintain that there are several IMRproperties-call these properties $/ 2 / . . P n$-and that for each IMR-property, Pi, there will be a prestmmptive. or pro tanto, principle: for any action, $A$, if $A$ exemplifies Pi then $A$ is presumptively morally right (or wrong); or in other words, $P i$ is alwatys rightmaking. "Pluralists are generalists because they think that in order to explain the rightness of $A$, it is not enough to recognize that $A$ exemplifies $P$, and that $P i$ is rightmaking here; they think that we must identify an exceptionless principle that states that $P i$ is always right-making, or that any action that exemplifies Pi is presumptively morally right.

The particularism-generalism debate is a debate over whether we must find and formulate exceptionless moral principles in order to provide an adequate alecount of the rightness (wrongness) of actions. Gencralists believe that an explanation is inadequate unless it is grounded in an exceptionless principle (cither an absolute principle: any action that exemplifies $P$ is morally right, or a contributory principle: Pi is alwatys rightmaking); particulanists disagree. However, even though monists and pluralists alre generalists, they differs with respect to the number of IMR-properties they allow; monists insist that there is only one IMR-property, while pluralists, like particulanists. believe that there is more than one.

19 Sec, for example, Ross (1930) Ch. 2, and Shafer-Landau (1997). 
For example, consider (AU) again. (AU) is a monist heory. According to (AU)

there is only one IMR-property-namely, utility-maximization. Il an atclion exemplilies this property, it is morally right; otherwise, it is morally wrong. Justice, for instance, can only be extrinsically morally relevant according to (AU); if justice is morally relevant, it is only in virtuc of its relation to utility-maximization. Pluralists, in contrast, hold that there are several morally relevant properties. So pluralists may clatim that being just, being truthlul, and being benelieent are all IMR-properties. Particularists, like pluralists, think that there are many IMR-properties, but unlike plutalists they hold that a property can be intrinsically morally relevant in some catses, but not in others. So, for example, particularists maty claim that the lace that an act exemplifies justice is intrinsically morally relevant on some occasions, but only extrinsically morally relevant, or even morally irrelevant, on other oceatsions. 20

\subsection{The Argument from Good Moral Advice}

In this section I present my argument for the conclusion that we have reason to prefer patricularist theories and pluralist theories to monist theories. The starting point of my argument is the following moral advice:

\footnotetext{
${ }^{20}$ One might think that if a property is morally relevant in virtue of its intrinsic nature and if the intrinsic nature of a property does not change from one case to another, then a property that is morally relevant in one case must be morally relevant in all calses. However, Jonathan Dancy-the philosopher most associalled with particularismalrgues that we should distinguish between favorers/disfavorers and enablers/disablers. According to Dancy, a leature that favors an action in one situation maty be disabled (or it could fail to be enabled) in another situation. Nevertheless, the absence of a disabler (or the presence of an enabler) in the first situation is not a part of the feature that fatvors the action. For Dancy's account of holism in the theory of reasons see his (1993), $(2000),(2003)$, and $(2004)$.
} 
(RI) Perform action $A$ only if after reflecting on and deliberating about the normative statts of $A$, you do not believe that $A$ is morally wrong. 21 I believe that (RD) is good moral advice; I will argue that there is strong intuitive support for the claim the agents can and shonld use (RD). Since my argument begins with the premise that (RD) is good moral advice, we can call this argument The Argumem from Good Moral Advice lor GMAl:

1. (RD) is good moral advice.

2. In order to explain (I), we must explain how it could be that the factors that agents consider when they reflect on and deliberate about the normative status of an action are morally relevant features of that action (either intrinsically or extrinsically).

3. Monist theories cannot explain how it could be that that the factors that agents consider when they reflect on and deliberatte about the normative status of an action are morally relevant features of that action.

4. Pluralist theories and particularist theories can explain how it could be that the factors that agents consider when they reflect on and deliberate about the normative status of an action are morally relevant features of that action.

5. Therefore, we have reason to prefer pluralist theories and particularist theories to monist theories.

\footnotetext{
21 (RD) is a very general form of moral advice, and it can be precisilied in various dilferent ways. For example Hébert’s decision procéclure in Hébert (1996) can be viewed as one possible precisilication of (RD). Ross (1930) seems to endorse some version of (RD) as well: "we are more likely to do our duty if we reflect to the best of our ability on the prima facie rightness or wrongness of various possible acts in virtue of the characteristics we perecive them to have, than if we act without reflection. With this greater likelihood we must be content." (p. 32).
} 
Our lirst order of business is to determine whether (RD) is, in fict, good moral advice. (RD) is meant to eapture the moral advice thatl eolloguially can be statled as lollows: 'Think belore you acl', or, "ll you think it's wrong, don't do il'. Now surely this advice is not always good advice. For instance, il a speedy action is called lor, one hatd better not stop and think before one acts. Furthermore, if one is completely ignorant about the situation one is lacing, or il one is exessively insensitive or irrational, thinking before acting is unlikely to help one choose correctly. So we must qualify premise (1). First, we should restrict the claim that (RD) is good moral advice to situations in which one hats lime lo deliberate before acling. Second, we should restriel this claim to a certain type of agents; (RD) is good moral advice for reasonably rational. sensitive, and well-informed agents (heneforth, RSI-agents). I will not allempt to provide a demarcaling criterion for reasonably rational, sensitive, and well-informed agent. Suffice it to saly that although the notion of RSI-agents is meant to excolude agents like those described above, it is supposed to include most ordinaty mature individualspeople like you and me. Premise (1), then, should be stated as lollows: (RD) is good moral advice for RSI-agents in siluatlons in which an immediate action is not required. However, for simplicity of exposition I will omit these qualilications in what follows. In order to ascertain whether (RD) is good moral advice we must determine whether agents can use (RD) and whether agents should use (RD). Let us address these questions in turn. In order to use (RD), one must be able to identily whether one believes, upon reflection and deliberation, that an action one is contemplating is morally wrong. I see no reatson to think that under normal conditions RSI-agents camnot tell 
whether they believe that a particular act is morally wrong. Therefore, I believe that agents can (usually) use (RD).

One might insist that there are oecasions in which one cannot use (RD); indeed, one might think that (RD) is unusable precisely in those instanees where moral advice is most needed. ${ }^{22}$ Consider, for example, the following situation. Due to your outstanding moral reputation, the Supreme Court has ruled that it is up to you to decide whether at particular patient in a persistent vegetative state should be taken off the feeding lube and allowed to die. You study the case carefully, but you are unsure whether it is morally permissible to disconnect the feeding tube. You decide to consult your wisest friend. You describe the case to your friend and you ansk her for guidance: "Do you have any advice for me?" you ask. "I do," she replies, "my advice to you is this: perform an action only if after reflecting on and deliberating about the normative status of that act. you do not believe it is morally wrong."

Your friend's advice is disappointing. Nevertheless, although it may well be appropriate to complain about the advice you received, I do not think that you c'annot use it: surely you can reflect on the normative status of a possible course of action, and choose not to perform it if you believe it is morally wrong. ${ }^{23}$

But if you can use your friend's advice, then why is her advice disappointing? There is an important difference between general moral advice and particular moral advice. (RD) is appropriate as general moral adviee, but it is quite unsaltisfying as advice for a particular case. When you ask your friend for advice regarding a concrete

\footnotetext{
22 Thanks to Gwen Bradford for pressing me on this issue.

${ }^{23}$ You would be unable to follow (RD) if you believed that all the options available to you (including non-action) are morally wrong,
} 
situation you are facing, it seems reasonable to expect your friend to help you struggle through considerations in favor and against various possible courses of action. In offering (RD) in response to your recuest for advice in the case described above, your friend violates certain conversational norms and/or certain norms of friendship (e.g., don't stalle the obvious; try to help your friends). This, I submit, is the reason why her advice is disappointing.

Lel us, then, evaluate (RD) in a context in which general moral advice is appropriate. Consider, for instance, the following scenario: you have just been appointed general manager of a large hospital. You decide to gather your employees for a moral pep talk, and you deliver a passionate speech on the importance of morality in the hospital selling. You conclude your talk by offering the following moral advice: "Before you perform any action, stop and think about the act you are about to perform (unless it's an emergency) and if you think it is wrong. don't do it!" It seems to me that it would be very odd if one of your employees were to come up lo you after your speech with the following complaint: "I"m sorry to say, boss, but I simply can't follow your" advice." I conclude, then, that although in particulat situations (RD) may be less than fully satislactory, it is, nonetheless, advice that agents can follow. The question now is whether (RD) is advice that agents should follow.

To my mind, the claim that agents should follow (RD) is simply a platitude about morality; it is a piece of moral data that any account of morality must respect. Moreover, I believe that pretheoretically the intuition that it is a good idea to think before we act is overwhelming. However, since there is reason to be suspicious of philosophers" claims concerning "pretheoretical intuitions," and since it is doubuful that 
anyone reading this paper has "pretheoretical intuitions", I will try, in what follows, to motivate the claim that agents should follow (RD).

Consider the following casse: A 74-year-old man, following the death of his wife. has severe depression with thoughts of suicide and marked vegetative symptoms. He hats accepted medications and counseling but remains emotionally unstable. His physician discovers that he may have prostate cancer. ${ }^{24}$

The physician has to decide what to do. Should she tell the patient about his condition? Should she wait until she has a definite prognosis or until the patient's mental condition improves? I will not try to answer these difficult questions here. Instead, I want to ans whether the physician should follow (RD). In order to answer this question we have to compare the physician's likelihood of choosing a morally right action if she follows (RD), to her likelihood of choosing a morally right action if she fails to follow (RD).

There are two kinds of ways for our physician to fail to follow (RD): (1) she could perform an act, $A$, without reflecting on and deliberating about the permissibility of $A$ - ior example, she could perform $A$ because it is the first act she happened to think of; or (2) she could performs $A$ even though after reflecting on and deliberating about the normative status of $A$, she comes to believes that $A$ is morally wrong. I suspect that most readers would advise our physician to use (RD) rather than to choose an act without reflecting on its normative statts, or to choose an act she believes is morally wrong. Moreover, I expect that many would advise the physician to use (RD) becanse they believe that by using (RD) our physician increases her likelihood of choosing a

24 This case description is quoted from Hébert (1996) p.78 (case 4.7) 
morally right action. 25 Indeed, if we do not believe that by using (RD) the physician increases her likelihood of choosing a morally right act. then in so far as we are interested in her doing the right thing, we need not ask the physician to reflect on the permissibility of her actions, or to ace in accordance with her eonsidered moral belicls. I find this result extremely counterintuitive, and I take this to show that there is strong intuitive support for the claim that RSl-agents should use (RD).

But perhaps my conclusion is too hasty. One might grant my intuition that in the case described our physician should follow (RD), but deny that agents should always, or even usually, follow (RD). One could point out that there are situations in which reflection and deliberation dererease one's likelihood of choosing a morally right action. For example, consider Mark Twain's portrayal of Huckleberry Finn. ${ }^{26}$ Huck helps his slave friend Jim to escape from his owner. Upon reflecting on his action, Huck believes that ansisting Jim is morally wrong. Yet he camnot bring himself to turn Jim in, even though he helieves that turning him in is the right thing to do. According to the story, then, had Huck followed (RD) he would have acted wrongly.

Another interesting example of a case in which an agent would have done beller by not following (RD) is described in the story Demtsches Regriem by Jorge Luis Borges. $^{27}$ This story is a first-person aceount of the aclions and thoughts of a fictional Nazi officer-Otto Dietrich zur Linde. In 1941. zur Linde was appointed subdirector of

\footnotetext{
25 There might be other reasons to recommend using (RD). One could argue that agents should follow (RD) not becatuse (or not only becaluse) it increases the likelihood of choosing correctly, but rather for reasons that have to do with moral responsibility, atutonomy, or the manifestation of good moral character. However, I will not discuss these alternatives here.

26 See Bennell (1974) and Arpaly (2003) for a discussion of this example, and for various other interesting cases.

${ }^{27}$ Reprinted in Borges (1998) pp. $229-234$
} 
the Tarnowit\% concentration camp. "Carrying out the duties atlendant on the position." he tells us,

was nol something I enjoyed, bul I never simned by omission. The coward proves himself among swords; the mereiful man, the compassionate man, seeks to be tested by jails and others" pain. Nayism is intrinsically a moral act, a stripping away of the old man, which is corrupt and depraved, in order to put on the new. In battle, amid the captains" outeries and the shouting, such transformation is common: it is not common in a crude dungeon, where insidious compassion tempts us with ancient acts of tenderness. I do not write that word "compassion" lightly: compassion on the part of the superior man is Zarathustra's ultimate sin.

Zur Linde, as we learn from the story, reflected on and deliberated about his actions. He believed that suctumbing to compassion is immoral, and he made a special effort not to perform acts that he believed were wrong. "I myself (I confess)," he writes, "almost committed | the sin of compassion | when the famous poet David Jerusalem wass sent to us from Breslau." Zur Linde admired Jerusalem's poetry, and he made a special effort not to give in to compassion in his dealings with Jerusalem. "I was severe with him; I let neither compassion nor his fame make me soft." Zur Linde tortured Jerusalem until eventually Jerusalem sueceeded in killing himself. Aceording to the story, then, zur Linde followed (RD) meticulously, and as a result he performed heinous acts. 29

\footnotetext{
${ }^{28}$ Bennetl (1974) describes Heinrich Himmler--leader of the S.S. - as one whose commitment 10 "bad morality" conflicted with his own feeling of sympathy. I do not know whether Borges had Himmler in mind when he wrote Deutsches Requiem. ${ }^{24}$. Dostoyevsky`s Raskolnikov is another example of this sort that comes to mind. Raskolnikov believed that it was not wrong for him to kill the old lady. And indeed. Borges has zur Linde mention Raskolnikov as a moral exemplar.
} 
These examples illustrate that there are situations in which agents are less likely to do the right thing if they follow (RD) than if they fail to follow (RD). Docs this prove that $(R D)$ is not good morial advice?

The claim that (RD) is good moral advice is certainly not a conceptual truth or otherwise necessary truth. We can catsily imagine worlds (maybe demon-worlds) in which (RD) is bad advice. Moreover, the claim that (RD) is good moral advice does not entail that on each and every occasion one would do better by following (RD). This claim is best understood as a strategic claim; the rightness-to-wrongness ratio of RSIagents who follows (RD) is likely to be greater than that of agents who fail to follow (RD). Consider, by comparison, the following prudential advice: (LA) Don't buy a lottery ticket if the expected utility is negative. The claim that (LA) is good advice is not a necessary truth; we can easily imagine worlds in which it would be prudent to buy lottery tickets with negative expected utility. However, one could think that (LA) is good prudential advice (in our world) even though one is well aware that following (LA) maly sometimes lead to worse outcomes than failing to follow it-als anyone who won a significant amount of money in a lottery would attest. If the number of lottery winners were substantially larger than it is, we might have hatd reatson to suspect that (LA) is bad advice. But given the winner-to-loser ratio in standard negative-expectedutility Iotteries, the fact that there are some winners does not undermine the elatm that (LA) is good advice. Similarly, if there are relatively lew cases in which one would do better by failing to follow (RD) rather than following it. then pointing out that there are a few such cases gives us no reason to believe that (RD) is not good moral advice. 
Unfortunately, it is not as easy to determine how common cases like those of Huck Finn and zur Linde are, an it is to determine the expected utility and the winnerto-loser mattio in standard lotteries. It may seem tempting to argue that although Huck acted rightly by failing to follow (RD) in his dealings with Jim, his overall rightness-towrongness ratio is likely to have been greater had he consistently followed (RD) than hald he faited to do so. But it is not quite so tempting to take this route with respect to zur Linde, whose atrocious actions seem to result from his unfattering compliance with (RD). Altematively, it maly seem tempting to argue that zur Linde is not a reassonably rational, sensitive, and well informed agent, but it is not as tempting to argue that Huck is not a RSI-igent. Moreover, in order to deny that zur Linde is a RSI-igent, we will have to specify a criterion for RSI-agents-al task I am not prepared to undertake here. Instead, I wish to sidestep these complicated cases. All I need to establish for purposes of the GMA argument is that we can identify a sufficiently large group of people for whom (RD) is good moral advice. If we can identify such a group, we will have to explain the lact that (RD) is good moral advice for them. And if particularist theories and pluralist theories can explain this fact, while monist theories cannot, then we have reason to favor the former theories over the latter.

With this goal in mind, let us return to the calse of our alforementioned physician. The physician, as described, is completely generic-l have not provided any peculial information about her. I did not specify, for instance. whether she is a consequentialist or a Kantian. Indeed, I did not specify whether she is committed to any particular moral theory at all. We do not know how many years of experience she has, whether she is a theist, or what features she considers when she reflects on and deliberates about the 
normative status of actions. Furthermore, the patucity of specifie details about the catse she is faced with suggests that there is very litte one could appeal to in order to explain why (RD) would be good advice in this case but not in others. Consequently, if one grants the intuition that in the case described our physician should follow (RD), it is hard to see what grounds one could have for denying that this intuition is quite generat. That is, unless one can identify something special about the particular features of the calse I have described, it is hard to see how one could deny that many physicians should follow (RD) in many siluations.

In contrast, we can identily a feature common to the Huck Finn calse and the zur Linde case that explains why in both these cases (RD) was not good moral advice; in both these cases the agents are committed to a "had morality". ${ }^{30}$ Huck Finn believes, like many of his contemporaries, that slaves are the property of their owners, and that helping a slave escape is morally on a par with stealing another"s properly. Zur Linde believes that the Aryan race is a superior race, and that showing compassion towards people of other races is morally wrong. 'There are, no doubt, many people who are committed to "bad moralities" of varying seopes; some "bad moralities" govern a small set of people's actions while others might govern most actions. Nevertheless, unless one grants that some people are not eommitted to wide seope bad moralities, it is hatrel to see how one could avoid moral skepticism. It is common practice in moral theorizing to take (some set of ) the moral intuitions of one's moral peers as the dat a that one's moral theory is supposed to explain. So it seems reasonable to expect that (RD) is good advice at least for some set of agents, in some set of situations. And as long as the relevant set

\footnotetext{
${ }^{30}$ I borrow the phrase bad morality" from Bennetl (1974).
} 
is large enough, then the fact that (RD) is good moral advice in these cases is a moral phenomenon that demands an explanation.

This concludes my defense of premise (1). I have argued, in Section 2.2, that if advice $S$ is good moral advice, we should be able to explain how the factors mentioned in condition $\psi$ help agents to track leattures that our moral theory identilies as morally relevant feattures of actions. So in order to explain the lact that (RD) is good moral advice, we must explain how it could be that the factors that agents consider when they reflect on and deliberate about the normative status of an action are morally relevant features of thatl action (either intrinsically or extrinsically).

The question now is this: can monist theories explain how it could be that the factors that agents ensider when they reflect on and cleliberate about the normative status of an action are morally relevant features of that action? Recall that according to monism. there is only one IMR-property. According 10 (AU), for example, the only IMR-property is the property of utility-maximization. So in order to explain the suecess of (RD), proponents of (AU) will have to explain how those factors that RSI-agents consider while reflecting on and deliberating about the permissibility of a particular act. reliably track the property of utility-maximization.

Consider, again, our physician from the abovementioned example. While reflecting on the normative status of a particular action, $A$, she may think of considerations like these: Will doing $A$ violate my patient's autonomy? Will it harm my patient? Will it violate my duty to be truthful to my patient? Will doing $A$ bring about bad consequences? Proponents of (AU) must explain how reflecting on lactors like these could possibly increase the physician's likelihood of choosing the act that 
maximizes utility. But how could they explain this? Surely there is no conceptual relation between these factors and utility-maximization: it is conceptually possible that doing $\Lambda$ would maximize utility (or fail to do so) regardless of whether in doing $\Lambda$ the physician violates her patient's autonomy, harms the pattent, or violates her duty to be truthful to him, and regardless of her beliefs about the value of the consequences of doing $A$. Therefore, if these considerations were reliable indicators of whether an act exemplifies utility-maximization, it would have to be a contingent fact.

But ean proponents of (AU) offer any reasons to believe that this contingent lact obtains? Mill seems to have thought that we can learn from experience that ecrain factors are reliable indicators of utility maximization. 31 But in order to be able to tearn from experience that factor $F$ is a reliable indicator of utility maximization, we must know whether those actions that exemplify Fusually maximize utility. That is, we must know that most actions that exemplified $F$ in the past in lact maximized utility. But there are reasons to think that (typically) we cannot know this.

One reason concerns our ignorance about the far-reaching causal ramifications of actions. Consider a particular actions, $A$, that exemplified leature $F$. In order to know that action $A$ maximized utility. we must know that $A$ had the best possible onteomes of all the actions available to the agent at the time she performed $A$. However, it is not clear how we could possibly know this if we do not know what many of the outcomes of $A$ are. And if, as seems platsible, the causal ramifications of (most) actions are far reaching into the future, then we actuatly do no know what many of the outcomes of actions are.

${ }^{31}$ Sec Mill's Utilitarianism, esp. Ch. 2 
Another dilficulty concerns the eomparative nature of the property of utility maximization. As stated ahove, In order lo know that action $A$ maximized utility, we must know that $A$ had the best possible outcomes of all the actions arailable to the agent at the time she performed $A$. This means that in order to know that action $A$ was right, we must know that there had been no alternative action that would have had better consequences than $A$. However, in (almost) all cireumstances, agents have numerous alternative actions available to them-arguably infinitely many-and it is not elear how we could know that $A$ had the best consequenees of all the actions available to the agent if we do not even know what all the other actions available to the agent were. 32

To put these points together: in order to know that feature $F$ is a reliable indieator of utility maximization, we must know that most actions that exemplified $F$ were such that the value of all their eonseguences was greater than the value of all the consequences of each and e'very one of the actions the agent eould have performed instead of the actions that exemplified $F$. Since it is unreasonable to think that we are typically in a position to know all these things, it is not clear what evidenee proponents of (AU) could muster to support the claim that some features are reliable indicators of utility maximization. ${ }^{33}$

Moreover, even if inductive support of this sort were available, it might not be suffieicnt. sine it is not enough to establish that in the past acts that exemplified the property of harm-avoidance, for instance, were typically the ones that exemplified

\footnotetext{
32 An agent could have perform many aetions similar to the one she actually performed by ehanging the manner in which she performed her action, or the exald time in which she performed it. The number of actions available to an agent depends, of course, on how we individuate actions.

33 See Lenman (2000) for reasons for thinking that we alle never justilied in believing of any action that it exemplifies utility-maximization
} 
utility-maximization. To see this, consider the following analogy: Suppose that I watched about one half of the Red-Sox games over the course of one basseball seasson. Suppose. further, that it turns out that the Red-Sox`s win/loss ratio is significantly greater for the games I watched, than it is for the games I did not watch. So over the course of this season the games that exemplified the property ol being watched by me were typically the ones that exemplilied the property of being won by the Red-Sox. But surely it would be rash to conclude that the Red-Sox are more likely to win their next game if I watch it rather than not watch it. In addition to inductive evidence of this sort, we need some account of how the relevant properties are related: that is, how the exemplification of one property could possibly increase the probability of the other one being exemplified. Overwhelming inductive evidence may give us reason to suspeet that an account of this sort is fortheoming. But in the absence of such an account it maly well be that the best explanation of the frequent co-instantiation of the two properties in the past is that an unlikely event oceurred. For example, the best explanation of the Prequent co-instantiation of the relevant properties in the Red-Sox example (given other things we know about the world) is that the co-instantiation of these properties is purely coincidental: after all, unlikely events cann, and do, occur.

To the best of my knowledge, no one has yet offered any realson to think that, in fact, the lactors that RSI-agents consider when they reflect on and deliberate about the normative status of actions are reliable inclicators of the exemplification of the property of utility-maximization. Moreover. I doubt that we have any evidenee, not to mention overwhelming evidence, for the co-instantiation of certain properties of actions that 
RSI-agents typically consider and the property of utility maximization. ${ }^{3 t}$ As a lesult, proponents of (AU) are poorly situated in order to explain how it could be that the factors that agents consider when they reflect on and deliberate about the normative status of all action are morally relevant leatures of that action

1 believe this point generalizes beyond ( $\mathrm{AU})$ to mamy monist theories. ${ }^{35}$ Recall that the intuition that our physician should use (RD) was elicited without specifying which feattures she considers in her deliberation about the permissibility of actions. So in order to explain how it could be that the factors that agents consider when they reflect on the normative status of an action are morally relevant features of that action, proponents of each monist theory would have to show that the pluality of factors that RSI-agents consider when they reflect on and deliberate about the normative status of

\footnotetext{
it See Feldman (2006) for an explanation of why a move to expected utility will not help here.
}

35 There may be some monist theories that can circumvent this problem. Consider, for example, the following monist interpretation of Ross"s theory of prima facie rightness: (MPFR) An acl, $A$, is morally right iff $A$ maximizes prima facie rightness. According to this theory, there is only one IMR-property-namely, prima facie-rightnessmaximization. Justice, benelicence, fidelity, and the other prima facie duties that Ross identifies are all extrinsically morally relevant; these properties are relevant in virtue ol their relation to the property of prima facio-rightness-maximization. Nevertheless, this relation between justice, lor example, and prima facic'rightness-maximization is, arguably, a conceptual relation. Monists of this varicty (with various lists of prima facie duties) may be able to explain how it is that leatures that RSI-agents consider ale (extrinsically) morally relevant. Somewhat similar interpretations of Ross"s View can be found in Feldman (1978): "An ace is morally right if and only if it is a prina facie duly and no alternative is a more stringent prima facio duty." (156), and Zimmerman (1996): "S has an overall obligation 10 do A ill S has a prima facie obligation to do A that overrides any prima facie obligation that S has not to do A." (172). In both these formulations it is not quite clear 10 me whether there is a conceptnal relation between the right making property (i.e., being the most stringent prima fac ie duty, or being a prima facie duty that overrides all other prima facie duties) and considerattions like justice, beneficence, etc., Since these formulations make use of technical terms, they are open to interpretation, so it is possible that these monistic interpretations of Ross also circumvent the problems for monist theories discussed in this paper. 
an action, reliably indicate whether that act exemplilies a single property-whichever property that specific monist theory identifies as the only IMR-property. For example, consider the following two alternatlive (monist) versions of Kantianism:

(K1) An act, $A$, is morally right if and only if in performing $A$ the agent of $A$ treals no one as mere means.

(K2) An act, $A$, is morally right il and only if the agent of $A$ can consistently will that the maxim she acts on be a universal law.

According $10(\mathrm{Kl})$, the only intrinsically morally relevant property of actions is the property of being such that in performing the action the agent of the act treats no one as mere neans. According to (K2) the only intrinsically morally relevant property is the property of heing such that the agent of the act can consistently will that the maxim she acts on be a tmiversal law. Proponents of each of these theories must explain how considering features like the ones listed above (Will doing A violate my patient"s autonomy? Will it harm my patient? Will it violate my duty to be truthful to my patient? Will doing A bring about bad consequences?) could possibly increase the physician's likelihood of choosing an action that exemplifies either one of these propertics. I have no argument for the conclusion that such an explanation cannot be had, but only that it has not yet been given, and that it is not cleall what this explanation might look like. And until this explanation is given, it seems to me that there is an explanatory burden that rests on the shoulders of monists that has not yet been met.

In contrast, particularists and pluralists need not claim that all the fatetors that RSI-agents consider when they reflect on the normative status of an action actually track a single property. Instead, they can claim that those factors that RSI-agents 
consider are typically genuinely morally relevant fealtures of actions. Of course, not all lactors that RSI-agents consider are intrinsically morally relevant. For example, in deliberating about the normative status of an action, one maly consider whether one would be prepared to make one's decision public. ${ }^{36}$ Surely the fact that an action hats the property of being such that the agent of the act is prepared to make it public is (typically) not an IMR-property. However, particularists and pluralists can explain why this property is (sometimes) extrinsically morally relevant; for example, they could saly that considering whether one is prepared to make one's decision public helps one to adopt an impartial perspective, which. in turn, helps the agent to recognize whether an action exemplifies other properties that, in this particular case, are morally relevant (e.g., being just or being beneficent). And this would explain how it could be that the factors that agents consider when they reflect on and deliberate about the normative status of an action are morally relevant feattures of that action.

So fat I have argued that particularists and pluralists can explain how it could be that factors that we consider when we reflect on and deliberate about the normative status of an action are morally relevant features of that action. The explanation is, in fact, quite simple: according to particularists and pluralists any property could be a morally relevant leature of an action, so surely the properties we consider in deliberating about the normative status of an action could be morally relevant features of that action. But in order to explain the fact that (RD) is good moral advice we need to do more than this; we must explain how it could be that the features that we typically consider are in fact morally relevant features of actions. Nevertheless, any theory that

\footnotetext{
${ }^{36}$ Sec Hébert (1996)
} 
cannot explain how it could be that the factors that agents consider when they reflect on and deliberate about the normative status of an action are morally relevant features of that action, will be unable to explain the fact that (RD) is good advice. So if I am right that particularists and pluralists can explain this fact while monists cannot, then, I believe, we have some reason to prefer particularism and pluralism to monism.

\subsection{Conclusion}

In conclusion, let me briefly summarize my argument. I maintain that there is strong intuitive support for the claim that (RD) is good moral advice. But if (RD) is good moral advice, we should be able to explain how it is that the plurality of factors that agents consider when they reflect on and deliberate about the normative status of an action are morally relevant features of that action. But since we have no reason to believe that the plurality of lactors that RSI-agents consider while reflecting on the permissibility of an action track one single property, it seems that monist theories are poorly situated to meet this explanatory burden. In contrast, particularists and pluralists need only to show that each of the factors that RSI-agents consider in deliberating about the normative status of actions is, or tracks, one of many IMR-properties. Consequently, it seems that these theories are better situated to explain the fact that (RD) is good moral advice. This, I have argued, gives us a reason to prefer particularist theorics and pluralist theories to monist theories. 


\section{CHAPTER 3}

\section{EXPI.ANATION IN ETHICS}

\subsection{Introduction}

In Chapter One I argued that the debate between particularists and generalists is best understood as a debate over which research program we ought to pursue.

Generalists. I claimed, are eommitted to a research program aceording to which we must find and formulate exceptionless moral principles in order to provide an adequate explanation of moral phenomena, whereas particularists are committed to an alternative researeh program according to which we can explain morality without appealing to exceptionless moral principles. So a key question concerning the particularismgeneralism debate is whether an adecquate explanation of morality is possible without an appeal to exceptionless moral principles. Surely, if the answer to this guestion is "No," then we have good reason to abandon the particularist research program. However. if the answer is "Yes," then given that exceptionless (explanatory) moral principles have not yet been found despite the remarkable efforts of some of the greatest philosophers in the past few centuries, we will have ample motivation to pursue the particularist research program.

The main question of this chapter, then, concerns the nature of explanation in ethics. Must moral explanations involve exceptionless moral prineiples? In order to answer this question I will examnine several theories of explanation. I proeed ats follows. In section 3.2 I discuss some reasons for thinking that moral explanation must be grounded in exceptionless moral principles, and I argue that a deductive approach to explanation is unmotivated. In section $3.3 \mathrm{I}$ argue that we have good reasons for 
thinking that not all explanations are deductive. In section $3.4 \mathrm{I}$ discuss non-deductive models of explanation based on ceteris paribus laws. In section 3.51 present a few nondeductive models of explanations that do not require laws all all. In section 3.6 I discuss the pragmatic nature of explanation, and I present van Fraassen's pragmatic theory of explanation. Finally, in section 3.7 I show that giving up on a deductive model of explanation not only undermines principle monism, but it gives us good reason to abandon pluralism as well.

\subsection{Explanation and Exeeptionless Gencralizations}

Moral theories are (among other things) in the business of explaining moral phenomena. Hence, one's views about moral explanation will greatly influence the kind of moral theories one in willing to countenance. The view that moral explanation must appeal to exceptionless moral principles was presupposed by many moral phitosophers in the past few centuries-as evideneed hy their persistent attempts to find and formulate such principles-but it was seldom explicitly argued for. The fact that this presupposition was acepted without argument does not mean that this presumption wats unmotivated. In Chapter One I proposed that the remarkable progress in the sciences spawned by the scientific revolution might have motivaled moral philosophers to search for exeeptionless moral principles. The discovery and formulation of scientific laws, and most notably Newton"s laws, has clearly led to astounding achievements in the sciences. So it was natural to expect that if we could find and formulate the "laws of morality." we could, perhaps, accomplish similar advances in ethics. Surely moral phenomena are complex and diverse, and it may not appear as though the moral landscape could be captured by a set of simple principles. But then again. prior to the 
publication of Newton's Principia in 1687, the thought that three simple and elegant principles could explain eelestial phenomena as well as the hehavior of massive objects on Earth was unfathomahle. So even those who respect Aristolle"s dictum, that "at wellschooled man is one who searches for that degree of precision in each kind of study which the nature of the subject at hand admits" (Nicomachecan Ethics I.3: 1094b24) may insist that although ethics, like science, does not appear to be the kind of study that admits of al greal deal of precision, it mal perhaps, like science, permil of more precision than it seens to allow at first sight-if only we manage to find the correct moral principles.

All this is to saly that there were, in fact, good reasons to pursue the generalist research program even though the underlying commitment of this program concerning the essentiality of exceptionless generalizations to proper explanation was never explicitly argued for. But if after a sufficiently long period of time a research program fails to provide the results one had hoped it would deliver, one may find it necessary to examine the fundamental commitments of the research program in question. And since we have not yet managed to find and formulate sat isfactory exceptionless explanatory moral principles, the generalist research program has, so far, failed to provide an adequate account of morality. So we should now ask whether there are any arguments in support of the generalist presumption, and whether there are any good reasons to object to the particularist commitment that (adequate) moral explanation need not appeal to exceptionless moral principles.

A natural place to look for such arguments is the literature on the nature of explanation. And indeed, the most influential essay in modern discussion of this topic- 
namely, Hempel and Oppenheim's seminal essaly 'Studies in the Logie of

Explanation - provides a detailed model of explanation aceording to which

exceptionless generalizations are essential for adequate explanations. 'The fundanental insight of Hempel and Oppenheim"s model, which is also known as the "covering law model", or the "D-N model" (Deductive-Nomological model), is that to explain at certain phenomenon is to demonstrate that this phenomenon had to occur. An explanation, on this model, has the form of a deductive argument. The conclusion of the argument is (at sentence describing) the phenomenon to be explained-the explantmdmm-and the premises of the argumen-(the sentences describing) the explannms-must logically imply the explanandum. Moreover, the explanans must include a statement of a general law, and this law must play an indispensabte role in the derivation of the explanandum.

Hempel and Oppenheim were interested primarily in the structure of sciemific explanation. Nevertheless, moral philosophers have also endorsed the idea that explanation is subsumplive in nature. John Ladd, for example, in at paper litled 'Ethics and Explanation" claims that "the aim of explanation... is an ordering of phenomena under general law...To the question "Why"." explanations answer by a subsumption under a general statement." (1952:499) In a footnote, Ladd directs the reader to Hempel and Oppenheim's essay for a more precise account of explanation. ${ }^{2}$ Since subsumption

\footnotetext{
' Hempel and Oppenheim (1948). For a discussion of the importance and influence of Hempel and Oppenheim's essaly, see Salmon (1989) and Woodward (2003al, 2003b). For example, in his introduction Salmon writes: "A large preponderance of the philosophical work on scientific explanation in the sueceeding four decades /after the publication of Hempel and Oppenheim's essayl has oecurred as a direct or indireed response to this anticle." (3-4)

${ }^{2}$ See Ladd (1952) In. I
} 
under general statement is. aceording to Ladd, the very essence of explanation, he concludes that there are no important dilferences between the basic pattern of explanation that Hempel and Oppenheim identily in empirical sciences and the basic paltern of" explanation in ehics. "Ethicall theory," he writes, "seeks to explain, and therefore uses the methods of explanation which are similar to those of the other empirical sciences such as psychology, physics, meteorology, linguistics, elc. .”

Surely if Ladd and Hempel and Oppenheim are right about the structure of explanation in ethies, then the particularist project is in trouble, because if in order to explain a certain phenomenon we must subsume this phenomenon under a general law, then in order to explain the rightness of $R$ we will have $t o$ find a general law (or principle) that "covers" $R$. That is, if Hempel and Oppenheim are right, then an explanation of the rightness of $R$ should have the following form:

1) Action $R$ has feature $\varphi$.

2) Every action that has feature $\varphi$ is morally right

3) (Therefore, action $R$ is morally right.<smiles>CCC(C)[18OH]</smiles>

\} Explanandum

Without the (exceptionless) principle stalled in line (2), the explanans would not logically imply the explanandum, and consequently, the explanation would be inadequate. So if an explanation that lails to conform to this model is defective, the particularist research program is doomed lrom the outsel.

But why should we think that all explanations must conform to this kind of deductive model of explanation? Ladd, alluding $10 \mathrm{Hempel}$ and Oppenheim again,

\footnotetext{
3 Ibid. p. 501 (emphasis added).
} 
claims that explanations "should provide us with statements that have "potential predictive forec." And the general laws cited in the explanans alford explanations with prediclive power. But Ladd does not explain why we should think that explanations must have predictive foree in the first place. Indeed, for Hempel and Oppenheim the fact that "the difterence between |explanation and prediction| is of pragmatic character" and that "an explanation is not fully adequate unless its explanans, if taken account of in time, could have served as a basis for predicting the phenomenon under consideration" (138) are not constraints on a theory of explanation, but consequences of the theory of explanation they propose.

So why do Hempel and Oppenheim think that explanations are subsumplive in nature? Interestingly, this question is not explicitly answered in their essaly. Hempel and Oppenheim tell us that their goal is "lo shed some light on the function and the essential characteristics of scientilic explanation | by means of an elementary survey of the basic pattern of scientific explanation." (135) They begin their survey with two illustrations of scientific explanations. The first is an explanation of the initial drop, and subsequent swift rise of the mercury level in al glass thermometer, when the thermometer is rapidly immersed in hot water. "How is this phenomenon to be explained?" they ask. (135) Now this (juestion is ambiguous. It could be understood as a question about how the abovementioned phenomenon is artually explatined by scientists. Alternatively, it could be interpreted ats a question about how this phenomenon ought to be explained. Hempel and Oppenheim seem to shift from the descriptive reading to the normative one.

\footnotetext{
4P. 499. Ladd borrows the phrase "potential predictive force" from Hempel and Oppenheim. Sec Hempel and Oppenheim (1948) p. 138.
} 
One might think that this shift from a descriptive reading to a normative reading is innocuous. Naturally, if we are to give an antalysis of the eonept of scientific explanation, it is a good idea to begin our inquiry with a few paradigmatic samples of scientific explanation-samples that exemplify, an clearly as possible, the eomponents of the proposed analysis. Indeed, providing paradigmatic exemplars eoukl be understood, plausibly enough, as a way to help the readers identily the concept Hempel and Oppenheim are trying to give an account of. But surprisingly, the illustrations Hempel and Oppenheim provide cto not exemplify the pattern of explanation they propose. In order to see this, it is worth eiting their sample explanation, and their analysis of this example, at length. "The increase in temperature," they write, affects at first only the glass lube of the thermometer: it expands and thus provides a larger space for the mercury inside, whose surface therefore drops. As soon as by heat conduction the rise in temperature reaches the mercury, however, the latter expands. and ats its coefficient of expansion is eonsiderably larger than that of glass, a rise of the mereury level results. - This account consists of statements of two kinds. Those of the first kind indicale certain conditions which alle realized prior to, or at the same time as, the phenomenon to be explained; we shatl refer to them briefly as antecedent conditions. In our illustration. the antecedent eonditions include, among others, the fact that the thermometer eonsists of a glass tube which is partly filled with mercury, and that it is immersed into hot water. The statements of the second kind express eertain general laws: in our ease, these include the laws of the thermie expansion of mercury and of glass, and a statement about the small thermic eoncluetivity of glass. The two sets of statements, if adequately and eompletely formulated, explain the phenomenon under consideration: They entail the eonsequenee that the mereury with first drop, then rise. Thus, the event under diseussion is explained by subsuming it under general laws, i.e., by showing that it oecurred in accordance with those laws, by virtue of the realization of certain specilied anteedent conditions. (135-6)

Hempel and Oppenheim begin by presenting a possible explannation of the phenomenon in question. Their proposed explanation may well be the answer one 
would receive from a scientist to the (juestion "How is this phenomenon to be explained?"- - first the glass tube expands, causing the mereury level to drop; then, when the mereury heats up, the mercury expands and the level of mercury in the tube rises. Next, Hempel and Oppenheim go on to analyze this proposed explanation. They chaim that this explanation involves two kinds of statements: ameeredent conditions and general law's. The antecedent conditions include "the fact that the thermometer consists of a glass lube which is partly filled with mercury, and that it is immersed into hot water." These features are indeed mentioned in the sample explanation presented in the first few sentences of the paragraph. However, the statements of general latws they identily - "the laws of the thermic expansion of mercury and of glass"-are not mentioned in the sample explanation at all. ${ }^{5}$ In claiming that explanations involve statements of general laws, Hempel and Oppenheim are no longer describing the sample scientilic explanation they have given us: instead they are offering a normative account of what scientilic explanation ought to look like. The last two sentences are particularly telling. "The two sets of statements |i.c., antecedent conditions and general law's], if adequately and completely formulated, explain the phenomenon under consideration." The qualification "if adequately and completely formulated" indicates that the sample "explanation" described in the beginning of the palagraph is, in laet, an inalequate explanation; only when the antecedent conditions and general laws are adequately and completely formulated, we will have properly explained the

\footnotetext{
5 One of the "statements of general laws" that Hempel and Oppenheim elaim their proposed explanation appleas to is "a statement about the small thermic conductivity of glass." Their explanation does mention that the "coeflicient of expansion |of mercury| is considerably larger than that of glass," but as stated, this is a statement of faet and not a statement of a general law.
} 
phenomenon in question. "Thus, the event under discussion," they claim, "is explained hy subsuming it under general laws." But the "thus" here is misleading. Hempel and Oppenheim proposed a reconstruction ol the sample explanation they originally presented as a subsumptive explanation, but they oflered no argument to support their claim that "the event under discussion is explained by subsuming it under general law." In lact, if we take the sample explanation at face value, the event under discussion is explained without mention ol' any general law at all.

Now surely there is nothing wrong with offering a reconstruction of a sample explanation; it is not uncommon lor philosophers of science to try to unmask the underlying structure of scientific concepts like 'scientific explanation' even if this structure is rarely, if ever, explicitly exemplilied in scientilic discourse. But if this is what Hempel and Oppenheim are doing, then the sample explanation they discuss provides no support for their analysis, nor does it help us to identify the concept they are trying to analyze. They could have begun their paper by stating their proposed analysis and showing that they can reconstruct sample explannation to fit the explanation schema they put forward. ${ }^{\prime}$

"The second example Hempel and Oppenheim present is no more helpful than the first: To an observer in a row boat, that part of an oall which is under water appears to be bent upwards. The phenomenon is explained by means ol general laws-mainly the law ol refraction and the law that water is an optically denser medium than air-and by relerence to certain antecedent conditions-especially the facts that part of the oar is in the water. part in the air, and that the oar is practically a straight piece of wood.- Thus, here again, the question "Why does the phenomenon happen?" is construed as meaning "according to what general laws, and by virtue ol what antecedent conditions does the phenomenon occur?" (136)

In this case Hempel and Oppenheim do not present the explanation of the phenomenon in question. Instead they simply assert "the phenomenon is explained by means of general laws... and by relerence to certain antecedent conditions." Again, the "thus" in 
To be clear, I have not argued that the covering law model is false or even problematic. Alt 1 have elaimed so far is that we have not yet been given any reason to think that explanations must have a deductive form: despite Hempel and Oppenheim?s rhetoric (e.g., "From the preeeding sumple calses let us now abstract some general chatracteristics of scientific explanation." (1.36)) their appeal to sample explanations offers no support for the pattern of explanation they propose, and als far as I ean tell, they offer no other atgument to molivate their deduetive model of explanation.

Now if there were no difficulties for Hempel and Oppenheim's model, and if there were no alternative theories of explanation, we might have had reason to aceept this model of explanation-even though Hempel and Oppenheim offer no argument to convince us that this is the correct model of explanation-in virtuc of its suecess, or in virtue of the absence of eompeling accounts. In the next section I will argue that deductive models of explanation face serious problems. In the subsequent sections I will present several alternative models of explanation.

\subsection{Are All Explanations Deductive"?}

One noticeable difficulty for applying the covering law model of explanation in ethics is that we have not yet managed to find and formulate exeeptionless moral principles that can be used in deductive explanations. Lying, for instance, is typically

the final sentence is misleading. Surely Hempel and Oppenheim construed the question "Why does the phenomenon happen?" as meaning "aceording to what general laws, and by virtue of what antecedent conditions does the phenomenon occur?" hut they offered no argument as to why it should be so construed. Moreover, their use of passive voice here is also ambiguous. The phrase "uhe question is consurued as" could be read as a descriptive claim-emphasizing the point that Hempel and Oppenheim in fael construed it in this way-or as a normative elaim-the question onght to be construed as they propose. In either case we have no algument for the claim that the question should be construed as Hempel and Oppenheim construe it. 
wrong (or wrong-making), but not always. ${ }^{7}$ So we cannot deduce that an act is wrong liom the fact that it involves lying. Usually, an act is right if it brings about the best conseguences, but not always." So we cannot deduce that an act is right from the fact that it leads to the best consequences.

The absence of exceptionless generalizations that can be used in deductive explanations is not unique to ethics. In the special sciences-e.g.. in biology. psychology, economics, and history-scientists have yet to find and formulate exceptionless laws. And since exceptionless laws are not currently available in these disciplines, it follows that if scientists provide any adequate explanations in these fields all all, their explanations conform to an alternative, non-deductive, model of explanation.

Interestingly. Hempel and Oppenheim were well aware of this problem, and they claim that (most) explanations in the special sciences are, in fact, incomplete. As an example of an explanation in the special sciences they present one popular explanation of the severe price drop at the US cotton exchanges in the fall of 1946. The price drop, according to this explanation. was due to the fact that a large-seale speculator began to liguidate his stocks, which was soon followed by many panicked liquidations by smaller speculators. According to Hempel and Oppenheim, even though

\footnotetext{
${ }^{7}$ For example, lying is not wrong (or even wrong-making) when playing a game in which lying is the point of the game (c.g., Diptomacy or Commaband). Other examples of lies that are, arguably, not wrong (or wrong-making): lying to a Nazi concentration camp guald: lying to a dying patient (c.g.. "everything is going to be all right"): Lying to a person about their appearance (c.g., just before going on stage to give an important lecture, your spousc asks you how she looks; it is probably not wrong to tell her that she looks greal even if she, in facl, doesn't-i.c., even if she looks nervous or pale etc.) "For example, the "organ harvest" secnario: it is wrong to kill an innocent passer-by (without her consent) in order to harvest her organs and to transplant them into five other patients who would otherwise dic.
} 
general regularities are not explicitly mentioned in this explanation, some general regularities are "referred to" or "implied" by it. For instance, this explantation, they claim, implies "some form of the law of supply and demand," and it relies on "regularities in the behavior of individuals who are trying to preserve or improve their economic position." (1+1) These laws, they admit, "cannot be formulated at present with satisfactory precision and generality." And eonsecuently, "the suggested explantation is surely incomplete, but its intention is unmistakably to account for the phenomenon by integrating it into a general pattern of economic and sociopsychological regularities." (1+1)

There are several difficulties with this analysis. First, the fate (if it is a fact) that the proposed explanation "refers to," "implies," or "relies on," several generalities, does not mean that these regularities are a part of the explanation. For example. factual claims "rely on" some evidence. But the evidence for the truth of the explanans need not be part of the explanation, even though the explanation "relies on" these facts. Similarly, the explanans may imply all kinds of statements that are not relevant to the explanation in hand. For example, any explanans trivially implies all tautologies, but these tautologies are not part of the explanation. Also, a generalization of the form (1) All Fis atre $G$ implies that (2) if a is $F$ then a is $G$, but claim (2) may be irrelevant to an explanation if the explanandum is that (3) b is $G$. So although (2) is implied by (1) it is not a part of the explanation of (3). Similarly, even if the explanation in question "implies" the law of supply and demand, and "relies on" some psychological regularities, these regularities need not be a part of the explanation."

9For a similar eriticism of Hempel and Oppenheim see Seriven (1962) 
Second, pare Hempel and Oppenheim, it is not "unmistakably" clear that the intention of this explanation is to subsume the particular event under an exceptionless generalization. As they point out, the proposed explanation does not explicitly mention any generalizations. What evidence is there, then, for the claim that the author of the explanation intended to subsume the event in (juestion under any generalization. not to mention the particular generalizations that Hempel and Oppenheim specify? Isn"t it possible that the intention is to explain the event in question by citing several events that are relevemt to its occurrence, but that do not nee'essitate its oceurrenee?

Finally, since the relevant laws and regularities "cannot be formulated at present with satisfactory precision and generality," this explanation fails to satisfy the conditions of adequacy that Hempel and Oppenheim identify-the explanans does not imply the explanandum. So why is this proposed explanation an "incomplete explanation" rather than simply a failed explanation. Indeed, how is it an "explanation" at all!" Perhaps the thought is that this "incomplete explanation" is an explanation because it approximates the "real explanation" of the phenomenon in question. In an earlier paper Hempel introduced the notion of explanation sketches; an explanation sketch is not a full-fledged explanation, but presumably it could be turned into one:

What the explanatory analyses of historical events offer is... in most cases not an explanation in one of the meanings developed above, but something that might be called an explanation sketch. Such a stetch consists of a more or less vague indication of the laws and initial conditions considered as relevant, and it needs "filling out" in order to turn into a full-fledged explanation. This filling-out requires further empirical research, for which the sketch suggests the direction. (Explanation sketches are common also outside of history: many

\footnotetext{
${ }^{10}$ See Scriven (1962)-esp. section 4.2-ror a critique of Hempel and Oppenheim 's notion of "complete explanation."
} 
explanations in psychoanalysis, for instance, illustrate this point.) ( I) 42:42)

Hempel and Oppenheim assume that although explanations in the special sciences ate incomplete, they give us some indication as to how they alle to be "lilled out," or supplemented so as to form complete explanations. In the aforementioned example, for instance, the proposed explanation indicates that we need to find an exceptionless formulation of the law of supply and demand, and one or more exceptionless regularities regarding human psychology and motivation in order to obtain a full-liledged explanation.

But a few problems remain. First it is still unclear how explanation sketches explain anything. Since we cannot deduce the explanandum liom the explanans in an explanation sketch, then either explanation sketches do not explain, or deduction is not required for explanation. Even if explanation sketches indicate to ts what we need to do in order to find a full-fledged explanation, they cannot explain alt all il Hempel and Oppenheim are right about the deductive nature of genuine explanation.

A related problem is that at present, it is an open question whether there are any strict laws. or exceptiontess (explanatory) gencralizations, in the special sciences. For example, it is an open question whether we can find and formulate a non-trivial (i.e.. explanatory) exceptionless version of the law of supply and demand, not to mention (strict) psychological laws, or (strict) historical laws. If it turns out that there are no (strict) laws in the special sciences, then it will follow, on Hempel and Oppenheim's aceount, that these sciences provide no explanations at all-mot even explanation sketches. Another way to put this point is this: it maty turn out that what we thought were explanation sketrhes were not explanations at all, becatuse the vague laws these 
explanations consist of eannot be filled out and turned into stried laws. This, to

paraphrase Hempel, "does not appear to aceord with sound common usage," which

directs us to saly that regardless of whether the law of supply and demand, for instanee,

could be "filled out" in order to avoid all possible exceptions, il does explain various

economic phenomena.

Finally, it is not clear that explanation sketches always, or even often, suggest a direction for "filling out" the explanation sketch in order to fit the Hempel-Oppenheim schena. Consider, for instance, the following explanation for why Germany declared war on Russia in Augusi 1914.

Arehduke Ferdinand, heir to the Austro-Hungarian throne, was assissinaled in Sarajevo by a Bosnian Serb on June 28, 1914. As a result, Emperor Franz Joseph of Austria-Hungary declared war on Serbia. Russia, as an ally of Serbia, declared war on Austria, which was followed by Germany declaring war on Russia on August 1, 1914.

Surely there is a lot more one could saly here as part of the explanation of the German declaration of war on Russia. One could elaborate on the socio-political situation in Europe, including the various agreements and power struggles between nations, and in this respect we could think of our proposed explanation ats an "explanation sketch." However, it certainly doesn"t look like the intention of this explanation is to subsume the event in question under an exceptionless law. It is not clear that this steetch "implies," "refers to," or "relies on" any exceptionless regularily. and this "sketch" doesn't seem to suggest any particular waly for filling it out in such a way that it would fit the Hempel-Oppenheim explanation sehema.

As we have seen, for Hempel and Oppenheim explanation stetehes are defective explanations-an explanation sketeh is merely a placeholder for the "real" explanation 
that we ought to look for, and it is only explanatory to the extent that it indicates to us how to obtain the "real" explanation. As Weingartner (1961) notes: "Hempel's article must be construed not as an argument in support of the thesis that historical explanation has a certain pattern, but rather as a claim that the explanations offered in history alle in certain ways and in varying degrees inadequate. Fulliledged explanations always have the same structure, whether they occur in science or history." (32) Roughly, Hempel’s line of thought is this: we have made a philosophical discovery regarding the form of proper explanation; explanations in the special sciences do not exemplify this form, and therefore, they are defective.

Other phitosophers take a dillerent approalch. "Many explanations in the special scienees, they clatim, are perfectly adequate. But Hempel and Oppenheim"s theory of explanation tells us that these explanations are defective. Therefore, Hempel and Oppenheim's account is false. Indeed, since most, if not all, of the explanations given in the special science (as well ats many of the explanations given in the hard sciencesincluding Hempel and Oppenheim's examples) ${ }^{12}$ do not exemplify the model of explanation that Hempel and Oppenheim develop, we may doubt whether Hempel and Oppenheim have given us an aceount of the most important or interesting sense of 'explanation.' William Dray, one of the main opponents of the Hempelian model. writes:

There is, in fact, some reason for thinking that what the eovering law theory gives us is the criterion of atechnical sense of "explanation" found only in marrowly scientific discourse, perhaps only among ecrtain philosophers of science... Hempel's formulation begins by laying down

\footnotetext{
"See, for example. Dray (1954. 1957) and Scriven (1959a, 1959b, 1962)

${ }^{12}$ Cartwright (1983) argues that there are no striet explanatory laws in physics. If she is right, then Hempel's model doesn't even apply in the hard sciences.
} 
the logical structure of explanation as he believes he linds it in physics: he then goes on to show that historical cases approximate to this in varying degrees. There is no apology for the direction of the analysis from physies, where the logical outline is boldly displatyed, to other fields, where traces of the model have to be found by dint of careful reconstruction... 'Explanation', as covering law theorists use it, is a technical term... But il scientists, for their own legitimate purposes, redefine "explain" so that it means roughly what covering law theorists say it does, then we are quite justified in advertising our awareness of what has been done by saying that, in fact, scientists do not seem to be much interested in explanation; they eare only for 'explanation' (as lechnically defined). (1957:76-78)

Hempel does not deny that the logical structure he identifies is not usually displayed in the practice of giving explanations in the special sciences, and indeed, in the hard sciences. However, for Hempel, once we have identified the logical structure of explanation, we can use this knowledge to evaluate proposed explanations, and to criticize explanations that fail to conform to this model. Weingartner explains the Hempelian philosophic methodology as follows: "|The starting point of philosophic reflection is an insight into what an explanation is; all that follows constitutes a reconstruction and claboration of that insight in terms of a philosophic position that does not directly depend upon an understanding of the patticular thing (historical explanation) being examined, but is grounded in philosophic considerations of a much broader sort." (1961:36-7)

Dray, by contrast, seems to think that we should take the practice of scientists-m ineluding scientists in the speeial seiences-more scriously. Scientists, at least somelimes, give what they and most of us take to be adequate explanations. But sinee scientists rarely, if ever, give explanations in a deductive form, and moreover, since in many cases we cannot restate their explanations in a deductive form, then it follows that 
Hempel's aceount is not an aceount of "scientific explanation' as the phratse is commonly used.

This disagreenent between Hempel and Dray concerns a profound dispute about philosophical methodology. At one extreme we find the view that philosophy is in the business of discovering a priori analyses, and therefore, considerations of actual applications of concepts have little, or no bearing on philosophical results. On the other extreme, we find the view that philosophers should only record, organize, and classify actual uses of valtious concepts; that we have no aceess to the meaning of a concept independent of the way this concept is used in natural language. Obviously, there are various "in between" views and it is beyond the seope of my project here to try to resolve this fundamental debate about the nature and goals of philosophical theorizing. Nevertheless, in this particular case it seems to me that Hempel's position is especially suspect, because Hempel's view not only entails that most, if not all, explanations in the special sciences are not genuine explanations, it maly also lead to the result that explanations in physies-those explanations which Hempel considered as paradigmatic instances of suceessful explanations-are also not genuine explanations. As Seriven points out:

The most striking demonstration that |even| explanations in physics are not natural subjects for the deductive model is afforded by the failure of Hempel, on his own admission, to produce a single example that meets the conditions. Certainly he gives a perfectly good example of at physical explanation... but he does not suceed in formulating it is such a way that the required conclusion is entailed by it. (1959b:459)

If, in fact, Hempel's view entails that very few "explanations" are genuine explanations, then we may reasonably conclude that the notion of explanation that Hempel analyzed is not the only notion of explanation that we are interested in, and that 
there is some other, non-deductive, sense of "explanation' that we actually employ in scientific discourse.

Interestingly, later on Hempel recognized that a deductive model of explanation is not the only model of explanation employed in the sciences. In his "Aspects of Scientific Explanation ${ }^{13}$ Hempel developed his inductive-statistical model of explanation (IS model) in order to account for explanations based on statistical laws. The explanandum of an IS-explanation cannot be dedueed from its explanans; all that ean be deduced is that the explanandum is more or less likely to oecur. For example, if some law entails that a eertain coin is $90 \%$ likely to land heads if tossed, we cannot use this law to deduce that this coin would land heads when tossed. Nevertheless. we can explain the event of this eoin landing heads by citing the fact that the coin was tossed, and that given the relevant law it was $90 \%$ likely to land heads. For Hempet, an ISexplanation is sucecssful to the extent that the explanans eonfers high probability on the explanimdunı.

For our purposes here, we need not discuss the difficulties for Hempel's ISmodel, and the various refinements of statistical explanations offered in the literature. ${ }^{14}$ The important point is that Hempel, like many other philosophers, recognized that not all explanations are deduetive. And by reeognizing this, Hempel seems to step closer towards Dray's preferred philosophical methodology. After all Hempel could have insisted that by a priori insight we discovered that explanations are essentially deductive. and sinee statistical explanations are not deductive, they are defective. Indeed, Roger Crisp seems to endorse this line of reasoning:

\footnotetext{
1.3 Hempel (1965)

${ }^{1+}$ For a discussion of these issues sec, for example, Salmon ( 1989 )
} 
At the quantum level, we might have some set of initial conditions s which issucs in outcome o. But we camnot strictly claim that simsess (c) becatuse we know that some identical set of initial conditions s* might issue in an outcome $p$ which is non-identical witho. What we have here is a case of genuine indeterminism, which is to that extent inceplicable: it just happens that way. 15

But Hempel, instead, admits that statistical explanations are possible. And indeed, it seems implausible, pare Crisp, to deny that the statistical laws of quantum mechanics ate explanatory. But similatly, it seem equally unreasonable to deny that the "laws" of psychology are explanatory, even if it turns out that they cannot be turned into striet laws. So it is hard to see what reasons one could have for thinking that statistical explanation is the only admissible form of non-deductive explanation.

In this section I have argued that there are various difficulties for Hempel's deductive model of explanation. Even if Hempel's account captures the logic of explanation in the physical seiences-which is far from obvious-it seem quite clear that it fails to capture the structure of explanation in the special sciences. Moreover, sinee we have not been given any argument for the claim that explanations are essentially deductive. and given Hempel's own admission that some explanations are not deduetive, we have good reason to explore alternative non-deductive models of explanation.

\footnotetext{
${ }^{15}$ Crisp (2007) p. 47 (my italics). Crisp seems to have an extremely restrictive notion of causation, and consequently, an implausibly restrictive notion of explanation. I suspect that Crisp's endorsement of these unreasonable commitments prevents him from recognizing the viability of the particularist rescarch program: "If some feature that is claimed to be an ultimate reason for action in one case fails as a reason in some other casc, then either the two features must be allowed to differ or we have followed the white rabbit into a world where anything can happen. Normative principles, that is to say, are like typical natural laws. Each system helps us to understand-in one case, why something happened; in the other, why someone should do something. Unexplained exceptions can only hinder our understanding, and spur us on to avoid them through further specification." (47)
} 


\subsection{Ceteris Parihus Explanation}

As I mentioned in the previous section. for Hempel and Oppenheim strict laws are essential for addequate explanations, sinee without strict laws we cannot deduce the explanandum from the explanans. There are several competing views on the nature of laws, but one thing they all agree on is that a strict law is (at least) a universally guantified conditional statement that asserts that whenever certain conditions obtain. other conditions obtain as well. Schematically, we call represent strict laws as follows: "all Fis are $G s$. If we find one instance of $(\mathrm{F} \& \sim \mathrm{G})$, then "all Fs are $G$ s' is false-i.c., all Fs are (is' is not a striet law. ${ }^{16}$

Several philosophers, however, have noted that strict laws are hard to come by-particularly in the special sciences. Pietroski and Rey, for example, write: "it seems that special sciences do not-and, indeed, probably could not-state gentuinely exeeptionless generalizations." (1995:83) Our current best "laws" in the special sciences are not immune to counterexamples unless we gualify these laws with "ceteris paribus" (i.c., "all thing being equal') clauses. As Lipton observes "Most laws are ecteris paribus laws. If we are being punctilious, what we say is not 'All Fs are G', but only 'All Fs are G. all else being equal'." (1999:155) Similarly, Silverberg claims that "If there are any psychological laws, they would be ceteris paribus laws. Between the oceurrence of any sort of psychological going-on and any subsequent sort of event. intervening disruptive factors can intrude. Between time $t 1$ and later time $t 2$ a

\footnotetext{
${ }^{16}$ Of course this is not a sufficient condition for lawhood, but only a necessary condition. We need to distinguish between laws and accidental generalizations that can be expressed as true universal conditionals.
} 
psychological system might go mat, or die, or the universe might disappear." (201) And likewise, Morreat maintains that

hedged laws are the only ones we can hope to find. Latws are commonly supposed to be truths, but interesting generalizations, without some modifier such as 'ceteris paribus', are by and lalge lalse. This is so in elhics, in history, and in non-basic sciences: economics, biology, psychology, and the rest. There are reasons to think it so in basic sciences like physics, 100. (1999:16.3)

Barring the dispute about the availability of strict laws in the physical seience. 17 it is clear that we have not yet found strict laws in many of the special sciences, and that at present we have to selle for hedged generalizations or ceteris paribus generalizations in those fields. Moreover, some philosophers have argued that the special sciences are incapable of establishing strict laws. 18

Following Pietroski and Rey and others, I will take as data lor any theory of explanation that special seienees like biology, psychology, economics, and history somelimes provide good explanations even when strict laws are unavailable. "This means that explanation can proceed without strict laws. Nevertheless, one might insist, with Hempel and Oppenheim, that explanation requires subsumplion under law.

Woodward (2002) succinctly stmmarizes this line of thought as follows:

Many philosophers hold the following sel of beliefs. (I) A genuine science must contain "laws". (2) Whatever else a law is, it must at least describe an exeeplionless regularity. In particular all laws have the "All As are Bs" form of ... universally quantified conditionals in which the condition in the antecedent of the law is "nomically sulficient" for the condition in its consequent. (3) Litws are required for successful explanation and to ground or support catusal claims. Even if the DN

\footnotetext{
${ }^{17}$ For more on this debate see, or example, Cartwright (1983. 1989), Pietroski and Rey (1995), and Earman, Roberts, and Smith (2002)

${ }^{18}$ See, for example, Earman and Roberts ( 1999)

19 See, for example, Fodor (1991), Pietroski and Rey (1995), Woodward (2002), and Earman. Roberts, and Smith (2002)
} 
model of explanation didn 't quite get the details right, explanation is at bottom a matter of providing nomically sufficient conditions for an explanandum and this repuires gencralizations that are laws. (4) Putling aside generalizations that ane explicitly probabilistic in lorm, if a generalization is to be testable at all (if it is to have empirical content rather than being vacuous), it must take the /universally quantilied eonditional f form ... If it does not, we cannot use the generalization to make determinate predictions. $(303)^{20}$

As Woodward sees it, it is the acceptance of elaims (1)-(4) that leads phitosophers to believe that there are genuine ceteris peribus laws; if one acepts (1)(4), then the special sciences must find and formulate laws not only for explanation, hut also in order to vindicate their status as genuine sciences. But since we cannot find strict laws in the special sciences, then perhaps we can make do with ceteris parihas laws instead. Ceteris paribus generalizations are defeasible, and they can survive exceptions. Unlike a striet law, the statement "ceteris paribus, all fis are $G$ s" is not refuted by one instance of ( $F \& \sim G)$.

Two questions arise: (1) Can ceteris paribas generalizations qualify as genuine laws? That is, can genuine laws have exceptions? And (2) Even if there are genuine ceteris paribus laws, can these laws explain anything? Let us address these questions in turn.

The two main worries concerning the ex istence of genuine ceteris paribus laws are these: (1) We do not have an informative aecount of the truth eonditions for ceteris paribus law statements, and consequently, some have argued that a celeris paribus

\footnotetext{
${ }^{20}$ See, also, Schiffer (1991): "Some philosophers believe that there are ceteris paribus laws and that without them there would be no speeial-science explanations, and hence no special sciences. These philosophers think that science is in the business of providing scientifie explanations, that sueh explanations require laws, and that there are no, or only very few, strict special-science laws; whence their appeal to ceteris paribus laws." (l)
} 
law-e.g. "e'teris paribus, all Fs are Gs"-asserts nothing more than the vacuous

tautology "All Fs are Gs, except when they ale not." 21 (2) Ceteris paribus laws make no predictions. The law 'ceteris paribms, all Fs are Gs', combined with the information that $x$ is $F$ (and together with any combination of atuxiliary hypotheses), does not entail that $x$ is $G$ (or even that with probably $p, x$ is $G)$.

To the best of my knowledge no one has yet offered an account of truth conditions for ceteris paribus law statements. However, several philosophers have proposed sufficient condition for the non-vacuity of ceteris paribus laws. For example, Pielroski and Rey suggest that "e'teris paribus, all fis are Gs" is non vacuous il" (roughly) whenever $x$ is $F$, but $x$ is not $G$, then there is an independently explanatory interlering factor at work; that is, there is a factor $H$ that explains why $x$ is not $G$, and $H$ also explatins something other than the fact that $x$ is not $G .^{22}$

This proposal is not without difficulties. Several philosophers have argued that it is too permissive-that is, too many statements qualify as ceteris paribus laws on this account. ${ }^{23}$ However, even if it is too permissive, it nevertheless shows thatl ceteris

${ }^{21}$ See, for example. Schiffer (1991), Earman, Roberts, and Smith (2002), and Woodward (2002).

${ }^{22}$ See Pielroski and Rey (1995). See also Fodor (1991), and Silverberg (1996).

${ }^{23}$ Sec, for example, Woodward (2002) and Ecarman, Roberts, and Smith (20(02). Woodward and Ecarman, Roberst, and Smith, claim that too many statements will qualify as ceteris poribus laws on Pielroski and Rey"s account. For example, Earman, Roberts, and Smith write: "Many substances that are salfe for human consumplion are white; for every substance that is white and is not salfe for human consumption, there presumably exists some explanation of its dangerousness (e.g., in terms of its chemical structure and the way it interacts with the human nervous system); these explanations are not ad hoc, but can be supported by a variety of kinds of evidenec; but none of this constitutes evidenee for the hypothesis that it is a law that CP, white substances are safe for human consumption." (294) Similarly, Woodward claims that Fodor"s account and Pictroski and Rey"s aceount are "far too permissive. On both proposals, the 
paribus statements are not vacuous-not aly general statement qualifies als a reteris paribus law. ${ }^{24}$ Moreover, even il this proposal cannot be refined and improved on, the problem of the absence of truth conditions for ceteris paribus law-statements maly not be so criticall. As Earman. Roherts, and Smilh explain:

This point li.e., the absence of an informative account of the truthconditions of ceferis paribus law-statements] is not fatal to CP laws, however. Perhaps it is unreasonable to demand truth conditions for CP law-statements. This could be because the concept of a CP law is a primitive concept, which is meaningful even though it cannot be defined in more basic terms. Or it could be because an assertability semantics or conceptual-role semantics, rather than at trutheonditional semantics. is appropriatle for CP law-statlements. Furthermore, one might well deny that it is necessary to have an aceeptable philosophieal account of the semantics for a given type of statement before granting that that type of statement plays an important role in science. And it is hard to deny that there are examples of statements qualified by CP elauses that seem to be perfectly meaningful. 25 (293)

However, the second worry-lhat reteris paribus laws make no predictions-is. according to Earman, Roberts, and Smith, conclusive. Since ceteris parilus laws make no predictions, they are untestable, and since they are untestable, they cannot partake in scientific theorizing.

But surely one could deny that reteris paribus laws make no predictions. For instance, the law "ceteris paribus, all Fs are $G$ s" predicts that if $x$ is $F$, and cotera are

generalization "All charged objects accelerate at $10 \mathrm{~m} / \mathrm{s}^{\wedge} 2 "$ qualifies a reteris paribus law." (3lo)

${ }^{24}$ Schurz (2001) criticizes Pietroski and Rey's aceount and he proposes an alternative account of ceteris paribus laws. Nevertheless. he admits that on Pietroski and Rey's account ceteris paribus laws are not vacuous, but only alunost veacuons.

25 Silverberg (1996) observes that the consequenees of denying that coteris paribus elauses are meaningful are unaceptable: "ceteris paribus conditions are unexeeptional instances of a very common, and needed, phenomenon in our coneepts and assertions. and hence | the | claim that ep eonditions are semantieally objectionable is a suggestion of unaceptably destructive import." (211) This is becaluse most eonditionals we assert are defeasible. 
paria, then $x$ will be $G$. The problem, ol course, is that we camnot specily the eonditions under which cetera are paria, or in other words. that we cannot provide inlormative truth conditions for the statement "e'tera are paria'. ${ }^{26}$ But this doesn't seem to be at different worry than the first-namely, that we cannot provide truth eonditions for ceteris paribus statements. So it secms that if the first problem is not insurmountablethat is, il we are willing to aceept the idea that ceteris paribus statements are meaningful even though we do not have an aceptable philosophical aceount of the semantics for these types ol statements-then the second problem should be surmountable ats well.

Furthermore, why should we think that predictions are deductive in the first place? Certainly we cannot deductively predict that a particulat $F$ is $G$ liom the law "reteris paribus, all Fs atre Gs'; that is, we cannot prediet this with certainty. But we make non-cleductive predictions all the time: we predict the weather; we prediet the outcome ol elections and sporting events; we make predictions about the stoek matret

\footnotetext{
${ }^{26}$ Lange $(20(1) 2)$ contends that judgment is required in the application of strict laws in specifie cases in much the same way that it is required for the application of ecteris paribus laws. Even il it were possible to replace the "ceteris paribus" clatuse with at fully explicit list of eonditions, the application of the "fully explicit" law "derives its content... by virtue of our implicit background understanding of what would count ats compelling reasons lor (or against) the correctness of applying it to a given case." (409) Once we realize this, we see that there is no special problem regatrding truth conditions lor, or predictions with. celeris paribus stalements. As Lallge explains, the content ol the "law of delinite proportion" stated as a ce'teris parihus law-i.e., Any chemical compound consists of elements in unvarying proportions by mass, celeris paribus-is no more vague thath a statement of this law without a ceteris paribus quantifier (if such a statement were possible)-e.g. Any chemical compound consists of elements in unvarying proportions by mass unless the eompound is a network solid or al polymer. The eontent of "network solid" in the second formulation is no less vague than the content of the ceteris paribus clause in the lirst. This, according to Lange, shows that "law need not be associated straightforwardly with a regularity. It maly be associated only with an inlerence rule that is "reliable" - i.e., that leads to conclusions close cnough to the truth for the intended purposes." (411)
} 
and the economy, and so forth. In all these cases our predictions are not deductive, and the elaim that our predictions might be false doesn "t undermine their statts as genuine predictions, nor does it prevent us from evaluating them as a good/bald or belter/worse predictions. Our grounds for making such prediction, as well as our justification for these predictions may well rest on var whs ceteris paribus generalizations. ${ }^{27}$ This observation indicates that recpuiring that all predictions are deductive-lhat is, that predictions must rely on strict laws, and must guarantee the occurrence of the event predicted-is not a constraint issued by the nature of the concept "prediction".

Finally, even if Earman, Roberts, and Smith are correct in salying that ceteris paribus laws are inadmissible entities for scientific theorizing because such laws make no predictions and as a result they are untestable, we may still think that ceteris paribus laws are admissible in ethies. Ethical "laws"-striet generalizations as well as ceteris paribus generalizations-are not "testable" in any straightforward way. So if our only reason to object to ceneris paribus laws in the sciences is that unlike strict laws, ceteris paribus laws are untestable, then either we must object to all "laws" in ethics, or we may as well allow ceteris paribus moral laws in our ethical theorizing as well. In other words, considerations of testability do not differentiate between strict laws and ceteris paribus laws in ethics.

It is worth mentioning here one aecount of eeteris paribus laws due to Peter Lipton (1999). ${ }^{28}$ According to Lipton cereris paribus laws are genuine laws. However

\footnotetext{
27 I am grateful to Gary Matthews for pointing this out to me.

28 This is not the only available aceount of ceteris paribus laws. One alternative account, due to Marc Lange, is based on a pragmatist aceount of lawhood. Lange argues that in order to see that ceteris paribus generalization are genuine laws, we should identily the distinetive role laws play in scientific theorizing, and recognize that cereris
} 
these laws need not identify exeeptionless generalizations. Instead celeris paribus laws "draw our attention to the stable dispositions and fores that underlie the flux of behaviour." (16.3) For example, "lo saly that glass breaks when dropped, reteris paribus, is to saly that glass is fragile and that this feature is not readily lost." (163) The crucial point is that reteris paribus laws "refer to stable dispositions that may be widely present even if only rarely directly manifested." (163-4)

According to Lipton, dispositions can help us make sense of ceteris paribus laws because, unlike properties which an object either has or lacks, dispositions are subject to a tripartite distinction: "displaying. present-but-not-displaying, or absent." (16.3) Roughly, Lipton's proposal is that ceteris paribus laws are true if they truly atlribute a disposition to a kind. Nevertheless, they have exeeptions becaluse a thing could fail to manifest a disposition that it has. So, for example. "ereris paribus mallehes light when struck", attributes the disposition to light when struck to individuals of the kind 'match'. In oxygen free environment, for example, a match would not light when struck, even though it has the disposition to light when struck. So the ceteris poribus law is true, even though there are cases in which the disposition will not be exemplified. In contrast, "erteris paribus, toothpicks light when struck" is false, because toothpicks do not have the disposition to light when struck, even if there were some situations in which toothpicks would light if struck.

parihus generalizations play the same role. See Lange (200(), 2003). For an application of this model to explanation in ethies see Lance and Litte (2007). Silverberg (1996) makes a similar point regarding ceteris paribus generalizations: "Ceteris paribus laws are laws which, if the qualifying condition expressed in their reteris paribus clauses were removed, could have counterexamples, and hence would require the qualification of their universality that ceteris paribus clauses express. Despite this need for qualification, the qualified prineiples are laws, since they retain considerable generality or scope, and possess considerable prediclive and/or explanatory value." (201) 
According to Lipton, the dispositional approach to cereris parihus laws solves

the vacuity problem for ceteris paribus law-statements, and it provides a way to distinguish between this semantic problem and the predictive problem discussed above:

We don't know when all things are equal, but the whole point of the dispositional view is in a sense that we do not need to know, sinee the disposition is present regardless. Of course some idea of when all things are equal (or equal enough) might be essential to applying the law to predict the manifestation of the underlying disposition, but the basie dispositional attribution seems sale. (166)

If, as seems plausible, there are aeceptable ways to test attributions of dispositions to kinds, then cereris paribus law-statements maty well be admissible in scientifie theorizing. 29

Now let's suppose that there are genuine ceteris paribus laws. Can such laws explain anything? For example, can we explain the lact that (3) $a$ is $G$, by noting that (1) $a$ is $F$, and that (2) "ceteris puribus, all Fs are Gs"? Surely, we cannot deduec (3) from (1) and (2). However, I have argued that the deductive model of explanation is unmotivated, and indeed, I have claimed that onee we allow for statistical explanation, we have already given up on a purely deduetive model of explanation anyway. Now onee we give up on a purely deductive model of explanation we ean see that (deduetive) predietion and explanation maly come apart: ${ }^{30}$ although we eamnol deductively prediet (3) from (1) and (2), we may still be able to explain (3) in terms of (1) and (2). One reason why (deduetive) predietion and explanation can come apant is, as Scriven

\footnotetext{
${ }^{29}$ For more on dispositionalism- the view that dispositions, rather than laws are the fundamental units of explanation-sec Cartwright (1989, 1983) and Mumford (1998). For an applieation of this view to ethics see Robinson (2006) (Note. however, that my understanding of the disagreement between particularists and generalists is very different from Robinson's).

3) As we have seen above. one need not aceept the elaim that predictions are deductive.
} 
observes, that "we have more data for explaining than we did for predicting." $(1959 \mathrm{~b}: 469)^{31}$

To illustrate this point, let us consider one of Hempel"s examples:

If a particular revolution is explained by reference to the growing discontent, on the part of a large part of the population, with certain prevailing conditions, it is cleat that a general regularity is assumed in this explanaltion, but we are halldy in a position to state just what extent and what specilic form the discontent has to assume, and what the environmental conditions have to be, to bring about a revolution. (1942:41)

Recall that aceording to Hempel, since we are not in a position to identify exceptionless generalizations that comnect population discontent and the oceurence of revolutions, an explanation of a particular revolution in those terms would be, at best, an explanation sketch; and as we have seen in the previous section, it is not clear how an explanalion skelch (for Hempel) could be explanatory all all.

Alternalively, suppose we could find and formulate a ceteris paribus law relating population discontent and the oceurences of revolutions: perhaps we could formulate a ceteris paribus law that looked something like this:

(CPR) Ceteris paribus, if a sulficiently large part of the population of a particular nation is sufliciently discontent with its current regime, then a revolution occurs. 32

Surely, we cannot use (CPR) to (deductively) predict the occurrence of at revolution in any particulal nation with erenainty. ${ }^{33}$ Even if we knew that $80 \%$ of the

\footnotetext{
${ }^{3}$ See Scriven (1959a) for an algument that shows that explanation and prediction can come apart based on a discussion of the explanatory power of evolutionary theory. See also Maclntyre (1981) Ch. 8.

32 do not contend that (CPR) is a genuine ceteris paribus law-indeed, as stated, it probably isn't. I only use (CPR) for illustrative purposes, and for the sake of the example, I will assume that it is a genuine ceteris paribus law.
} 
population of nation $N$ are discontent with their eurrent regime, we do not know whether $80 \%$ is a "sufficiently large part of the population" or whether these $80 \%$ are "sufficiently discontent", and, of course, we do not know whether cetera are paria. So it is clearly impossible to (deductively) predict with certainty the occurrence of at revolution batsed on (CPR) and statements of initial conditions. Nevertheless, suppose we know that a revolution has oceurred in nation $N$, and we now want to explain this oceurrence. If we know that a large portion of the population of nation $N$ were diseontent, then this fate together with (CPR) is at least a c'andidate explanation. And if we cannot find an alternative (platusible) explanation of the oceurrence of the revolution, then we may well aceept this candiclate explanation as an adequate explanation of the revolution, even though its explanams does not logically imply the explanandum. ${ }^{34}$

\subsection{Explanation without Laws}

The claim that there are genuine ceteris paribus laws is highly contentious. Indeed, according to some theories of laws, it is impossible for laws to have exceptions, and consequently, the notion of a "defeasible law" or a "ceteris paribus law" is, on these

\footnotetext{
${ }^{33}$ As noted above, we maly prediet that a revolution will oceur in nation $N$, and we may justify our prediction by appealing to (CPR) without using (CPR) to deduce that at revolution will occur.

${ }^{34}$ This is a simplified version of a kind of explanation that Scriven (1959b) calls "selection explanations". "What we have is al range of formally possible explanations... and on the basis of the lacts of the case, we select one of the anteedents as the explanation. It is the particular fact, not the general proposition or the derivation, which provides the explanation in such cases.. The point of the explanation is to locate the relevant causal antecedent, not to prove that it is a possible one." (462)
} 
theories, simply an incoherent notion. ${ }^{35}$ Now il we were correct in atssuming that special sciences like biology, psychology, ceonomics, and history sometimes provide good explanations even when strict laws are unavailable, then those who deny that ceteris paribus law statements refer to genuine laws, must conclude that laws are not required for explanation-that is, that an explanation could be perfectly adecuate without appealing to any genuine laws all all. ${ }^{36}$ In this section I will brielly describe a few models of explanation without laws.

The lirst account is due to James Woodwall. Woodward (2002) claims that there is no such thing as ceteris paribus laws. Insteal he argues that "lt is... fatse that successful explanation requires laws and false that the provision of a nomically sufficient condition for an explanandum is cither necessary or sufficient for explaining it." (304) Nevertheless, he believes that ceteris poribus generalizations can play a role in scientilic explanation. "While I reject the ideat that the generalizations found in the

35 For example, Armstrong's view, according to which laws are grounded in identities between universals, seems to preclude the possibility of laws that have exceptions. See Lance and Litlle (2007)

${ }^{36}$ Schiller ( 1991 ) writes: "When / read biology, I have a hard time linding anything that looks like a law-invoking explanation, and I think I know why. Suppose you just invented the spring-activated mousctrap and had to explain how it worked. You woukl explain that, when the device works, it's because the mouse nibbles al cheese placed on a release mechatism; the movement catused by the nibbling releases a bar attached to a stretched spring: ete. But you wouldn`t mention any laws. Maybe if you went on in an explanatory chain long enough, you'd get to laws: but they’d be laws of physics, not laws of mousetrap theory. In the same way, much of biology is concened to explain how valrous mechanisms work-think of the explanation of photosynthesis-and such explanations seem not to invoke any biological laws, strict or ceferis paribus...since |cognitive psychology, too, is concerned with| explaining how mechanisms work, there"s no obvious reason such explanations should need laws, strict or ceteris peribus." ( 16) Schilfer does not explicitly saly whether he thinks that "complete" explanations in biology and cognitive psychology mmst mention the physical laws that ground the operation of the mechanisms they explain. His last lemark, however-that there is no obvious reason such explanation should need laws-suggests that he believes that explanations are perfectly adecpuate without mention of any laws. 
special sciences are ceteris parihus laws." he writes, "I fully agree that many of those generalizations are "scientifically legitimate", that they are testable and in fact strongly supported by evidence, and that they describe causal relationships and figure in explanations." (306)

Woodward claims that there are no good analyses of the meaning of ceteris paribus claims, and that there are no good reasons for thinking that there are ceteris paribus laws in the first place. He points out that the locution "ceteris paribus" is rarely used in the special sciences, and consequently, it is not clear what the standard of suceess for analyses of celeris paribus laws would be. Moreover, Woodward observes that philosophers use ceteris paribus clauses to qualify laws in various different ways, and he argues that there is no reason to think that a single analysis of "ceteris paribus law" could capture all these different instances of laws qualified by a ceteris paribus clauses. ${ }^{37}$

Woodward's proposal, then, is that exception-full generalizations, though not latws, can be used in explanation. To demonstrate this, Woodward considers the following example:

(E) Administration $\mathrm{A}$ (where this consists [of] administration of drugs $\mathrm{D}$ according to protocol $P$ ) to human beings with tumors of type $T$ causes recovery $R$ (where recovery is understood to mean that the tumors of type T disappear and remain absent for some specilied period - e.g. five years). (307)

Woodward contends that for some values of A. T. and R. (E) is true, and strongly supported by evidence. After considering and rejecting various reformulations

\footnotetext{
${ }^{37}$ For a classification of various distinct kinds of ceteris paribus laws see Morteau (1999) and Schurz (2002).
} 
of (E) as a celeris proribus law (for reasons similar to those discussed in the previous section). Woodward proposes an alternative aceount of the explanatory value of (E).

Woodward notes that we can test claims like (E) by performing randomized tests. Patients with tumors of type Tean be randomly divided in to two groups. One group receives treatment $\mathrm{A}$, and the other receives no treatment. If our sample is lange enough, then the randomization guarantees that factors besides A that may affeet recovery are roughly evenly distributed between the two groups. So if we find a statistically significant grealter recovery rate in the group that received A, we can conclude that administration A to patients with tumor of type T makes a difference with respeet to R. It is important to realize that we can determine that A makes a difference with respect to R even though we do not have a more precise generalization regalding the specific conditions under which A causes R. "The notion of administration of treatment being relevant to or making a difference for recovery," Woodward explains, is captured by the notion of the counterfactual dependence of R on A, where the antecedents of the relevant counterfactuals are understood as realized by processes that have the characteristics of idealized experimental interventions... what is required for the truth of (E) is simply that for some individuals. recovery counterlactually depends on some possible intervention that realizes A. It is not required that for all people with tumors of type T, recovery counterlactually depends on A. Instead, it is consistent with the truth of (E) that some people have no possibility of recovering even il given $\mathrm{A}$. Nor is it reguired that all interventions realizing A change whether recovery occurs (or the probability of recovery oceurring) for all or even some individuals. (317)

Instead of a subsumptive model of explanation aceording to which to explatin is to subsume under a general law, Woodward proposes that to explain is to cite a feature (or a set of features) that makes a difference to the oceurrence of the explanandum. And since we can identify features that make a difference without identifying exceptionless 
generalization, then exceptionless gencratizations are not required for explanation. Once we realize that nomic necessity is not required for explantion. we can see that laws-strict. or ceneris perihns-are not required for explanation, and that we can make sense of the explanatory value of (E) even though we cannot restate it as a strict-or ceteris paribus- law.

A different account of non-law-based explanation is due to Michacl Scriven (1959b, 1962). Scriven's insight is that we ought not to confuse an explanation with the justification of the explanation. Recall that for Hempel, (strict) laws are required for explanation becatuse an explanation must guarante' the occurrence of the explanandum; if the explanation lacks a true general proposition that connects the explanans with the explanandum, then the occurrence of the explanans doesn't mignely imply the occurrence of the explanandum. Seriven claims that Hempel's insistence on alwalys including laws as part of the explanation is unwarranted-it conflates the explanation itself with our reasons for thinking that the explanation is a good explanation.

Scriven notes that an explanation could be defective or deficient in (at least) three different ways: it could be inacenrate, if the explanatus is ill supported by the evidenee: inadeynate, if the explantans does not fully explain the explanandum: or irrelevemt, if the explanation is of the wrong kind (e.g., causal explanation rather than psychological explanation). Corresponding to these three possible deficiencies, are three types of justilications for explanations: Truth-justifying gromuds are the grounds for thinking that the explanation is accurate-i.c., our evidence for the truth of the explanans; Role-jnstifying grounds are our grounds for thinking that our explanalion is 
adequate (at least in the relevant context); Type-justifying gromuds are our grounds for thinking that one type of explanation is recpuired rather than another.

Seriven argues that just as the truth-justifying grounds and the type-justifying grounds need not be included as a part of the explanation, so do the role-justilying grounds. If, upon giving an explanation, we are asked why we think the explanans are true, we will mention the truth justifying grounds of the explanation-i.e., our evidence for the truth of the explanans-but these need not be a part of the explanation.

Similarly, if, upon giving an explanation, we are asked why we think the explanans support the explanandum, we will mention the role justifying grounds of the explanation-which may include al general (strict) law that connects the explanans with the explanandum-but these, too, need not be a part of the explanation.

Moreover. Scriven contends that the role-justifying grounds need not involve strict laws at all. He illustrates this by presenting a case "where we can be sure beyond any reasonable doubt that we have a correct explanation" and yet, we cannot provide strict laws as role-justiliers.

As you reach for the dietionary, your knee catches the edge of the table and thus turns over the ink-bottle, the contents of which proceed to run over the table's edge and ruin the carpet. If you are subsequently asked to explain how the carpet was damaged you have a complete explanation. You did it, by knocking over the ink. The certainty of this explanation is primevall. It has absolutely nothing to do with your knowledge of the relevant laws of physies: a cave-man could supply the same account and be quite as certain of it... its certainty has nothing to do with your ability to quote the laws... if you were asked to produce the role-justifying grounds for your explanation. what could you do? Yon could not produce any true muiversal hypothesis in which the antecedent wals identifiably present (i.c. which avoids such terms as "knock hard enough"), and the consequent is the elfeet to be explained... The simple fact must be faced that certain evidence is adequate to guarantee certain explanations without the benelit of deduction from laws. (456) 
Scriven suggests that instead of laws, we should appeal to mormic statements ats the role-justifying grounds for good explanations of particulat events. Scriven elucidates the notion of a mormic stotement with a few examples. (NI) "Rhombi" means the same as "equilateral parallelograms"; 38 (N2) The penalty for revoke, in bridge, is two tricks: (N3) Strict Orthodox Jews fast on the day of atonement: (N4) Other things being equal a greater number of troops is an advantage in battle; (N5) A rise in the tariff chatacteristically produces a decline in the value of imports. Statements like (NI)-(N5) are not analytic, and they are also not refutable by a few counter instances (e.g., a few erring students who use "Rhombi" and "equilatteral parallelograms" in a noninterchangeable way, do not undermine (N1); An Orthodox Jew who doesn't fast due to illness, doesn't undermine (N3) etc.) Yet more, these claims are not statistical claims. (N2) could be true even if most bridge players do not apply a two-trick penalty for revoke; and (N4) could be true even if in most battles ever fought the armies with the greater number of troops lost the battle. According to Scriven, "The normic statement says that everything falls into a certain category except those to which certain special comditions apply. And, although the normic statement itself does not explicitly list what count as exceptional conditions, it employs a vocabulary which reminds us of out knowledge of this, our trained judgment of exceptions." (1959b:466)

Moral statements like (N6) Lying is wrong making; and (N7) One ought to bring about the hest conseguences, could also be understood as normic statements. The fact that we cannot explicitly list the special conditions under which lying is not wrong making. for example, need not disqualify (N6) ats the role-justifying grounds for a good

\footnotetext{
${ }^{38}$ Scriven explains that unlike the sentence "Rhombi are equilateral parallelograms," (N1) is not analytic because its denial is not self-contradictory.
} 
explanation of the wrongness of a particulat act of lying. And the latet that trained judgment is required in order to determine whether the lact that a particular act involves lying explaius why this act is wrong, need not trouble us; since we do not have a sattisfactory analysis of "lying"-or any other interesting philosophical concept, for that matter-then even if (N6) were a strict law. we would still need to apply trained judgment in order to determine whether a particular act involves lying in the first place. 39

Since Seriven contends that the special sciences provide good explanations even though strie laws are, for the most part, unavailable, he concludes that normic statements are essential to the explanation of particular oceurrences:

Explanation of an individual oceurrence must use normic role-justifying grounds because (1) there aren't any true universal hypotheses to speak of and (b) statistical statements are too weak-lhey abandon the hold on the individual case. The normic statement tells one what had to happen in this case, unless certain exeeptional circumstances obtained: and the historical judgment is made (and open to verification) that these circumstances did not obtain. (467)

Finally, we should briefly mention Dray's suggestion for non-law-based explanations. ${ }^{4()}$ Contra Hempel and Oppenheim, Dray thinks that an explanation need not (always) demonstrate that the explanandum had to occur; sometimes an explanation need only to show that the explanandum could oceur. In other words, in some contexts, all we need to show is that the occurrence of the explanandum is possible, even though it is not necesisary.

\footnotetext{
39) See fin. 26 above.

40) See Dray (1954, 1957). The citations in the text are from Dray (1954) unless noted otherwise.
} 
To mark this distinction, Dray differentiates between explaining w/y somlething happened, and explaining how it could lave hetppened. "In explaining why something happened," he writes, "we rebut the presumption that it need tot have happened, by showing that, in the light of certain considerations (facts and laws), it had to happen." (20) In contrast, "in explaining how something could have happened, we rebut the presumption that it rould uot have happened, by showing that, in the light of certain further facts, there is after all no good reason for supposing that it could not have happened." (20) Dray contends that tlese two kinds of explantations are distinet because they provide answers to different guestions, and there is no reason to think that one kind of explantation is more fundamental than the other.

In order to show that something could have happened, we need not lind premises from which its oceurrence logically follows. Instead, all we need to do is to tell a plausible story about how it could have happened. And according to Dray, historical explanations are often of this kind. So. he concludes,

an historical explanation may thus amount to telling the story of when actually latppened, and telling it in such a way that the various transitions... raise no eyebrows. The story is told int such a way that presumptions of the form, 'But surely that couldn't have happened!', are rebutted in advance. Answers to likely objections atre built into the narrative, which maly thus have explanatory force (27)

Draly does not deny that on occasion we may want more than the story of the event in question. Nevertheless, the telling of any particular story about what actually happened is meant to answer the question how this occurrence could have happened. If we ask a different question-c.g., 'Why this occurrence and not a different occurrence?' or, "Why this story and not a different story? - we should expect a different answer. But this does not undermine the adequacy of the proposed explantation as an answer to the 
question for which it was presented. It is certainly no surprise that dilferent questions demand different answers, and one ought not to expect that an explanation offered ats an answer to one question would also answer all possible follow-up guestions, since if this were required, no explanation would have been possible al all.

In this section I have presented three accounts of explanation that are not based on laws, strict or ceteris paribus. For our purposes here, we need not deeide whether to explain is to cite a feature that makes a difference to the oceurrence of the explanandum, whether explanations of particular occurrences ought to be grounded in normic statements, of whether explanations are (sometimes) storics of what actually happened. The important point for us is that there are alternatives to the deductive model of explanations. And sinee the deduetive model of explanation is, at best, ineomplete, there is no reason to think that explanation in ethics must eonform to the deductive model. Indeed, given the kind of phenomena that ethics is about, it seems reasonable to expect that the kind of explanations we will find in ethies would be more similat to explanation in the special seience than to those we find in the physical sciences.

\subsection{Explanation as a Pragmatic Phenomenon}

One of the hallmatrs of Hempel's theory of explatuation is that Hempel altempts to provide a symartical condition for the adeguacy of explanations; an explanation is adequate only if the explanandum syntactically follows from the explanans. However, several philosophers, and most notably Scriven, have argued that "Explanation is not a syntactical but a pragmatie notion," (1959b:452) and eonsequently, any syntactical constraints are bound to be too restrictive. According to Scriven, the only thing we can 
say about explanation without attificially limiting the concept is that "explanations must produce understanding, and not simply knowledge." (451) Scriven insists that tying explanation to understanding in this way does not imply that the standatds for the adequacy of explanations are purely subjective, becaluse "there are objective tests for understanding just as for knowing or inferring. They happen not to be syntactieal tests as are (supposedly) those for deducing." (452) Unfortunately, though, Scriven doesn't have a lot to say about the notion of understanding.

Hempel, in his $1965^{\circ}$ 'Aspeets of Scientific Explanation', admits that there is a pragmatic sense of "explanation": "To explain something to a person is to make it plain and intelligible to him. to make him understand it." (425) However, in this pragmatic sense, the very same account could constitute an explanation for one person and not for another. So this pragmatic sense of explanation affords a relativised notion of explanation: $E$ is an explanation for a particular individual; there are no explanations simpliciter. Hempel acknowledges that the pragmatic aspects of explanation are interesting and important. Nevertheless, he contends that we must try to find an objective aceount of seientific explanation, which conforms to the objective (i.e., non agent relative) standards of seientific research. The covering law model of explanation is meant to satisfy this demand for objectivity. Moreover, in response to Scriven's critique of his deductive model, Hempel declares:

To call attention to the important pragmatic facets of explanation and to indieate the diverse procedures that may be appropriate in different cases to dispel the perplexity reflected in someone's quest for an explantation is not to show that a nonpragmatic model of seientifie explanation must be hopelessly inadequate... It is therefore beside the point to complain that the covering-law models do not elosely match the form in which working seientists actually present their explanations. (427-8) 
Hempel is clearly correct in saying that merely calling attention to pragematic facets of explamation does not show that all nonpragmatic models of explanation mmst be inadecuate. But this response seems to misconstrue Seriven's objection. Scriven doesn't merely point out that the covering law model is not exemplified in scientilic discourse-which, as Hempel observes, would have been besides the point-but rather, Seriven claims that many perfectly adecuate explanations c(ammot be restated ats deductive arguments in which the (sentence describing the) explanandum follows from the (sentences describing the) explanans. So Hempel's response to Scriven is misguided.

Moreover, Hempel secms to conflate explanation as a pragmatic notion with explanation as a subjective notion. To say that explanation is a pragmatic notion is to saly that what qualifies ats an adequatc explanation is context sensitive, but it need not be agent relative in any objectionable way. In lact, developments in the study of formal pragmatics in the 70 's made possible the development of a pragmatic theory of explanation. So one final approach to explanation we ought to consider here is a theory of explanation that takes scriously the pragmatic natture of explantition, and Bas van Fratassen (1980) developed such a theory.

Van Fraassen summarizes his view as follows: Explanation is a three-term relation, between theory, fact, and context. No wonder that no single relation between theory and fact ever managed to fit more than a few examples! Being an explanation is essentially relative, for an explanation is an amswer... Since an explanation is an answer, it is evaluated vis-à-vis a question, which is a request for information. But exactly what is requested by means of the question "Why is it the calse that $P$ ?", differs from context to context. (156) 
An explanation, aceording to van Fratssen is an answer to a why-question. ${ }^{41}$

Van Fratassen identilies why-questions with an ordered triple $<\mathrm{Pk}, \mathrm{X}, \mathrm{R}>$, where $\mathrm{Pk}$ is the topic of the question (or the explanandum), $\mathrm{X}$ is the contrast class, and $\mathrm{R}$ is the relevence relation. It is important to realize that the same interrogative sentence can express different questions on difference oceasions in which it is uttered. For example, consider the question: "Why is act $\Lambda$ morally wrong?" This sentenee maly express (at least) two different questions: (1) "Why is act $A$ (rather than act $B$ ) morally wrong?" or (2) "Why is act $A$ morally wrong (rather than morally right)?" The topic of the question in both cases is the same-i.e. that act $A$ is morally wrong-but the relevant contrast class is diflerent: in the former question the eontrast class includes: (PI) 'Act $A$ is morally wrong': (P2) "Act B is morally wrong'; etc.; whereas the contrast class of the latter question includes: (P1) 'Act $A$ is morally wrong'; (P2) 'Act $A$ is morally right'. A direct answer to a why-question will take the form: Pk in contrast to the rest of $\mathrm{X}$ because $A$, where $A$ is a proposition that beass relation $\mathrm{R}$ to the couple $\langle\mathrm{Pk}, \mathrm{X}\rangle$. And an explanation, aecording to van Fratassen, is a direct answer to a why-question. We evaluate explanations in (at least) three ways: (i) how likely is this explanation to be true (given our background knowledge); (ii) to what extent does the explanation favor Pk, rather than other members of the eontrast class; (iii) how this explanation compares with other possible explanations.

\footnotetext{
4 Van Fraassen, following Hempel and Oppenheim, identilies explanation as an answer to a why-question. But as Dray (1954, 1957, 1959), Scriven (1959b, 1962), and Salmon ( 1989 ) point out, not all answers to why-questions are explanations, and not all explanations are answers to why-questions. Yet although the details of van Fratasen's aceount are not quite right, his main insight-that whether a particular alecount qualifies an adequate explanation depends on the context in which the explanation is given-is still worth noting. For a eritique of van Fraassen"s account, see Kitcher and Salmon (1987) and Salmon (1989)
} 
For example, suppose we want to explain why atc $A$ is morally wrong (rather than morally right). The topic, or the explanandum is that act $A$ is wrong. The contrast class is $\{A$ is morally wrong, $A$ is morally right $\}$. A possible answer to the question is that $A$ is wrong (rather than right) because $A$ involves the breaking of a promise. The quality of this explanation depends on considerations like the following: Does $A$ in fact involve the breaking of a promise? To what extent does the fact that $A$ involves the breaking of a promise support the claim that $A$ is wrong rather than right? How does this explanation companre to other possible explanations (c.g." "A is wrong (rather than right) because $A$ involves hurting an innocent by-stander") etc.

Note that an adequate explanation, on this model. need not include laws all all. Furthermore, an explanation need not show that the explanandum hatd to oceur; instead, it only has to show that the explanandum is more likely than the contextually salient alternatives in the contrast clatss, given (the contextually salient fealtures of) our background knowledge. ${ }^{42}$ So, for example, the fact that a particular action involves the breaking of a promise might be a perfectly good explanation of its wrongness on one occasion, even though on a different occasion the fact that an action involves the breaking of a promise may be irrelevant to the explanation of its wrongness.

\subsection{Explanation in Ethics}

In the previous sections I have shown that we have very good reasons for believing that adequate explanations need not appeal to exceptionless principles. I hatve argued that the most influential account of explanation according to which

\footnotetext{
42 In this respect, van Fralassen's model is similar to what Scriven (1959) calls "selection explanations". See note 34 above.
} 
exceptionless generalizations are essential to proper explanation is unnotivated.

Moreover. since the special sciences sometimes provide adequate explanations even when exceptionless generalization are not available, then even if the deductive model were a successful account of explanation in the physieal sciences, we would have to identify another non-deductive model of explanation to account for explanation in other areals. Finally, I have shown that other accounts of explanation are readily available. In particular I've discussed explanations that are based on the availability of ce'teris paribus laws, and explanations that do no require laws al all. I conclude that a survey of the literature on scientific explanattion not only does not vindicate the generalist presumption that explanation must appeal to exeeptionless principles, but rather it shows that this presumption is widely regarded as untenable. Indeed, this survey of the literature on explanation demonstrates that we are used to, and comfortable with explanations that are not grounded in exceptionless generalizations in (almost) all areas of inquiry.

My discussion in the previous sections was focused on accounts of scientific explanation, and clearly there are many differences between empirical sciences and ethies. In order to employ any one of the models of explanation I presented in the previous section in ethics, some modifications would be called for. For example. Woodward's thesis- hat to explain is to cite a feature that makes a difference to occurrence of the explanandum-is cashed out in terms of randomized tests. It is crucial for Woodward's account that we can identify that a feature is (causally) relevant without identifying the specific conditions under which it makes a difference. The way we do this, according to Woodward, is though randomized tests where we can 
justifiably assume that other relevant (or interfering) lactors are (roughly) equally distributed between the test group and the control group. But randomized tests are not standard praetice in moral theorizing, so clearly some modificattions, or al least clarifications, are in order if we are to adopt this model of explanation ats an account of explanation in ethics.

Other models of explanation are more easily adapted to fit the moral realm. Explanations based on ceteris paribns laws, or explanations grounded in normic sentences, for instance, as well as explanations relative to an implicit contrast class, could quite effortlessly be "Iransferred" to ethics.

In Chapter Two I diseussed two types of generalist approaches: principle monism and principle pluralism. Monists, as I explained, elaim that there is only one intrinsically morally relevant property-call it $P$-and that every action that exemplifies $P$ is morally right. Pluralists maintain that there are several intrinsically morally relevant properties-call these properties $P I . . . P n-$ and that for each intrinsieally morally relevant property, $P i$, there will be a presumptive, or pro tento, prineiple: for any action, $A$, if $A$ exemplifies $P i$ then $A$ is presumptively morally right (or wrong). I have argued that both monists and pluralists are generalists beause they both believe that an explantation of the rightness of an action is inadequate unless it is grounded in an exeeptionless moral principle, strict or pro tanto.

We call now see that only monism is eompatible with a deductive model of explanation. For monists the explanation of the rightness of $A$ is that $A$ exemplifies $P$, and that every action that exemplifies $P$ is morally right: the explanandum logieally follows form the explanans. For pluralists, in eontrast, an explanation of the rightness of 
$A$ is not deductive, becaluse even if $A$ exemplifies $P i$, and every action that exemplifies

$P i$ is presumptively morally right, it does not follow that $\Lambda$ is morally right (in this calse),

but only that $A$ is presumprively morally right. Ross (1930), for example, was well

aware of this difficulty. "Our judgements about our particular duties," he explains.

are not logieal eonclusions from self-evident premises. The only possible premisses would be the general principtes stating their prinut facie rightness or wrongness qua having the different chatracteristics they do have: and even if we could (als we cannot) apprehend the extent to which an act will tend on the one hand, for example, to bring about advantages for our benefactors, and on the other hand to bring about disadvantages for fellow men who are not our benefactors, there is no principle by which we can draw the conclusion that it is on the whole right or on the whole wrong. In this respect the judgement as to the rightness of a particular act is just like the judgement as to the beauty of at particular nattural object or work of art. A poem is, for instance, in respect of certain qualities beatutiful and in respect of certain others not beautiful; and our judgement as to the degree of beauty it possesses on the whole is never reached hy logical reasoning from the apprehension of its particular beauties or particular defects. Both in this and in the moral case we have more or less probable opinions which are not logically justified conclusions from the general principles that are recognized as self-evident. (31)

Pluralists, like particularists, must endorse a non-deductive model of explanation. But onee we have given up on at deductive model of explanation, it is not clear what extra explanatory value is gained from being eommitted to the claim that every action that exemplifies $P i$ is presumptively morally wrong, as opposed to the claim that $P i$ is typically wrong-making.

Ross believed that the fact that a fulfitlment of a promise is always rightmaking. for instance, is self evident.

What eomes first in time is the apprehension of the self-evident prima facie rightness of an individual act of a particular type. From this we come by reflection to apprehend the self-evident general prineiple of prima facie duty. (33) 
For Ross, then, the commitment to the existence of exceptionless presumplive principles is not based on their role in explaining moral phenomena, but rather it is due simply to their self-evidence. However, it is not clear why Ross thinks that these principles are self-evident. Presumably, Ross thinks that we observe a few actions that involve promise keeping. and we notice that in those cases promise keeping is rightmaking. By reflecting on these cases we can see, according to Ross, that promise keeping is always morally relevant. But it is not clear how one could conclude from a particular case, or a set of cases, that promise keeping is alwedrs morally relevant. ${ }^{43}$ And once we give up on a deductive model of explanation-as pluralists must-whe commitment to the claim that promise keeping is always morally relevant is not only unmotivated but also unnecessary. So if my argument in Chapter Two is correct-1hat is, if we have reason to prefer particularism and pluralism to monism-then we might as well prefer particularism to pluralism, since pluralists' commitment to the availability of strict presumptive principles seems to have theoretical costs, and no theoretical benefits.

\subsection{Conclusion}

The claim that moral explanation must appeal to exeeptionless principles has rarely been argued for. ${ }^{4 t}$ Nevertheless, many philosophers find the particularist research program objectionable because they believe that giving up on the search for exceptionless moral principles is tantamount to giving up on moral theorizing. I hope to

\footnotetext{
${ }^{43}$ For a critique of Ross's self-evidence claim and the epistemological difficulties involved, see Dincy (1983).

th I have found only one paper that directly addresses the question of explanation in ethics-Lidd ( 1952).
} 
have shown in this chapter that this is mere dogma-il is based on an undefended, and indeed, an indefensible notion of explanation. A carcful study of the literature on explanation reveals that a deductive approach to explanation is unmolivated, and moreover, that it is widely regarded as an inadequate account of explanation in the social sciences, and arguably in the physical sciences as well.

In this chapter I have not recommended any particular non-deductive model of explanation. I believe that any one of the non-deductive models discussed in sections 3.4-3.6 is compatible with particularism-once the proper adjustnents are made to aceommodate moral explanation rather than scientific explanation. Indeed, different particularist theories may endorse and defend different models of explanation, and the structure of each individual particularist theory maly well depend on the specific details of the non-deductive theory of explanation it is committed to. For instance, some particularist theories may try to identify ceteris paribus moral generalizations or moral normic sentenees, while other theories may look for moral dispositions, or moral difference makers.

It is important to keep in mind that each of the theories of explanation discussed in this chapter is not without difficulties. Explanation, like all other philosophically interesting concepts, is a difficult notion to analyze. and the plurality of theories of explanation may lead us to conclude with Roth, that "there is no good reason to believe that there is just one correct explication of the notion of explanation." (I988:3) Be that as it may, the plurality of theories of explantation, the difficulties they all face, and the fact that there is no consensus about which theory of explanation is correct, should 
convince us that one cannot dismiss a competing moral theory simply by pointing out that there are difficulties for the account of explanation this theory is committed to.

Onc might still insist that since there are known difficulties for all the alceounts of explanation currently available, then we have reason to look for exceptionless moral principles. One could argue that such principles, if lound, would provide a simpler explanation of moral phenomena than any one of the alternatives discussed above. But first, the simplicity of the explanation will depend, of course, on whether the exceptionless principles involved are actually simple. If the only exceptionless principles we find are extremely complex, then the explanation in which they are employed may well be no simpler than its competitors.

Second, even though simplicity counts in favor of a theory, it is not the only virtue a theory must exemplify. In our efforts to eliminate counterexamples, we may inalvertently rob our principles of their explanatory power, for example, by restricting the range of situations to which they apply, or due to ad hoc modifications to circumvent exceptions.

Finally, we must not forget that moral phenomena is undeniably complex, and as Hayek (1967) observes "a simple theory of phenomena which are in their nature complex...is probably merely of necessity false-alt least without a specified ceteris paribus assumption, after the full statement of which the theory would no longer be simple." (28) Einstein is remarked upon as salying. "Everything should be as simple as possible but no simpler." And this is no less true in ethics than it is in the sciences. 45

\footnotetext{
45 In his paper 'The Tyranny of Principles' Toulmin reports on a quotation, attributed to H. L. Mencken, that hangs in the staff lounge at The Hastings Center: "For Every human problem, there is a solution that is simple, neal. and wrong." ( $1981: 31)$
} 


\section{CHAP'TER 4}

\section{PARTICULARISM IN ARISTOTLE'S ETHICS}

\subsection{Introduction}

One striking feature of Aristotle's Nicomachean Ethics is that unlike many modern moral treatises, Aristotle's work is not concerned with finding and formulating exceptionless moral principles. Aristotle seems perfectly comfortable discussing generatizations that are true "for the most part," or hedged generalizations-i.e., generalizations that are true only "in the right times, with reference to the right objects, towards the right people, with the right motive, and in the right way." This sharp contrast between Aristotle's approach to the study of morality and the standard modern style of ethical theorizing is thought provoking. As Sarah Broadic observes,

That Aristotle provides no ground-level normative ethics, and is apparently quite untroubled by any lack of a system here, gives us food for thought. He so blatantly fails to produce the kind of position that it is a modern tradition to expect as a main deliverance of philosophical ethics - and he is not wringing his hands! (2006:353)

Why didn't Aristotle-surely one of the greatest philosophers of all times. whose work covers almost all areas of philosophy-try to develop a ground-level normative ethics? Why didn't he try to find and formulate exceptionless moral principles"?

In this chapter I will attempt to answer these questions. I will argue that even though Aristotle is not in the business of formulating exceptionless moral principles he does, pace Broadie, provide a ground-level normative ethics-that is. he provides a theory that purports to explain the rightness of particular actions. I will suggest that the reason Aristotle did not try to formulate exceptionless moral principles is that he simply 
didn't think that such principles alle neessary in order to provide an adecuate aceount of morality: or in other words, I will argue that we can interpret Aristotle ats presenting a particularist moral theory.

I will proceed as follows: lirst, by focusing on Aristodle's proclatimed goals and methods in the Nicomadean Ethics, and by reviewing several commentaries on his project, I will present a prima facie case for a particularist reading of the text (Section 4.2). Next, I will argue that Aristote is not trying to help us to identify which of the range of actions available to us is morally right, but rather, that his theory is meant to teach us how to explain why those acts that we know are right have the normative status they do. I will suggest that Aristotle's doetrine of the mean is not intended to serve as a decision procedure, but as an explanatory schema that we should apply in order to explain why right acts are right (section 4.3 ).

In 11.2 Aristotle famously asserts that "we are not condueting this inquiry in order to know what virtue is, but in order to become good." (1 103627, Ostwald trans.) In section 4.41 will discuss Aristotle's practical ambitions for his ethical work, and I will explain how these goals are consistent with the interpretation l propose in section 4.3

\subsection{A Prima Facie Casc for a Particularist Interpretation}

In 11.2, right after Aristotle explains that virtue is formed by habit, and just before he begins a detailed presentation of his theory of virtues and the doctrine of the mean. Aristotle pauses in order to emphasize a point he has already made-indeed, a 
point he rehearses several times throughout the Ethics'-eoncerning the nature and goal of ethical theorizing:

But this must be agreed upon beforehand, that the whole account of matters of eonduct must be given in outline and not precisely, as we said at the very beginning that the aceounts we demand must be in aceordance with the subject matter; matters concerned with conduct and questions of what is good for us have no fixity, any more than matters of health. The general account being of this nature, the aceount of particular cases is yet more lacking in exactness; for they do not fall under any art or precept but the agents themselves must in each calse consider what is appropriate to the occasion, as happens also in the art of medicine or ol navigation. ( $1103133.5-1104$ a9, Ross trans.)

Aristotle's repeated rematks about the nature of the subject matter that moral theories are concerned with-i.e., subject matter that lacks fixity-are congruent with a particularist approach to morality. Moreover, his comstant reminders that we ought not to seek mathematical precision in ethical theorizing, his comments on the incliminable role of pereption and practical wisdom in making correct moral judgments. as well ats his characteristic emphasis on the role of habituation in moral development, seem to invite a particularist interpretation of his project. And indeed, some commentators interpret these remarks as an explicit rejection of the generalist program.

\footnotetext{
${ }^{1}$ For example, 1.3,1094b13-26: "Our discussion will be adequate if it achives clarity within the limits of the subject matter. For precision camnot be expected in the treatment of all subjects alike, any more than it can be expected in all manulactured articles. Problems of what is noble and just, which politics examines, present so much variety and irregularity that some people believe that they exist only by convention and not by nature. The problem of the good, too, present a simila kind of irregularity ... Therefore. in a discussion of such subjects, which has to start from a basis of this kind. we must be satisfied to indicate the truth with a rough and general sketch: when the subject and the basis of a discussion consist of matters that hold good only as a general rule, but not always, the conclusions realiced must be of the same order. The various points that are made must be received in the same spirit. For a tvell-schooled man is one who searches for that degree of precision in each kind of study which the nature of the subject in hand admits: it is obviously just as foolish to aceept arguments of probability from a mathematician as to demand strict demonstrations from an orator." (Ostwald trans.) See also 1.7: 1098a25-30, I.13: 1102a23-26, V.10: 1137b.13-32, and 1X.2: 1165a12-14.
} 
For example, Jonathan Dancy, the leading modern particularist, describes the virtuous agent as one who has been equipped, through training, with a full range of moral sensitivities. Dancy argues that the virtuous person is not one who has aceess to at set of principles she can use to subsume new cases under. Instead, what she brings to each new situation is "a countless ability to discern what matters where it matters." (1993:50) Dancy then goes on to suggest that this conception of the virtuous agent is in the spirit of Aristotle's Ethics: "Anyone who hats read Aristotle's Nicomarheom Ethices will discern the Aristotelian style of this account of virtue, both in its refusial to see moral judgment as the subsumption of a new calse under a previously formulated moral principles and in its stress on the role of moral education." (1993:50)

Similarly, John McDowell, finds support for his arguments against principlebased virtue ethics in Aristotle"s work: "My aim is to sketch the outlines of a different view, to be found in the philosophical tratition which llowers in Aristotle's ethics." (1979: 141) Although McDowell never explicilly counts himself as a particularist, his interpretation of Aristotle seems quite friendly to a particularist approach to morality. "'To an unprejudiced eye," he writes,

it should seem quite implausible that any reasonably adult moral outlook admits of any such codification |i.e., codilicaltion in terms of a set principles, which are apl for serving as major premises in syllogisms]. As Aristotle consistently says, the best generalizations about how one should behave hold only for the most part. (1979:148)

In his commentary on Aristotle's Nicomachean Ethics, Harold Joachim claims that when Aristotle notes the eomplexity and the lack of fixity of the subject matter of ethics he is not merely asserting, "as a modern writer on ethics might saly," (1951:15) that morality deals with extremely complex phenomena, and as a result the formulation 
of exceptionless moral principles is an alluous lask that we have not yet accomplished.

Instead, Aristotle's view, according to Joachim, is that

Conduct belongs to a sphere of reality in which there is no necessityno necessary laws, but at most general rules with exceptions. Hence to discover and formulate the general rules, the probable conclusions, ete., is to attain to the only "knowledge' possible in this sphere. A tissue of probable judgments, in which the uneertainty is recognized and the necessity of exceptions admitted, is the aecurate reflection of the facts." $(1951: 15)$

Aceording to Joachim's interpretation, then, Aristotle's view is not only that we do not need exeeptionless principles in our moral theorizing, but rather that given the subject matter of ethies, it is impossible to formulate exceptionless moral prineiples.

Myles Burnyeat seems to endorse an interpretation of Aristotle not much different from those proposed by Daney, McDowell, and Joachim. "Now the noble and the just," he writes,

do not, in Aristotle's view admit of neat formulation in rules or traditional preeepts. It takes an educated person, a capacity going beyond the application of general rules, to tell what is required for the practice of the virtues in specilic situations. (1980:72)

Burnyeat, like the other commentators discussed above, believes that on Aristotle's view morality cannot be codified by a set of exceptionless prineiples. The capacity to make eorrect moral judgments is not acquired by learning a set of moral principles, because the appropriate evaluative attitude cannot be eodified by sueh principles: "What Aristotle is pointing to is our ability to internalize fiom a seattered range of particular eases a general evaluative attitude which is not reducible to rules or precepts." (1980:72)

Finally, Robert Louden is also impressed by Aristotle's repealed comments on the lack of fixity of the subject matter of moral theorizing: 
The radical varrability and indefiniteness of the subject matter of practical science implies that it is not possible to formulate rules which hold in all cases. Instead, the use of a "Lesibian rule" which adapts itself to changing individual circumstances is needed. (1 1.37b.30-32) (1991:162)

Unlike scientific knowledge, the conclusions of practical sciences are "never rigidly universal" (163) This, Louden explains, is due to the fact that "what is called for in the way of action cannot be fully determined independently of the context within which one is deliberating: the account of particular cases "does not fall under any art or set of rules, but the agents themsetves must in each case consider what is appropriate to the occasion.' (1104a7-9)" (162)

In a recent paper, Rebeccal Stangl summarizes the kind of stipport that particularists find in Aristotelian virtue ethics:

There is all obvious affinity between virtue elhics and particularism. Both stress the complexity of the moral life, the inadequacy of rulefollowing as a guide to moral deliberation, and the importance of judgment in discerning the morally relevant features of particular situations." (fortheoming) ${ }^{2}$

All the observations and commentaries that I have cited in this section emphasize what Aristotle is not doing. He is not looking for exeeptionless principles, and he is not trying to provide a moral theory of the kind that moral generatists are looking for. These features of Aristotle's account of morality make a prima facte calse for a particularist interpreting of the Nicomacheon Ethics. But as I explained in Chapter

\footnotetext{
${ }^{2}$ Interestingly, Stangl directs her readers to Crisp (1996b) and Crisp and Slote (1997b) "for examples of the assumplion that virtue ethics must be particularist in some sense." (fil. 1) However, given Crisp's unequivocal rejection of particularism (Crisp 2000 \& 2007 ) it is surprising that Stangl finds any kind of support for a particularist reading of Aristotle in Crisp. I take this to show that there is still a great deal of confusion regarding the nature of particularism; there is still no agreement in the current debate about what particularism amounts 10 , and what exactly particularists are committed to.
} 
One, particularism is not merely a negative claim about what moral theories cannot do. For all that has been said so far, Aristotle might reject not only generalism, but particularism as well-perhaps he simply wasn t interested in offering a ground-level normative ethics; maybe, for instance, he was not interested in explaining the rightness of actions, but rather, he was only concerned with questions regarding the nature of good moral character. 3

So in order to show that Aristotle can be read as a particularist we need to do more than simply to show that he is not a generalist. We must make claar how his theory explains moral phenomena, including the rightness or wrongness of actions, without appealing to exceptionless moral principle. In the following sections I will show how Aristotle's theory can accomplish this task.

\subsection{The Starting Point for Moral Theorizing}

In this section I will arguc that Aristotle is offering a theory that purports to explain the rightness and wrongness of actions. I will claim that Aristotle is not providing necessary and sufficient conditions lor the rightness of actions in order to accomplish this task, but that he is offering a schema for explaining why those acts that are right are right. The doctrine of the mean. I propose, is an explanatory sehema for the rightness of actions; it is a template, or a pattern, that we can employ in order to explain the rightness of particular actions. Aristotle, I will argue, is not trying to help us figure Out which of the actions available to us are right because he is assuming that a student who is qualified to hear his lectures is alleady capable of doing this. Instead, what Aristotle offers is an explanation of why actions have the normative status they have.

\footnotetext{
Sec, for example, Pincoffs (1971) and Talylor (1988).
} 
A natural place for us to begin our discussion of Aristotle's positive account of morality is the passage in 1.4 in which Aristotle explicilly comments on philosophical methodology and on the starting points for moral theorizing:

II Nor must we overlook the fact that arguments which proceed from fundamental principles are different from arguments that lead up to them. Plato, too, rightly recognized this as a problem and used to atsk whether the discussion was proceeding from or leading up to fundamental principles, just as in a race course there is a difference between rumning from the judges to the far end of the track and running back again. 121 Now, we must start with the known. But this term has two connotations: "what is known to us" and "what is known" pure and simple. Therefore, we should start perhaps with what is known to us. 13] For that reason, to be a competent student of what is right and just, and of politics generally, one must first have received a proper upbringing in moral conduct. | 4 The aceeplance of a fact as lact is the starting point, and if this is sufficiently clear, there will be no lurther need to ast why it is so. 151 A man with this kind of background has or can easily aceunire the foundations from which he must start. [6] But if he neither has nor' can acquire them, let him lend an ear to Hesiod's words:

That man is all-best who himself works out every problem...

That man, 100, is admirable who follows one who speaks well.

He who cannot see the truth for himself, nor, hearing it from others.

Store it alvay in his mind, that man is ullerly useless. (1095:1311095b12, Ostwald trans.)

One of the difficulties in interpreling this passage concerns the use of the word arche and its cognates. Arehe, in its most concrete sense, means heginning (or starting point) but it is also used for lirst principle (or fundamental principle). ${ }^{4}$ Different translators choose different renderings of the various occurences of this word, and their choices give rise to alternative readings of this passage. ${ }^{5}$ The interpretation 1 am about to propose is based on Ostwald's translation of this passiage."

\footnotetext{
${ }^{4}$ See Ostwald (1962) Glossary of Technical terms pp. 303. See also Irwin (1978) esp. fin. 18, and Burnycal (1980) esp. pp. 70-74

"Ross's translation, like Irwin's and Burnyeat's translations, are quite similar to Ostwald's translation cited in the main text. However, Broadie and Rowe translate 1095b7 as follows: "But such a person either has the relevant first principles, or might
} 
Following Burnyeal (1980), I understand Aristotle here as engaged in al

dialectical inquiry towards fïst principles | I|. This inquiry towards first principles, Aristotle argues, must begin with what is known to us |21: those things that are known to us can serve as our starting point. But what ate the things that Aristolle thinks are known to us"? What are our starling points?

Our starting points, I suggest, are the normative statuses of parlicular aclions. As Burnyeat observes, "the ancient commentators are agreed that Aristotle has in mind knowledge about actions in accordance with the virtues; these actions are the things familial to us from which we must start, and what we know about them is that they are noble or just." (1980:71-72) In other words, we must start our moral theorizing from our judgments about particular actions. In order to have eorrect starting points for moral theorizing, then, we must be able to identify right acts as right, and wrong acts as wrong. We need not know why those actions have the nomative status we identily them as having |5|: one could engage in moral theorizing even if one does not know why right acts are right, as long as one has the ability to identify that they are right, or at the very least, if one is willing to acept the judgments of "one who speaks well" as

casily grasp them." (Instead of Ostwald"s: "A man with this kind of background hats or can casily acquire the foundations from which he must statl," or Ross"s: "the man who has been well brought up has or can easily get starling points," or lrwin's: "Someone who is well brought up has the beginnings, or can casily acquire them," or Burnyeal "s: "Such a person has, or can casily get hold of, beginnings (starting points)." The difference here is important. On Ostwald"s translation, als well als on Ross"s, Irwin"s, and Burnyeal's, the things that the well brought up person has, or can easily acquire, alre the correct starting points for the study of ethics. According to Broadic and Rowe's translation, the things the well brought up person has, or ean easily acquire, are the first principles-that is, those things that our current study is trying to obtain. Sec lrwin (1978) fn. 18 and Irwin (1999) p. 176-7 for a discussion of this issue.

${ }^{6}$ My interpretation is also compatible with the translations by Ross. Irwin, and Burnyeat-see fn. 5 above. 
one's stating points $|6|]^{7}$ This is the reason why Aristotle insists that a competent student is one who has had a good moral upbringing |3|. A person who is brought up well should be able to tell noble acts from ignoble ones; he is expected to be able to identily courageous acts, or just acts, and he is expected to be able to tell them apart from those acts that are cowardly or unjust. The student need not know why a given act is right, but he ought to know that it is right. And following Burnyeat (again), I believe that Aristotle's goal in the Ethics is to teach his students why those acts she identifies ats right, are right.

But how eould one identily particular actions as right actions il one doesn 't know why these acts are right? Aristotle thinks that with proper education, one could form habits that enable one to distinguish right actions from wrong ones. But since habituation is required, the acquisition of this skill involves a lengthy process: one must experience a wide range of situation in order for one's ability to identify right actions to be sulficiently reliable in order to pick out the correct starting points. ${ }^{8}$ This is one reason why in I.3 Aristotle insists that young men are not the target atudience for his lectures: "for they are inexperieneed in the actions that eonstitute life, and what is said will stant from these and will be about these." (1095a3-4. Broadie \& Rowe trans.) Our

\footnotetext{
${ }^{7}$ Aristotle is well aware of the infinite regress involved in demanding an explanation for all our statting points, and he claitus that our statting points in matters of deliberation are particular facts: "Nor can we deliberate about particular facts, e.g., whether this is a loal of bread or whether this loaf of bread has been properly baked: such facts are the object of sense pereption. And if we continue deliberating each point in turn, we shall have to go on to inlinity." (III.3: 1113 al-3. Ostwald trans.)

${ }^{8}$ The elaim that one could know that an action is right without knowing why it is right may seem less purzling if we consider the lace that a native speaker of a language ean often tell whether a sentenee is grammatieal even in calses in which she might not know why it is so. Of eourse only native speakers who have been "brought up well" with resepect to language would be able to do this eorrectly, and young people are less likely to have this ability.
} 
discussion, Aristotle tells us, concerns the rightness of actions, but it also begins with correct judgments about which particular actions are right. Our ability to identify right acts as right is acquired through habituation, and the habits we form depend on the kind of moral upbringing we get. If we are not properly educated, and as a result we do not form the right habits, we would not have the right starting points for moral theorizing, and we would be "utterly useless" |6]; if our initial judgments about the normative status of actions are incorrect, then surely the first principles we discover by way of a dialectical incuiry starting from these judgments are likely to be false. Having correct starting points is key to a sucessful dialectical inquiry. "Hence it is no small matter," Aristotle concludes, "whether one habit or another is inculcated in us from carly childhood: on the contrary, it makes a considerable difference, or, rather, all the difference." (II.1: 1103b23-24, Ostwald trans.)

In 1.7 Aristotle reminds us again that we must not repuire the same degree of precision in all areas of inquiry, and that the appropriate degree of precision for each investigation depends on the nature of the subject matter being explored, as well as the purpose of the investigation (1098:26-28). He illustrates this last point with an example: a geometrician and a carpenter may both be interested in right angles, but their purposes are cuite different; the carpenter"s interest concerns the usefulness of right angles to his carpentry work, whereas the geometrician is interested in the very nature of right angles. Aristotle then goes on to say the following:

|6| We should proceed in just the same way in other areas 100 , so that the side issues do not overwhelm the main ones. [7| One should not demand to know the reason why, either, in the same way in all matters: in some cases, it will suffice if thet something is so has been well shown, $|8|$ as indeed is true of starting points; some are glasped by induction, some by perception, some by a sort of habituation, and others 
in other ways: 191 one must try 10 get hold of each sort in the appropriate way, and take calle that they are well matked out, | 10] since they have greal importance in relation to what comes later. For the start of something seems to be more than hall of the whole, and through it many of the things being looked for seem to become evident." (1098a.33$1098 \mathrm{~b} 7$, Broadic \& Rowe trans.)

In this passage Aristotle tells us that inguiries can differ not only with respect to their appropriate degree of precision |7|, but also in the way in which their starting points are obtained $|8|{ }^{10}$ Moreover, Aristotle insists that it is important to obtain the starting points for each inquiry in the appropriate way $|9|$. "Each kind of starting point," Burnyeal explains,

comes with a mole of acepuisition appropriate to it; to give a couple of examples from the ancient commentators, we learn by induction that all men breathe, by pereption that fire is hot. In ethics the appropriate mode log at least some starting points is habituation... The thesis is that we first learn (come to see) what is noble and just not by experience of or induction from a series of instances, nor by intuition (intellectual or perceptual), but by learning 10 do noble and just things, by being habituates to noble and just conduct. (73)

Finally, Aristotle stresses again the importance of having the correct starting points || $0 \mid$.

Aristotle's goal, as I have mentioned above, is to help us understand why those acts that we identify as right-our stanting points-are, in fact, right. But he warns us that the kind of explanation we ought to seek should be appropriate to the subject matter we are dealing with |7|. When we explain the Pythagorean theorem, for example-that is, when we explain why for any right triangle, the area of the square whose sicle is the

\footnotetext{
"In this passage Broadie \& Rowe translate arche as "starting point," as does Burnyeat. In contrast, Ross, Irwin, and Ostwald opt for "first principle" (or "principle." or "fundamental principle," respectively).

10 Aristotle again emphasizes here that in the case of starting points we need not know why they are so, but it is sufficient to know that they are so |7]-|8|. Sec also, 111.3: 1113 al -3 and fin. 7 above.
} 
hypotenuse is ecgual to the sum of the areas of the squares whose sides are the two legs-we can give a demonstrattive expalanation. We can produce a deductive argument for the conclusion that the Pythagorean theorem is true. But we "should not demand to know the reason why in the same way in all matters." Explanations of the rightness of actions. which is what we are after here, will not be deductive explanations, and given the subject matter of ethics, they cannot be: "pure science involves demonstration," Aristotle tells us, "while things whose starting points or first causes can be other than they are do not admit of demonstrations." (V1.5: 1140a34, Ostwald trans.)

After reminding us in 11.2 that the subject matter of ethies lacks fixity, and as a result, our aceount will not be very precise-especially in terms of its application to particular actions (1103b35-1104a9 eited in section 4.2 above)-Aristotle goes on to say this: "But though our present account is of this mature we must give what help we can." (1104a10. Ross trans.) What immediately follows, are Aristotle's observations regatrding the harmful effects of excess and deficieney, and the positive effects of the proportionate amount, or the mean. These observations. Aristotle tells us, hold true for health and strength as well as for characteristics like temperance, courage, and other virtues. To ale in accordanee with the mean is not only the way to acquire virtuous characteristics, but is also the mark of virtuous actions.

These comments on the mean, it seems, are meant to be helpful in some way or other. But what kind of help does Aristotle intend his comments on the mean to have? Broadie (1991) proposes the following hypothesis:

|Aristotle| could be deceived into thinking the doctrine of the mean useful in ways in which in fact it is not. This may be what happens in NE 1I.2, where he bewails the impossibility of giving exact rules for correct particular responses (1104a5-9): then salys that he must give 
what help he can ( 110 tal $0-11$ ); and then goes on to discuss, not responses, but dispositions." ( $|0|-2)$

Now I agree with Broadic that if Aristotle had thought that his comments on the mean are supposed to help us identify the right response in various situations, he was mistaken about their usefulness. However, I doubt that this is what Aristotle had in mind. Indeed, in VI.I Aristotle denies that he thinks his advice about the mean is helpful in determining what we ought to do:

We stated eartier that we must choose the median, and not exeess of defieiency, and that the median is what right reason dictates... but this statement, true though it is, lacks clarity. In all other fields of endeavor in which scientific knowledge is possible, it is indeed true to saly that we must exert ourselves or relax neither too much nor too little, but to an intermediate extent and as right reason demands. But if this is the only thing a person knows, he will be none the wiser: he will, for example. not know what kind of medicines to apply to his body. if he is merely told to apply whatever medical seience preseribes and in at manner in which a medical expert applies them." (1 1 38619-35. Ostwald trans.)

So what kind of help are these eomments on the mean supposed to provide? I propose that these remalks are meant to help us explain why those acts that we already know are virtuous, are virtuous. If we ean tell-as we must be able to in order to obtain starting points for our ethical incuiry - that a particular act is courageous, for instance, we now know that this action lies in the mean. So we can explain its rightness by pointing out that this act is neither exeessive nor deficient. This, of course, is merely at rudimentary sketch of an explanatory sehema-Aristotle provides us with additional details about virtues in general in the remainder of book II, and with more specific detaits on how to fill out this schema for each particular virtue in books III through Vbut we can now already identify the basic strueture of the explanation: if an act is right. then we should be able to identify a seale on which it is neither exeessive nor defieient. 
Aristotle is well aware of the fact that what he has given us so far is extremely undeveloped, and indeed, he goes on to expound on this explanatory model in several phases. First, right alter presenting the bare bones of the proposed explanatory sehema. Aristotle discusses some general features of virtues: he tells us that a matrk of an action performed virtuously is that the agent of the action takes pleasure in performing the aetion (II.3); he distinguishes between a virtuous action and an action performed virtuously (II.4); and he identilies the genus and differentia of virtue (II.5-6). By the end of II.6 we get Aristotle's definition of virtue: "We may thus conelude that virtue or excellence is a characteristic involving choice, and that it eonsists in observing the mean relative to us, a mean which is defïned by a rational principle, such as a man of practical wisdom would use to determine it." (1106b35-1 107al, Ostwald trans.) Now this provides us with a bit more detail regarding the explanation of why particular actions are virtuous. Consider: "Why is this action of standing one's ground in battle eourageous?" We can now answer this question as follows: "This aetion is courageous because the agent chooses to perform this action, and it is located in the mean (relative to the agent $)^{11}$ of some relevant scate." Moreover, we now know that if the agent takes pleasure in performing this courageous action, then he is not only performing a virtuous action, but also performing it virtuously.

But this explanatory model is still extremely rudimentary, and we must learn how to fill out this schema informatively for particular eases in order to provide explanations of the rightness or wrongness of the relevant actions. Aristotle turns to this in II.7:

\footnotetext{
"Sec II.6: 1106a30-b4.
} 
However, this general statement is not enough; we must also show that it fits particular instances. For in a diseussion of moral actions, although the general stattements have a wider range of application, statements on particular points have more truth in them: actions are concerned with particulars and our statements must harmonize with them." (1 107a28-33. Ostwald trans.)

We already know that in order to explain why a particular act is virtuous we must locate this action in the mean of some relevant scale-this statement has a wide range of application-but in oreder to appreciate its truth. we must see how it applies to particular virtuous actions and make sure that the results of the application of the schema harmonizes with the facts-i.c., that the application of this explanatory sctiemat generates eorrect result. So in II.7 Aristotle lists various sciales that are relevant to caleh virtuc.

Moreover, when possible, Aristotle also introduces the relevant vocabulary we should use in our explanation. For example, if we want to explain why an act is courageous, we should probably locate the agent's emotional state while performing the action as a mean on a scalc (or seales) ${ }^{12}$ of feal and conlidence; the agent might be leckless if he exeeds in confidence, or concardly if he is deficient in confidence. If we want to explain why an action is generous we should probably locate the action ats a mean on a scalc ranging from stinginess to extravagance.

Aristotle goes on to list relevant seales for other virtues. Yet he is well atware that even now we have only been given a rough skekch-"For our present purposes, we

\footnotetext{
12 The feclings of fear and confidence ale, quite plausibly, two distinct types of emotions rather than extremes of one type of emotion (see, for example. Pears (1980)). My proposed interpretation of Aristotle is compatible with both realings-whether Aristotle intended courage to be concerned with one scale or with two different seales. The main point is that if an action is eourageous, then the explanation of this fact involves locating the action performed and/or the agent's emotion as a mean on the relevant sciale(s).
} 
must rest eontent with an outline and a summary, but we shall later define these qualities more precisely" (1107b15. Ostwald trans.)-illbeit a bit more substantive than what we had so far. By the end of 11.7, if we are asked, for example, why Ms. Smith's at of donating $\$ 100,000$ to cancer research is generous, we could say that she chose to perform this action, and that given her economic and social situation. donating $\$ 100,000$ to this cause was neither stringy nor extravagant. Moreover, if we know that she took pleasure in her generous donation, we know that she has acted generously. It is important to note that this explanatory schema does not generate deduetive explanations. From the fact that Ms. Smith's action was neither stringy nor extravagant it does not follow that her action was right or virtuous. There may have been other, more urgent, catuses to donate too, or there eould have been good reasons not to donate to the particular organization that she had ehosen. Unlike the Hempelian model of explanation (discussed in Chapter Three), this model of explanation is not syntaetieal. and the explanandum does not logieally follow form the explanans. (Reeall that Aristotle elaims that we "should not demand to know the reason why in the same way in all matters," and that explanations in ethics "do not admit of demonstrations.") This is why it is important for Aristotle that we already know that the action is right before we explain why it is right: that the act is right is part of the data we have available to us when we explain why it is so.

I helieve that my proposal helps us to make sense of several features of Aristotle's work that eommentators have found perplexing. First, it helps us understand the importanee of the doctrine of the mean for Aristotle's project. Some readers of the 
Niconacheran Ethics have been puzzled by the seriousness with which Aristotle approaches the doetrine of the mean. As Broadie (1991) puts is:

Aristotle regards | the doctrine of the mean | as an important contribution. to judge by the solemnity with which he intoduces it and the many pages where he strains over the details of its application. Yet the doctrine often gets a disappointed reception. It seems at fïst to offer special illumination, but in the end, according to its critics, it only cleals with truisms together with a questionable taxonomy of virtues and vices. (95)

On my reading, the doctrine of the mean platys an important explanatory role which lies at the heart of Aristotle's project. Apart from presenting the explanatory schema itself. Aristotle equips us with a rich theoretical framework and extensive vocabulary that we ought to employ in our explanations of the rightness of those acts that are right; this is why he methodically gives us the names of the virtues and vices that have names, as well as the names of the qualities that resemble virtues, but are not quite virtues.

Moreover, since the details of the explanation in each particular case will differ based on the particular features of that aetion whose rightness we want to explain, it is important to give many examples of how this is done. This is why Aristotle gives us many examples of the application of the generic schema. In the case of courage, for instance, Aristotle suggests different possible objects of fear (c.g., death, poverty, discase), and various contexts in which one could exemplify courage (e.g.. in battle, at sea, in illness). "He is courageous," we are told,

who endures and fears the right things, for the right motive, in the right mamner, and at the right time, and who displays eonfidence in similal ways. For a courageous man feels and acts aceording to the merits of each case and as reason guides him." (III.7: 1 115b19-20, Ositwald trans.) 
When we explain the rightness of a particular courageous action, we must replace the hedges ("the right things," "in the right manner," elc..) with the specifies of the particular action: ${ }^{13}$ for example, his action was courageous because he joined the army and risked his life in order to protect his country, when no non-military option was available in order to resolve the conflict (and so forth). The only generie thing we could saly about eourageous actions is that they are done for the sake of the noble (III.7:

\section{$1115623-24)$.}

We also get examples of types of excess and deficiency (1115b25-1116a3), and a list of characteristics similar to courage that are not quite courage (III.8), including some famous examples of cases in which these qualities were displayed. (1116:20-25). With these finer distinetions, we should be able to explain why certain actions that may appear courageous are not completely courageous; for instance, although an act may seem like a courageous act it only resembles courage if the agent aets as a result of excessive optimism. or if she performs an action in ignorance of the dangers this action involves (1117a10-27). And the same holds for other virtues: the more examples we get of the application of the general schema with respect to different virtues, and the more examples we get of various states that are similar to virtue but differ from it, the more eonfident we will be about the appropriateness of our generie schemat, and the better prepared we will be to apply it in new situations. "It will be no bad plan," Aristotle tells us in IV.7, "lo deseribe these states |that have no namel als well; for we shall both know

\footnotetext{
${ }^{13}$ See, for example, III.1: "What sort of things are to be chosen, and in return for what, it is not easy to state; for there are many differences in the particular cases." $(1110 \mathrm{~b} 8$. Ross trans.) And 111.4: "What is good and pleasant differs with different characteristics and conditions, and perhaps the chief distinction of a man of high moral standards is his ability to see the truth in each particular moral question, since he is, ats it were, the standard and mecisure for such questions." (1113,3131-34. Ostwald trans.)
} 
the facts about character better if we go through them in detail, and we shall be

convineed that the virtues are means if we see this to be so in all catses." (1 1 27al 4-16.

Ross (1ans.)

Rosalind Hursthouse expresses another dilliculty that my proposed interpretation helps to resolve. In her essaly 'A False Doetrine of the Mean', she argues, as the litle of her paper aptly indicates, that the doctrine of the mean is lalse. "What 1 want to illustrate," she tells us, "is that right objeret and right oceresiom...cannot be specified ats means, and that, more generally, some vices that correspond to the virtues of temperance, courage, and what is ustally tramslated as "patience" or "gentleness"the right disposition with respect to anger-camnot be understood ats dispositions to exhibit or lect an emotion (a pothoss) too much or too little." (1980:61-2)

Hursthouse provides several examples of vicious acts that cannot be described as excessive or deficient, and concludes that "Some of the wrong objects which the greedy and wicked person enjoy would still be wrong simply in so far as they were contrary to what is honorable; if they were cases of excess this would be aceidental."

(64) Another example she considers involves adultery:

It might be that one had moderate, or even unnaturally low, sexual drive. But if one has any sexual drive at all and cares naught for what is honorable, then one will be disposed to commit licentious ats of "adultery"."(66) 15

\footnotetext{
It More accurately, her target is Urmson's (1973) interpretation of the doctrine of the mean.

15 It is peculial that Hursthouse includes this particulat example, since, as I am sure she is well aware, Aristolle specilically discusses adultery as an example of a wrong action that cannot be describes as 'too much...' or 'too little...' and as an action that cannot be performed with the right woman, at the right time and so forth: "In cases of this sort. let us say adultery, rightness and wrongness do not depend on commitling it with the right woman att the right time and in the right manner, but the mere lact of committing such actions at all is to do wrong. It would be just as absurd to suppose that there is a mean.
} 
Similarly, with respect to courage she argues that there are some objects that are not appropriate objects of fear, and these objects camnot be described as "too much of ...' or "too little of...' These observations, Hursthouse claims, raise the following questions:

Why does Aristotle talk in terms of excess and deficiency, too... and 100... at all? Why should he not rest content with saying that men maly go wrong in coumtless ways, but hit the target and achieve excellence in only one (1106b30fi) rather than even suggesting that, for each virtue, there are just two opposed ways of going wrong? $(68)^{16}$

The answer to Hursthouse's questions, I maintain, is this: Aristotle identification of the virtuous act as lying in the mean between excess and deficiency is the essence of the explanatory schema he proposes. It is true that actions can go wrong in countless ways, but this statement doesn t explain why the right ones are right.

Now it is important to realize that Aristotle's schema is supposed to help us explain why right actions are right; the explanation involves finding the relevant scale on which the action (or emotion) is in the mean. But even though the rightness of every right action ought to be explained by locating some scale on which this action is a median (relative to the agent and /or the situation), it does not follow that the wrongness

an excess, and a deficieney in an unjust or a cowardly or a self-indulgent act." (1107a15-19, Ostwald trans.)

${ }^{16}$ Hursthouse's own answer to this question is this: "The explanation is-that"s just the way we happen to be: we just do wrong in these two ways. Similarly, the explanation of why the two vices should be opposed, as excess to deficiency is-lhal's just the waly things happen to turn out; fear works that way with us. The possibility of the "fearless phobic' shows that things might have been otherwise. If he were as eommon as the cowardly and the fearless, there would be three viees not two. If he and the cowardly were common and no-one was fearless, there would be two vices but they would not be opposed ones" (69). I find this solution unsatisfying. There are instances where Aristotle asserts that one of the extremes is uncommon; nevertheless, Aristotle insists on identifying the retevant virtues as a means between two extremes, which are vices. 
ol every wrong action ought to be explained by identifying a scale on which it is excessive or deficient. As I see it, being in the mean on the relevant scalle is a necessary, but not sufficient, condition for the rightness of an atetion. So if there is no relevant scale to locate an action on, this action cannot be right. Furthermore, an adequate explanation of the rightness of an action will also have to replace the "hedges" of the generic schema-i.e., the right time, the right object, the right people. ete., - with the specific details of the catse in hand.

Following Hursthouse's lead. Broadic (1991) also questions the generality of the doctrine of the mean as follows:

Although some wrong responses atre wrong because they are too high or too low on some seale or other, not all wrong responses can be fatulted in such a way, unless metaphorically. What does a person do too much or too little when he agrees to sell secrets to a foreign power? (100)

The answer to Broadie's guestion will depend, of course, on the particular details of the case we are evaluating. Il in this particular situation selling secrets to a foreign power is the right thing to do, then the agent's act might be wrong becattse he was too greedy, or because he wasn t scared enough, or too sealred, or what not. However. more typical acts of treason ate not right actions. Il there ate no good reasons to sell secrets to a foreign power, for example, then an act of selling secrets to a foreign power would be wrong not in virtue of being excessive or deficient, but in virtue of not being a mean on any relevant scale. In II.6 Aristotle is quite explicit about this point:

Not every action nor every emotion admits of a mean. There alre some actions and emotions whose very names connote baseness, e.g. spite, shamelessness, envy; and among actions, adultery, theft, and murder. These and similar emotions and actions imply by their very names that they are bad: it is not their excess nor their deficiency which is called bad. It is, therefore, impossible ever to do right in performing them: to perform them is always to do wrong. In cases of this sort, let us say 
addultery, rightness and wrongness do not depend on committing it with the right woman at the right time and in the right manner, but the mere fact of committing such actions all all is to do wrong. It would be just ats absurd to suppose that there is at mean, an excess, and a deficiency in an unjust or a cowardly or a self-indulgent act. (1107a9-19. Ositwald trans.)

In this passage Aristotle tells us that some emotions and actions are wrong not in virtue of being excessive or defieient. A typical case of murder is simply wrong even though it would be absurd to describe it as 'too much ...' or '100 little...' Contrary to some eommentators who reat this paragraph as indicating that Aristotle-his repeated comments on the lack of lixity in ethics not withstanding-does, in fict, think that morality can be codified (e.g., murder is al ways morally wrong), ${ }^{17}$ I believe that this passage demonstrates that Aristotle thinks that there is an alsymmetry between the explanation of why right acts are right, and why wrong ones are wrong. In order to explain the rightness of an action we must follow Aristotle's explanatory schema. This schemat is meant to explain why right acts are right, and why some acts that may appear right are, in fact, wrong in virtue of being exeessive or deficient on the relevant scale, or in virtue of failing to properly discharge the "hedges" (in the right time, with the right object, etc.,). But there are some wrong actions and emotions whose very deseription ought to be sufficient in order to establish their wrongness-their very names imply that they are batd-so no further explanation I required.

Now it is certainly true that Aristolle's discussion of vicious acts focuses on wrong ats that involve excess and deficiency. I think there are two reasons for this. First. discussion of the vices involved in excess and deficiency help us to understand the

${ }^{17}$ See, for example, Irwin (2000) 
relevant virtues better; it shouvs us how the explanation of the rightness of actions would work in calses where one performs a right action in which the same seale is involved.

Second, and more importintly-and this, I helieve, provides further evidence lor my interprelation of Aristotle as offering an explanatory sehema-the wrongness of a standard case of treason. to return to Broadic's example, is not a phenomenon that (typically) requires an explanation. When one knows full well the details of a (paradigmatie) particular act of treason, and there are no doubts about the facts of the case, the question: "Why was it wrong for Mr. Smith to betray his fellow citizens?" is rarely, if ever, asked. Indeed, it seems natural to expect that anyone who ansis this question is missing some important fact about the case we are evaluating. 18 And while it is common in molern moral ethical works to ask questions like "Why is torturing babies for fun wrong?", we do not lind these kinds of questions in Aristotle. Aristotle may well have though that the wrongness of treason, or the wrongness of torturing babies, is simply obvious and that since it is obvious, no explanation is reculired; indeed, it seems plausible to assume that the kind of person who is puzzled about why these acts are wrong would be disqualified as a proper hearer of Aristotle's lectures.

The closest Aristotle comes to diseussing cases like these is in V11.5, where he mentions "the female who, they say, rips open pregnant women and devours the infants. or of the things in which some of the tribes about the Black Sea that have gone savage are said to delight-in raw meat or in human flesh, or in lending their children to one another to least upon-or of the story told of Phalaris," (1 148620-23) and "the man who sacrifieed and ate his mother, or with the slave who ate the liver of his fellow."

\footnotetext{
${ }^{18}$ See Gass (1957) on whal he calls "clear cases."
} 
(1 148b25-6. Ross trans.) All that Aristolle has 10 saly about these cases is that they are instances of brutish chatacteristics, and brutishness, he tells us, is beyond the limits of vice.

Another interesting problem that my aceount resolves is a puzzle that has been largely ignored by most commentators. In his discussion of pleasure as the mark of virtue in II.3, Aristotle mentions and eriticizes those who define virtues as "states of freedom from emotion and of quictude." (1 104b23, Ostwald trans.) His critique of this account of virtue maly seem quite odd. He says: "However, they / who so define virtuel make the mistake of using these tems absolutely and without adding such qualifications as "in the right mamner," "at the right time, and so forth." (1 104b24-25, Ostwald trans.) Now Aristotle’s own definition of virtue as it appears in II.6 (quoted above) is incompatible with the definition of virtue as "freedom from emotion and quictude." And elearly enough, it is also incompatible with the definition of virtue as "states of freedom from emotions and quictude in the right manner, at the right time, and so forth." For Aristotle, an essential component of virtuous activity is the right emotional response; a virtuous action is not an act that is free from emotion, but rather an act that involves the appropriate emotion. So what should we make of Aristotle's critique of this view?

As I see it. Aristotle's criticism of this view is categorical; this view is not to be rejected in virtue of its content, although we soon learn that its content is false as well, but rather it ought to be rejected because it is the wrong kind of definition. Virtue simply cannot be delined absolutely and without adding such qualifications as in the right manner,' "at the right time." so we can dismiss uncualified definition even before 
we assess their content. Now this comment appears in II.3, shortly after Aristotle insists that despite the lack of fixity in ethics, "we must give what help we cann." (as discussed above). This point is important becaluse it reveals that Aristotle believes that the explanations of the rightness of actions cannof be deductive; the "principtes" of" rightness we ought to seck will be hedged generalization, or ceteris paribus generalizations. But although we camnot formulate necessary and sufficient condition for right actions, we can construct moral theories that consist of hedged generalizations that enable us to explain moral phenomena.

One might worry that the explanatory schema that I am attributing to Aristotle is valuous in the sense that we may be able to construct an explanation in alecordance with this schema for any action, regardless of whether it is right or wrong. In other words, that we can identify a seale on which the action we are evaluating is a mean, and that we can discharge the hedges with specilic features of the action we are evaluating, gives us no indication that the action is, in fact, right. But first, as we have seen in the passage from II.6 (1 107a9- 19, quoted above), according to Aristotle not every action or emotion can be located on a mean on some scalle or other: "Il would be ... absurd to suppose thall there is a mean, an excess, and a deficiency in an unjust or a cowardly or a selfindulgent act." (1107al9, Ostwald trans.) And second, we must not forget that this explanatory schema is not supposed to help us identily right actions; that the acts we identify as right are right is our staring point.

\subsection{The Practical Goal of Aristotle's Nicomachean Ethics}

So far, I have claimed that Aristotle's goal is to help us understand why those acts that we already know are right have the normative status they have. In other words, 
I proposed that Aristote is not trying to answer the guestion "Which of the actions available to me is morally right?" but rather, his account is meant to answer a different questions, namely: "Given that, as I already know, this action is morally right, what is it about this action that makes it right?"

One might object to this interpretation of Aristotle's project because it may seem as though this interpretation does not do justice to Aristotle's proclaimed practical ambitions in the Nicomachean Ethics. In 1.3 Aristotle tells us that "the end of this kind of study fi.e., the study of political science and ethics/ is not knowledge but action." (1095a6, Ostwald) And in II.2 Aristotle repeats this point: "The purpose of the present study is not, as it is in other inquiries, the attainment of theoretical knowledge: we are not conducting this inquiry in order to know what virtue is, but in order to become good, else there would be no advantage in studying it."19 (1103b26-29. Ostwald trans.) But if my proposed interpretation were correct, the objector might argue, then Aristotle's project is entirely theoretical; if 1 am right, then Aristotle's account does not help us to identify morally right actions, but instead it only provides us with theoretical knowledge about why right acts are right. However, since it is unreasonable to think that Aristotle so radically missed the practical target he has set for this inquiry, we must reject the particularist reading of the Nicomachean Ethics that I put forward in the previous section.

That Aristotle expects his work on ethics to be practically useful might seem surprising regardless of whether we interpret him as presenting a particularist account of morality. Joachim (1951) in his commentary on the Ethics is, in fact, puzzled by

${ }^{19}$ See also 1.2: 1094:a22-4 and X.9: 1179:a35-b4 
Aristotle's practical atspirations. Joachim claims that Aristotle s's comments on the practical goal of his inquiry suggest that Aristotle is minterested in theoretical knowledge conceming human conduct.

The reasoning about human conduct and character, |Aristotle| insists, is only with a view to influencing action. His object is not understandingmerely to understand, apparently, even if possible, is valueless-but to guide and improve life." (15)

Having stated Aristotle's goals as he does, Joachim is, perhaps unsurprisingly,

disappointed with the kind of pratelical advice Aristotle has to offer. Indeed, he claims that in this respect Aristotle's ethical writings are in al glaring dissonance with

Aristotle"s own description of his project: "It is difficult to sympathize with Aristotle"s views here," he writes.

diflicult even to state them fairly, because they represent a position so different from that of most modern philosophy. Why should not the philosopher reflect upon the conduct of his contemporaries and of preceding generations... why should not his reflection be directed simply to understand, i.e., to attain to that measure of insight which is possible for human intelligenee in this sphere? ... And why, linally, should a speculative inquiry into the phenomena of conduet be rejected ats worthless? ... Aristotle's own practice hardly squales with his theory...in fact. |Aristotle:s | own intelligence is actively engaged in the theoretical study of eonduct and in that study it is free and unprevented by emotion or by the aims of action: and very lew thinkers have eontributed so much to the theoretical investigation of the lates of conduct as Aristotle himself has done in the Niremachean Eilhics and the Politics." (1.5-16)

It seems to me that Joachim is clearly correet in highlighting the late that a large portion of Aristotle's ethical work-indecd, arguably all of it-is distinctively theoretical in nature, and that Aristotlex's lasting contribution to moral philosophy consists in the sophisticated and insightful theoretical framework he constructed. Moreover, given Aristotle’s wide range of philosophical interests, it would be yuite 
surprising if Aristotle had thought that one ought not to reflect on moral eonduct-be it one"s own conduct or the conduct of others-or if he hat thought that theoretical knowledge in matters of conduct is worthless. As Joachim rightly asks, why would Aristotle think that theoretical knowledge in other areas of incuiry is valuable, while in matters of conduct it is worthless? So what should we make of Aristotle's repeated remarks regarding the practical goals of his inquiry?

In order to answer this question, and in order to evaluate the objection to the particularist interpretation of Aristotle mentioned above, we have to get elear on the nature of Aristotle's practical ambitions. What would it take for an ethical treatise to be practical"? How could a series of lectures (or a book) help us "to become good"?

One way for an ethical treatise to help us to become good is by formulating a (correct) decision procedure - an algorithm that takes as its input information available to the agent and gives as its output an action that the agent ought to perform. However, one would search in vain through the pages of the Nicomachean Ethices for anything that resembles a practicable decision procedure. And eonsequently, one who thought that Aristotle's goal is to help us to identify which of the many actions available to us at any given moment is an act that we ought to perform, is bound to find Aristotles account wanting. But if Aristotle is not trying to formulate a decision procedure, how does he expect his work to help us to become good?

I propose that Aristotle's main practical ambition is to help his students perform those actions that they already know are right in a virtuous manner. As we have seen. Aristotle distinguished between performing a virtuous action, and performing an action virtuously (II.4). A endainon life, according to Aristotle, is a life that involves virtuous 
activity in the strong sense-that is, a life that consists of not only virtuous actions, but of virtuous actions performed virtuously. As we shall see, Aristotle does not think that one could learn how to ace virtuously merely by gaining theorelical knowledge. Nevertheless, he does believe that theorelical knowledge is necessary for acting virtuously, or at least, that it could help one learn how to act virtuously. By understanding why right acts are right, and what it takes to perform these acts virtuously, we maly be able to understand in what ways we miss this mark when we do. and possibly modify our actions in order to habituate the proper emotional responses that would enable us to hit the mark, or at least come closer to the matk, in luture actions.

At the very beginning of the Nicomachean Ethics Aristotle algues that there must be one chicf good which is the end of all our actions, and he indicates that the molivation for his inguiry is practical. "If, then, there is some end of the things we do, which we desire for jts own silke," Aristotle writes in I.2.

elearly this must be the good and the chicf good. Will not the knowledge of it, then, have a great influence on life? Shall we not, like atehers who have a mark to aim atl, be more likely to hit upon what is right?" (1094al8-24, Ross trans.)

The purpose of this inquily, we are told, is to identily the chiel good. Knowledge of this good is supposed to be uscful or practical in the same way in which identifying a larget is useful or beneficial to an archer. In the remainder of Book I, we learn more about the chicf good; we find out that different kinds of things have different functions, and that what is good for each kind of thing is to perform its function well. Thus we learn that "the good of man is an activity of the soul in conformity with excellence or virtue." (I.7: 1098a15. Ostwald trans.) In book II, as we have seen in the previous 
section, we get an aceount of the nature of virtue and virtuous activity. ${ }^{20}$ Knowledge of the chief good, which includes knowledge of particulat virtues and the doctrine of the mean, is meant to be useful by way of setting at target for us to aim att.

It is important to realize that having a target to aim at is important not only in order to determine whether a shot is suecessful, but also in order to identify where those shots that miss the bull's eye hit relative to it. Indeed, knowing in what direction one missed the bull's eye is essential in order to calibrate the sights of one's weapon, or in order to be able to correct for one's mistakes in those shots that were unsuceessful. A qualified student for these lectures can already tell whether an atet is virtuous-i.e.. whether it hit the bull's eye-but without a target to aim at, she would not know in what way she missed the matk when she did-i.e., where those shots that missed the bull's eye hit relative to it -and what she needs to do in order to hit the matk in the future.

The allehery metaphor is instructive in another way. Having a target to aim at, though elearly helpful in hitting the mark, is not enough: we are not likely to hit the bull's eye consistently unless we practice the alt of archery. Yet the fact that we must practice archery in addition to identilying the target in order to be able to hit the bull's

${ }^{20}$ For an interesting discussion of the relationship between Aristotle's thoughts on eudaimonia in Book 1, and his theory of the moral virtues see Broadie (2006). Broadie identifies two levels of molal theorizing in Aristotle, which she dubs "atrehitectonic" and "ground-level" (or "guotidian"). The architectonic level is focused on the final goal of human activity-endaimonia-and its goal is to "articulate and implement the best arrangement overall for life in human socicty." (3.5l) Architectonic thinking, according to Broadie, is independent of any particular context. Instead, it is concerned with "lifeshaping arrangements that are hatd to reverse: those that make the context of everything else." (351) Ground-level practical thinking, in contratst, concerns practical thinking about particular actions within given contexts. According to Broadic "Arehitectonic thinking engaged in by Aristotle is first and foremost what is producing the whole inquiry ... the Iground-level] thinking that typifies the phromimos figures only as one of the subject matters ... |it is | part of [the architectonic] goal as correctly elucidated." $(351-2)$ 
eye does not undermine the practical signifieance of having a larget to aim atl, nor does it entail that learning to identily our target is not learning something of gleall pratctical import.

With these observations in mind, let us examine Aristotle”s comments ahout his practical ambitions more carcfully, starting with his comment in I.3:

Il a young man is not equipped to be a student of politics; for he hats no experience in the actions which lile demands of him, and these actions form the hasis and subject matter of the discussion. 12/ Moreover, since he follows his emotions, his study will be pointless and unprolitable, for the end of this kind of study is not knowledge but action. [3| Whether he is young in years or immature in chatracter makes no diflerence; for his deficiency is not a matter of lime but of living and of pursuing all his interests under the influence of his emotions. |4| Knowledge brings no benefit to this kind of person, just as it brings none to the morally weak. 15| But those who regulate their desires and actions by a rational principle will greatly benelit from a knowledge of this subject." (I.3: 1095:3-12 Ostwald trans.)

One reason why young men are not Aristolle's preferred atudience is their lack of experience [1], as we discussed in the previous section. But there is another reason: young men tend to follow their emotions. And this is why the study of ethics would not help them in action 121. Our goal is not merely theoretical; in order to become c'uderimon it is not enough to know that all our actions aim at emdermomia, or that we ought to ate virtuously, or even to know what virtue is. This knowledge might help us to achieve this goal. But this knowledge will not help us to become good if we do not put this knowledge 10 use, in much the same way that for an archer, having a talget fo aim at will not help her hit the bull's eye if she doesn't make use of the knowledge she gains by seeing where her missed shots hit relative to the bull's eye. One who is guided by one's emotions, like the weak willed person, is clearly not guided by one's knowledge, and consequently knowledge of why right actions are right, or why some actions that 
resemble virtuous actions are not virtuous, provides no practical benefits to those who act impulsively |4|. And this is no less true of adults who ale impulsively than it is of young men $|3|$.

Pace Joachim, I do not think that Aristotle believes that theoretical knowledge is worthless; instead, it seems to me that Aristotle thinks that theoretical knowledge has great instrumental value-alt least for certain kinds of people. Those whose actions can be guided by reason will greatly benefit from the knowledge they will gain from these leetures 15]. So Aristotle's practical goal is to provide knowledge to those people who ean put it to use, and he is well aware that not many people can do this:

Argument and teaching, I am afraid, are not effeclive in all cases: the soul of the listener must first have been conditioned by habits to the right kind of likes and dislikes... for a man whose life is guided by emotion will not listen to an argument that dissuades him, nor will he understand it. How ean we possibly persuade a man like that to ehange his ways? And in general it seems that emotion does not yield to argument but only to force. Therefore, there must first be a eharaeter that somehow has an affinity for excellenee or virtue, a eharacter that loves what is noble and feels disgust al what is base. (X.9: 1179b24-30, Ostwald trans.)

So proper students for these lectures must not only be able to identify virtuous actions, but they must also be the kind of persons who are motivated to become virtuous, and can overcome their emotions and "regulate their desires and actions by a rational principle."

It is worth noting that Aristotle says nothing that is incompatible with the thought that theoretical knowledge in ethics is intrinsically valuable. So given Aristotle's interests in theoretical knowledge in all other areas of inquiry, it is, perhaps. more platusible to read Aristotle as arguing that in so far as we are interested in acting well, theoretical knowledge has instrumental value. And although theoretical 
knowledge about matters of eonduct also has intrinsic value independent of its contribution to helping us to become endaimom, for the purposes of our enrrent inquiry we should focus on ils instrumental value.

In II.2. Aristolle discusses the unique practical purpose of the study of ethics:

|6| The purpose of the present study is not, as it is in other incuiries, the attainment of theoretical knowledge: 17 | we ate not eonducting this inquiry in order to know what virtue is. but in order to become good, else there would be no advantage in studying it. [8| For that reason, it becomes necessally to examine the problem of action, and to ask how they are to be performed. $|9|$ For, as we have said, the actions determine what kind of characteristics are developed. (1 103b26-30, Ostwald trans.)

Some inquiries are conducted solely for the sake of intellectual edification, yed this investigation has an additional goal |6|; in ethics and in politics we are also concerned with acting well. Since a significant portion of the Niconacherem Ethics is devoted to elucidating what virtue is, it is platusible to understand Aristotle's claim that "we are not conducting this inquiry in order to know what virtue is," ass salying that we are not conducting this inquiry me'rely in order to know what virtue is. Aristotle's comments in X.9 seem to support this interpretation:

The aim of studies about action, ats we saly, is surely not to study and know about a given thing, but rather to act on our knowledge. Hence knowing abomt vintue is not enomgh, but we must also try to possess and exercise virtue, or become good in any other way. (1 179b l-4, Irwin (rans. My ltallics)

Our goal is to become endainom, and knowledge of what virtue is, in so far as it is a means to this end, is advantageous 171. But even though knowledge in these matters might well be intrinsically valuable. its contribution to good conduct is not automatic. fn order to see how knowledge relates to action we must understand how alctions are performed |8|, and how actions relate to character and virtue $|9|$. 
In Il.t Aristotle turns to the question how virtuous actions are performed when

they are performed virtuously, and how such action atre related to the virtuous person's character:

[10| But in the calse of the virtues an act is not performed justly or with self-eontrol if the act itself is of al certain kind, but only if in addition the agent hals certain characteristics als he performs it: | $11 \mid$ lirst of all, he must know what he is doing; | 2 | secondly, he must choose 10 act the way he does, and he must choose it for its own sake; |13| and in the third place, the act must spring from a firm and unchangeable character...|14| In other words, alets ale called just and self-controlled when they are the kind of acts which a just and self-controlled man would perform: |15] but the just and self-controlled man is not he who performs these acts, but he who performs them in the way just and self-eontrolled men do. (1) 05 a129-b9. Ostwald trans.)

In this passage we learn that in order to become eudaimon it is not enough to perform virtuous actions, but we must perform these aclions virtuously |]0|. In order to act virtuously one must know what one is doing 111 ; one must choose the action one is perlorming for its own sake |12|, and. finally, the action must "spring from" one"s character |13]. So even though we were able to identify virtuous actions even before we began reading Aristotle's work, we now know that there is more to acting virtuously than performing virtuous actions | 141: we must learn how to perform these actions in the way that a virtuous person would perform them |15|. And this is exactly what Aristotle hopes to teach us.

Teaching people how to act virtuously is clearly a practical goal. Nevertheless, one of the requirements for acting virtuously is that one must know what one is doing: so at least some knowledge is required. Now it is not completely clear what knowledge Aristotle has in mind here, 21 but it seems platusible to read Aristotle as claiming that one

21 See, for instance, Talylor (2006), esp. pp. 83-94. 
must know why the action one is performing is right in order to act virtuously.

Aristotle's claim that knowledge is the least important condlition of the three eonditions he mentions ( $1105 \mathrm{~b} 2$ ) is compatible with this interpretaltion, sinee we can imagine people performing virtuous actions even though they lack knowledge of moral theory, and hence do not know why the right actions they perform are right. The knowledge requirement, it seems, can be compensilted for by ample experience, as Aristotle explains in V1.11:

We ought to pay as much attention to the sayings and opinions, undemonstrated though they are, of wise and experienced older men as we do to demonstrated truths. For experience hat given such men an eye with which they can see correctly." (1143b1 1-14, Osiwald, 1'ans.)

And igain in X.9:

Of course, there is probably nothing to prevent even a person with no scientific knowledge from taking good care of a particular case, if he has aceurately observed by experience what happens in a particular case, just as there are some who seem to be their own best physicians, even though they are incapable of giving aid to another. Nevertheless, if al man wants to master a skill or art of some theoretical knowledge, he ought, one would think, probably to go to a universal principle, and to gain knowledge of it as hest as possible. For, as we have stated, it is with this that the sciences are concerned. ( I 180hl6-23, Ostwald trans.)

While the knowledge requirement has "little or no importance" because it can be made up for by sufficient experience, the other requirements "count not for a little but are all-decisive." (1 105b3) One must act from a stable character in order to act virtuously, and clearly enough, one camnot develop the proper characteristics simply by engaging in philosophical theorizing:

| $16 \mid$ Thus our assertion that a man becomes just by performing just acts and self'-controlled by performing acts of self-control is correct: without performing them, nobody could ever be on the way to becoming good. 117| Yet most men do not perlorm such acts, but by taking refuge in argunent they think that they are engaged in philosophy and that they 
will become good in this way. $|18|$ ln so doing, they act like sick men who listen attentively, what the doctor salys, but lail to do any of the things he prescribes. $199 \mid$ That kind of philosophical aclivily will not bring health to the soul any more than this sort of treatment will produce a healthy body. (110.5b10-18, Ostwald trans.)

In order to develop the proper characteristics, one must form the right habits: and in order to form the right habits, one must engage in the right kinds of activities. So in order to develop a virtuous character one must perlorm virtuous actions |16|.

Philosophical theorizing is no substitute for genuine moral practice |17/. The failure of "those who take refuge in argument" is not that they seek theoretical knowledge, but that they wrongly believe that theorelical knowledge is all that is needed in order to become endaimon |17]. But theoretical knowledge is important-indeed. this knowledge is necessary, though not sufficient, for a healthy soul-since it provides us with a target to aim att. Aristotle's metaphor is, again, illuminating: a sick man must listen to what the doctor salys, and must also follow the doctor's instructions in order to get healthy. Our theoretical study is analogous to the doctor's orders |19|. And those who believe that theoretical knowledge is all that is reguired are akin to those who listen to the doctor but fail to follow the doctor's advice [18].

Recall that the qualified students for Aristotle's lectures can already identify right actions, and they can already tell apart virtuous actions from vicious ones. Yet although such students can typically know whether the actions they perform are right or wrong, they might not know why they have the normattive status they have, and consecpuently, they might not know what they need to do in order to act virtuously in the future. However, once they study Aristotle's lectures they will learn why right alcts are right, and consequently, they may understand why and how their actions that weren t 
right missed their matk, and why and how the acts they got right were sucecssful. If they understand in what way they missed their mark when they did, they maly be able to correct for these mistakes in the future. For example, while 1 might have known that my behavior in battle wals not virtuous, I can now know that it wasn I virtuous because I felt too much fear. I now know that in order to act virtuously l need to be less fearful and more confident, and I can choose to perform actions to help me to become less fearful. Likewise, I might have known that my act of donating $\$ 50$ to charity was not virtuous, but I now know that it wasn't virtuous because given my financial situation, I should have donalled more.

"It is no catsy lask to be good," Aristotle tells us in II.9,

for in everything it is no easy lask to find the middle, e.g. fo find the middle of a circle is not for every one but for him who knows; so, too, any one can get angry-lhat is easy-or give or spend money; but to do this to the right person, to the right extent. at the right time, with the right motive, and in the right way, that is not for every one. nor is it calsy. (1109a24-29, Rosis trans.)

Yet although becoming good is undoubtedly difficult, once we ale able to recognize how we go wrong when we do, we maly be able to fix it. And in 11.9 Aristotle gives us some practical advice on how we should do this. "Hence he who aims at the intermediate must first depant from what is the more contraly to it." (1109a31, Ross trans.) Since we can tell whether particular acts are virtuous, and since we now know why the virtuous acts are virtuous, we can tell that with respect to some virtues it is more common to err towards one extreme rather than the other (c.g., with respect to courage, it is more common to err in the direction of cowardice than it is to err in the direction of recklessness.) So it is reasonable to expect that we are likely to err in this direction as well. 
But of eourse, not all people ane alike. So it is important to pay attention to our

own inclinations: "But we must consider the things towards which we ourselves also are casily carried away: for some of us tend to one thing. some to another." (1109b2, Ross trans.) Since we can now identify where our action is relattive to the virtuous action, we can try to pull ourselves in the right direction: "We must drag ourselves away to the contraty extreme: for we shall get into the intermediate state by drawing well away from error, ats people do in straightening sticks that are bent." ( 1109 b5, Ross trans.) We do not have direct control over our emotions. so we eannot simply decide to feel less angry, for example, if we recognize that we are angrier than we ought to be. But we can choose not to act out of anger, and we ean paly attention to our emotion and try, as best we can, to calm down. "It is no easy task to he good," but presumably, if we understand the way in which we err when we do err, and if we are willing to focus our atlention on lrying to become good, it is not impossible to change our characteristics. "It is by doing this." Aristotle summarizes at the end of book II,

that we shall best be able to hit the mean. But this is no doubt difficult, and especially in individual cases; for it is not easy to determine both how and with whom and on what provocation and how long one should be angry ... such things depend on particulat facts, and the decision rests with perception. So much, then, is plain, that the intermediate state is in all things to be praised, hut that we must ineline sometimes towats the exeess. sometimes towards the deficiency; for so shall we most easily hit the mean and what is right. (1109b13-26. Ross trans.)

Aristotle's lectures equip us with theoretical knowledge that allows us to understand why right aet are right, and the ways in which actions can fail to be done virtuously. With this knowledge we can locate each action on the target relative to the bull"s eye-i.e., an action performed virtuously. Onee we locate an aetion relative to the bull's eye, we ean see why it is that we missed our matk, and consequently, we can lake 
measures to improve our suecess in the future. The measures we can take alle indirectwe camnot change our emotional responses and our character instantaneously by volitional fiat. But once we understand what kind of actions we need to perform in order to modify our emotional responses and chanacter in the right direetion, we alle more likely to hit the mark in the future. In this sense, then, the theoretical knowledge we gain from Aristotle's lectures is practically useful. Those who have had a decent upbringing should be able to identify right acts as right, and wrong ones as wrong. But although they can tell right from wrong they may not know in what ways the wrong actions are wrong, and what needs to be changed in order to make them right.

Nevertheless, if we understand why right actions alle right, and if we are the kind of people who can "regulate their desires and actions by rational principle," then Aristotle"s lectures could help us to become good.

\subsection{Aristotle and Moral Explanation}

I have argued that Aristotle offers an explanatory schema. If we are anked to explain why a particular act is right, we should identify the relevant scale and show that on this scale the action (or the relevant emotion) lies in the mean relative to the agenti.c. that the action (or emotion) in question is neither excessive nor deficient-and that the action was performed in the right time, towards the right people, with the right motive, and so forth. But why, one might ask, would this qualify as an explanation of the rightness of this action?

Now this is a difficult question to answer for several reasons. First, it is not elear what kind of an answer would be aceeptable. Perhaps what we need in order to answer this question is a theory of explanation. But as we have seen in Chapter Three, there is 
no agreement about what the correct theory of explanation is, or even on what conditions an explanation must satisfy. So any answer to this question is bound to be contentious.

Second, the question "Why is this an explanation?" is a question we could ask about any proposed explanation, and we could reiterate the questions with respect to whatever answer we receive to our original question. For example, consider some proposed explanation, $E$, of the rightness of some action, $A$. We could atsk, "Why is $E$ an explanation of the rightness of $A$ ?" Now suppose someone argued that $E$ is an explanation because it satisfies condition $C$. It seems that we could very well ask, "Why is the fulfillment of condition $C$ an explanation?" And surely, if one were to propose an answer to this question. we could reiterate again and ask, "Why is this an explanaltion?" It seems that at some point we would have to resort to a response of the form "This is just what an explanation is!"

So perhaps there is no reason to reject an answer of this kind to our original question. Consider: "Why does Aristotle's schema explain the rightness of an action?" "Because to show that an action lies in the mean relative to the agent, and that it is performed at the right time, with the right motives, and so forth, is just what an explanation of the rightness of an action is!" Indeed, although Aristotle doesn 1 explicitly talk in terms of explanations, we could read the Niconuchean Ethics ats olfering a theory of explanation of rightness and wrongness of actions. Moreover, by explieating the considerations that led Aristotle to deline virtue as he did, and the relationship he identifies between virtuous activily and e'nderimonia, we could, perhaps. alleviate some of the dissatisfaction with this kind of response, since this would 
demonstrate that the explanatory schema Aristotle put forward is the product of a comprehensive theoretical framework.

But maybe we could saly a bit more in order to motivate the elaim that a properly filled out schema of the form I proposed on behalf or Aristotle is explanatory. An explanation to the effect that a particulat action is right entails that any action that is relevermly similar to this one must atso be right. But while in the physical sciences we can somelimes (maybe often) specify in practically useful terms the conditions under which objects or situations are "relevantly similar," in ethics, and perhaps in the social sciences in general, we camnot do this: "The decision depends on the particular fatets and on perception." (IV: I126b4, Ross trans.)

Nevetheless, Aristotle might endorse a generalized principles like this: a particular action, $A$, is right for a particular agent, $P$, in situation $S$, if and only if, $A$ would be a right action for anyone relevantly like $P$ in any situation relevantly like $S$. And perhaps the explanatory schema I proposed on behall of Aristotle allows us to identify the ways in which actions, situation, and agents are relevantly similar with respect to the rightness of actions. Thus, although we camnot eapture these kinds of similarities with a set of exeeptionless generalization expressed in practically useful terms. we can formulate a schema that would enable those who have been brought up well to explain the ways in which right actions are similat to one another.

Now since we know that if an action is right. then there is some seale on which it is in the mean, we also know that if there is no seale on which an action is in the mean. then the action is wrong. Nevertheless. Aristotle's proposed explanatory schema in its general form is almost vacuous. And Aristotle, as we have seen, is well aware of this 
fact: he thinks that simply stating the schema in its general form doesn't explain much (VI.1: 1138b19-35, cited ahove). Only when we find the relevant scale on which the action lies in the mean, and when we replace the schematlic hedges with particulat fealures of the case in hand, will we have a genuine explanation.

\subsection{Conclusion}

Aristotle's is not trying to answer the moral skeptic. For Aristotle, our starting points for moral theorizing are the normative statuses of actions, in much the same way as our starting points for theorizing about motion are the ways in which particular bodies move, and our starting points for theorizing about history are historical events. The theories we construct in our attempts to explain the motion of bodies, for example. try to answer questions like these: "Why do bodies move as they do?" Or "Why does this particular body moves as it does?" We are not trying to answer the question whether an object moves as it appeass to move; that it moves ats it appears to move is our starting point. Similarly, when we try to explain past events-say, why a particulat battle oceurred when it did, and unfolded ats it had-we are not trying to answer the question whether this battle actually took place; that the battle took place when it did is our starting point. Similarly, when we try to explain why a particulat action is right, we are not asking whether it is right: that the act is right is part of our datal. And Aristolle's lectures are aimed towards students who can correctly identify right actions ats right.

Yet although Aristotle's preferred students can correctly identify right and wrong actions. Aristotle thinks that his lectures could help such students to become good. Given the data about right and wrong actions, Aristotle constructs a theory that enables his students to understand the ways in which wrong actions miss their mark. 
Surely, if one's judgments about rightness of actions are mistaken, one's judgments about the way in which various actions miss their mark are bound to be wrong as well. Nevertheless, those who have had proper moral upbringing- hose who have formed the right habits, who can identify right acts when they see them, who can control their actions by rational principle, and who have the right likes and dislikes-can profit from Aristotle's lectures. They would learn what an explanation of the rightness of actions ought to look like, and they would learn how to correctly substitute the generie features of the explanatory schema with the relevant particular features of the actions they evaluate. Moreover, by recognizing the ways in which their own actions miss their mark when they do, they coukd choose to perform actions that will help them acquire the right habits in order to hit the matk in the future.

Aristotle's explanation of the rightness of particular actions is not based on the availability of exceptionless moral principles. Aristotle believes that the moral landscape is extremely complex, and that there is very litlle we could saly about morality by way of exeeptionless universally quantified statements. Nevertheless, this does not mean that we cannot discuss moral phenomena intelligibly, or that we cannot construct explanatory moral theories, as Aristotle's Nicomacheom Ethics so aptly illustrates. This, I believe. provides a direct demonstration that particularism is a viable research program. Indeed, if my proposed interpretation of Aristotle is plausible, then the most influential moral theory in the history of philosophy is, arguably, a particularist theory. 


\section{BSIBLIOGRAPHY}

Achinstein, P., (1983) The Natme of Explanation (Oxlord University Press)

(1971) Law and Explanotion: An Essay in the Philosophy of Science (Oxford Universily Press)

Ankersmith, F. and Kellner, H., (eds.) (1995) A New Philosophy of History (The University of Chicago Press)

Anscombe. G. E. M., (1958) 'Modern Moral Philosophy' Philosophy 33:1-19

Anton, J. P. and Preus, A., (eds.) (1991) Essons in Ancient Greek Philosophy IV: Aristotle's Etlines (State University of New York Press)

Arpaly, N., (2003) Unprincipled Vintme: An Inquiry into Moral Ageney (Oxford Universily Press)

Audi, R., (2006) 'Ethical Generality and Moral Judgment', in Dreier (2006) pp. 28.5304

(2004) The Good in the Right: A Theory of Intwition and Intrinsic Vahe

(Princeton: Princeton University Press)

Bakhurst. D., (2005) 'Panticularism and Moral Education' Philosophical Explorations, $8: 265-279$

Bales, R. E., (1971) 'Act-Utilitarianism: Account of Right-making Characteristics or Decision-Making Procedure?’ American Philosophical Quarterly 8:257-265

Bartley, W. W., (1962) 'Achilles, the Tortoise, and Explanation in Science and History', The British .lommal for the Philosophy of Scicnce, 13(49):15-33

Baum, R., and Shechan, W. (1997) In Search of Planet Vulcan (Basic Books)

Beall, J. C., (ed.) (2007) The Re'enge of the Liar (Oxford University Press)

Bennell, J., (1974) 'The Conscience of Huckleberry Finn', Philosophy' 49:123-134

Borges, J. L., (1998) Collected Fïrtions (Penguin Books)

Broad, C. D., (1930) Five Types of Moral Theories (Routledge \& Kegan Paul)

Broadic, S., (2006) "Aristotle and Contemporary Ethics", in Kraut (2006) pp. 342-361

----- (1991) Ethics with Aristotle (Oxford University Press)

Broadie, S. and Rowe, C., (2002) Aristotle Nicomacheom Ethics: Trams/ation. Introdnction, and Commentary (Oxford University Press) 
Brody, B.. (ed.) (1988) Moral Theory and Moral Indgenent in Medical Etlries (Kluwer Academic Publishers)

Bromberger, S., (1966) "Why Questions", in Colodny (1966) pp. 86-111

Burnyeat, M. F., (1980) 'Aristotle on Learning to be Good', in Rorty (1980) pp. 69-92

Carroll, J., W., (2003) 'Laws of Nature', The Stanford Encrelopedien of Philosopley. Zalta, E. N., (ed.), URL = <hıtp://plato.stanford.edu/entries/laws-of-nature/>

Cartwright, N., (2002) "In Favor of Laws that are not Ceteris Paribus After All", Erkennmin, 57:425-439.

----- (1989) Nenme's Capuritic's and Their Measmrements (Oxford Universily Press) (1983) How the Lan's of Physics Lie (Oxford University Press)

Colodny, R. G., (ed.) (1966) Mind and Cossmos: Essans in Comemporary Srience and Plirlosophy. (University of Pittsburgh Press)

Copp, D., (ed.) (2006) The Oxford Hendhook of Ethical Theory (New-York: Oxford University Press)

Crisp, R., (20(07) 'Ethics Without Reasons?’, Jomrnal of Moral Philosophly, 4(1):4()-40

----- (2000) 'Particularizing Particularism', in Hooker' and Little (2000) pp. 23-47

(ed.) (1996a) How Shonld One Live?" Essegss on the Virmes (Oxford University Press)

---- (1996b) 'Modern Moral Philosophy and the Virtues', in Crisp (1996a) pp. 1-18

Crisp, R., and Slote, M., (eds.) (1997a) Virme Ethics (Oxford University Press)

----- (1997b) 'Introduction', in Crisp and Slote pp. 1-25

Cruzer, H. J., (1996) 'Aristotle's Bad Advice about Becoming Good', Philosophy. $71: 139-146$

Cullity, G., (20)2) 'Particularism and Presumplive Reasons" Proceselings of the' Aristotelian Society, suppl. 76:169-190

Dancy, J., (2007) 'Defending the Right', Iomrmal of Moral Philosophy: 4:85-98

(2005) "Moral Particularisn", The Stanford Encyelopedia of Philosophy (Summer 20(05 Edition), Edward N. Zalta (ed.), URL = <http://plato.stanford.edu/archives/sum2005/entrics/moral-particularism/>.

----- (2004) Ethics Withom Principles (Oxford: Clarendon Press) 
----- (2003) 'What Do Reasons Do'?. The Southern Journal of Philosoply, 41:95-11.3

----- (2000) 'The Particularist's Progress', in Hooker and Little (2000) pp. 1.30-1.56

----.-(1999) 'Defending Particularism', Me'taphilosophy, 30:25-32

----- (1993) Moral Reasons (Blackwell Publishers)

----- (1992) 'Externalism for Internalists' Philosophical lssnes, 2:93-114

-.--- (1991) 'An Ethic of Prima Facic Duties’ in Singer (1991) pp. 219-229

-....-(1991) 'Intuitionism' in Singer (1991) pp. 411-420

----- (1983) 'Ethical Particularism and Morally Relevant Properties’, Mind, 92:530-547

-...-. (1981) 'On Moral Properties', Mind, 90:367-385

Danto, A. C.. (1995) 'The Decline and Fall of the Analytical Philosophy of History', in Ankersmil and Kellner (1995) pp. 7()-85

Degler, C. N., (1963) 'Do Historians Use Covering Laws?', in Hook (1963) pp. 205211

Dray, W., (el.) (1966) Plitosophical Analysis and History (Harper \& Row Publishers)

---- (1959) "Explaining What" in History", in Gardiner (1959) pp. 402-408

(1957) Laws and Explanation in History (Oxford: Clarendon Press)

(1954) 'Explanatory Narrative in History', The Philosophical Quarterly, 4(14):1527

Dreyfus. H. L., and Dreyfus, S. E., (1990) 'What is Morality? A Phenomenological Account of the Development of Ethical Expertise' in Rasmussen (1990) pp. 237 264

Dreier, J., (ed.) (2006) Comtemporary Delbates in Moral Theory (Blackwell Publishing)

Ducasse, C. J., (1940) 'The Nature and Function of Theory in Ethics', Ethics. 51(1):2237

Dworkin, G.. (1995) 'Unprincipled Ethics', Midwest Studies in Philosoply', vol. 20: Moral Concepts, 224-2.39

Earman, J., Roberts, J., and Smith, S., (20)2) 'Ceteris Paribus Lost' Erkennmis $57: 281-3() 1$ 
Earman, J., and Roberts, J., (1999) "Coneris Paribus, There is No Problem of Provisos" Syatlese $118: 439-478$

Fara, M.. (2006) 'Dispositions', The Stanford Encyclopedia of Philosophly. Zallat. E. N., (ed.). URL $=<$ http://plato.stanford.edu/entries/dispositions/s

---- (2005) 'Dispositions and Habituals', Not̂s, 39:43-82

Fay, B., Golob, E. O., and Vamn, R. T., (eds.) (1987) Lomis O. Mink: Historical Understanding (Comell University Press)

Feigl. H., and Maxwell, G., (eds.) (1962) Minnesone Studies in the Philosophỵ of Srience, Vol. 3: Srientific Eyplanation, Spare, and Time (Minneapolis: University of Minnesota Press)

Feldman, F., (2006) 'Actual Utility, The Objection from Impracticality, and the Move to Expected Utility', Philosophicoll Studies, 129:49-79

----- (1978) Introductory Ethics (Prentice Hall)

Fodor, J., (1991) "You Can Fool Some of the People All of the Time. Everything Else Equal: Hedged Laws and Psychological Explanations", Mind 100:19-34

-..-- (1989) 'Making Mind Matter More', Philosophical Topic's. 17:59-79

Frazicr, R. L., (1995) 'Moral Relevance and Ceteris Paribus Principles", Ronio, 8:113125

----- (1994) 'Act-Utilitarianism and Decision Procedures", Utilitas, 6:43-53

Gardiner, P., (ed.) (1974) The Philosophy of History (Oxford University Press)

----- (ed.) (1959) Theories of History (The Free Press)

Gass, W. H., (1957) "The Case of the Obliging Stranger", The Philosophrical Review', $66(2): 193-204$

Glymour, C., (2002) "A Semantic and Methodology for Ceteris Paribus Hypotheses". Erkemulnis, 57:395-405

Haidt, J., (2001) 'The Emotional Dog and its Rational Tail: A Social Intuitionist Approach to Moral Judgment’, Psychological Revien', 108:814-834

Hall, A., (1894) 'A Suggestion in the Theory of Mereury' Astronomical Jomrnal, 14:4951

Harcourt, E.. (2007) 'Crisp's "Ethics Without Reasons?": A Note on Invariance", Jommal of Moral Philosoply, 4:50-54 
Hare, R. M.. (1952) The Language of Morals (Oxford: Clarendon Press)

Harman, G., (2000) 'The Nonexistence of Character Traits' Proceedtingss of the' Aristotelian Society, 100:223-226

--.-- (1999) 'Moral Philosophy Meets Social Psychology: Virtue Ethies and the Fundamental Attribution Error'. Proceedings of the Aristotelian Society 99:315331

Halyek. F. A.. (1967) Studies in Philosophy, Politics, and Economics (Routledge \& Kegan Paul)

Hébert, P. C.. (1996) Doing Right: A Practical Guide to Ethics for Medical Trainees and Physicians (Oxford University Press)

Hempel, C. G., (1965a) 'Aspeets of Scientific Explaration' in Hempel (1965b) pp. 331496

--- (1965b) Aspects of Scientific Explanation and Other Essays in the Philosophy of Science (Free Press)

---- (1942) 'The Function of General Law in History', The .Ionrnal of Pliilosophy', $39: 35-48$

Hempel, C. G., and Oppenhein, P., (1948) 'Studies in the Logic of Explanation" Phitosophy of Science, 15(2):135-175

Hofweber, T.. (2007) 'Validity, Paradox, and the Ileal of Deductive Logic', in Beall (2008) pp. $145-1.58$

Holton, R., (2002) 'Principles and Particularisms', Proceedings of the Aristotelicm Socicty, suppl. 76:191-210

Hook. S.. (ed.) (1963) Philosophy and History: A Symposinm (New York University Press)

Hooker, B., (2000) 'Moral Particularism: Wrong and Bad', in Hooker and Little (2000)) pp. $1-22$

Hooker. B., and Little, M., (eds.) (2000) Moral Particnlarisn (Oxford: Oxford University Press)

Hurstouse, R., (1999) On Virtne Ethics (Oxford University Press)

----- (1980) 'A False Doctrine of the Mean', Proceedings of the Aristotelian Society. $81: 57-72$

Irwin. T., H.. (2000) 'Ethics as an Inexact Science: Aristotle's Ambitions for Moral Theory', in Hooker and Little (2000) pp. 100-129 
(1999) Aristonle Nicomadrean Enhics: Tramslated with Introdurtion. Notes, and Glossary, $2^{\text {nd }}$ (elition (Hackett Publishing Company)

(1978) 'First Principles in Aristotle's Ethics', Mirluest Shudies in Philosophy.

$3: 252-272$

Jackison, F., Pettit, P., and Smith, M., (2000) 'Ethical Patrticularism and Palterns', in Hooker and Little (2000) pp. 79-99

Joachim, H. H., (1951) Aristolle: The Niconracheam Ethics (Oxford University Press)

Jonsen, A. R., \& Toulmin, S., (1988) The Abuse of Casmisty (Berkeley: University of California Press)

Kincaid, H., (1990) 'Defending Laws in the Social Sciences" Philosophly of Sorial Srience 20:56-83

Kirchin, S., (2007) 'Moral Particularism: An Introduction', Jomrnal of Moral Philosophy, 4:8-15

----- (2007) "Pallicularism and Defiault Vallency". Jommal of Moral Philosophly. 4:1632

Kitcher, P., (1981) 'Explanatory Unification', Philosophy' of Srience', 48:507-5.31

Kitcher, P. and Salmon. W.. (1987) 'Van Fratassen on Explanation'. The denrmal of Pliklosophy, 84:315-330

Körner, S., (ed.) (1975) Explanation (Yale University Press)

Kraut, R.. (ed.) (2006) The Blackwe'l Guide to Aristonle's Nicomacheom Ethics (Blackwell Publishing)

Ladkl, J., (1952) 'Ethics and Explanation', The Jomrnal of Philosophy', 49(15):499-504

Lakatos, I., (1970) 'Falsification and the Methodology of Scientific Research

Programmes, reprinted in Warrall and Curric (1978) pp. 8-101

Lange, M., (2002) "Who's Afraid of Ceteris Paribms Laws? Or: How I Leaned to Stop Worrying and Love Them' Erkennmis 57:407-423

(2000) Namral Laws in Sciemifir Practice (Oxford University Press)

Lance, M., and Little, M., (2007) 'Where the Laws Are', in Shafer-Landau (2007) pp. 149-171

(2006a) 'Particularism and Antitheory', in Copp (2006) pp. 567-594

(2006b) 'Defending Moral Particularism' in Dreicr (2006) pp. 305-321 
(2004) 'Defeasibility and the Normative Grasp of Context', Erkenmmis, 61:4.35455

Laudan. L., (1977) Progress and its Problems (Berkeley: University of California Press)

Lemman, J., (2000) 'Consequentialism and Cluelessmess", Philosophly and Puhlic Affritis, 29:342-370

Lipton, p., (1999) 'All Else Being Equal', Philosophly', 74:15.5-168

Little. M. O., (2001) 'On Knowing the 'Why:' Particularism and Moral Theory', Hastings Center Re'port, 32-40

-..-. (2000) 'Moral Generalism Revisited', in Hooker and Little (2000) pp. 276-304

Louden, R. B., (1991) 'Aristotle's Practical Particularism', in Anton \& Preus (1991) pp. 159-178

MacIntyre, A., (1981) Afier Virluc: A Study in Moral Theory (University of Notre Dame Press)

Mandelbaum. M., (1962) "Historical Explanation: The Problem of "Covering Laws". History' and Theory, 1(3):229-242

Matthews. G. B.. (1999) Socratic Perplexity and the Natme of Philosoplyy (Oxford University Press)

McDowell, J.. (1988) 'Comments on T. H. Irwin's 'Some Rational Aspects of Incontinence"”. The Somliern Jomrnal of Philosophy. Supp. 27:89-102

----- (1979) 'Virtue and Reason' in Crisp \& Slote (1997) pp. $141-162$

McGrath. S., (2004) 'Moral Knowledge by Perception' Philosoplical Perspectives. 18:209-228

McIntyre, L. C.. (1996) Lans and Explanation in the Social Sriences: Defending a Srience of Humam Belmavior (Westview Press)

McKeever, S., and Ridge, M., (2007) 'Turning of Default Reasons', Jomrmal of Moral Philosoplig. 4:55-76

-.--- (2006) Principled Enhics: Generalisun as a Regulative Ideal (Oxford: Clarendon Press)

----- (2005a) 'The Many Moral Particularisms', Cancolian Jomrnal of Ploilosophy, 35:83-106 
----- (2005b) 'What Does Holism Have to do with Moral Particularism?', Ratio, 18:9310.3

McNaughton, D., (1998) 'Ross, W.D.' in E. Craig (Ed.), Rourledge Encyclopedia of Philosophy (Routledge) Retrieved June 14. 2008, from http://www.rep.routledge.com/article/L128

McNatughton, D., (1988) Moral Vision (Blackwell Publishing)

McNaughton, D., and Rawling, P., (200()) 'Unprincipled Ethics", in Hooker" and Little (200()) pp. 256-275

Mill, J. S., (2002) (originally published in 1861 ) Urilitarianisu (Hackett Publishing Company)

Montague, P., (1986) 'In Defense of Moral Principles", Philosopliveal and Phe'momenologiral Ressearr/, 46:643-654

Morreau, M., (1999) 'Other Things Being Equal', Philosophical Sindies, 96:16.3-181

Mumford, S., (1998) Dispositious (Oxford University Press)

Murray, T. H., (1996) 'Attending to Particulars' The' Hastiugs Conter Report, 26:29-30

Norman, R., (2007) 'Particularism and Reasons: A Reply to Kirchin', Jommal of Moral Philosophy, 4:33-39

Oakley, J., (1996) "Varictics of Virtuc Ethics", Ratio, 9:128-152

Ostwald, M.. (trans.) (1962) Aristotle: Niromarle'an Ethics (Macmillan Publishing Company)

Pears, D., (1980) 'Courage as a Mean', in Rorty (1980) pp. $171-188$

Peitroski, P. M.. (1993) 'Prima Facic Obligations, Cetcris Paribus Latws in Moral Theory', Ethics, 193:489-515

Pietrosky, P., and Rey, G., (1995) 'When Other Things Aren't Equal: Saving Ceteris Paribus Laws from Vacuity", British Jommal for the Philosophy of Srience 46:81-110

Pincolfs, E., (1971) 'Quandary Ethics', Mind, 80:552-571

Pitt. J. C., (ed.) (1988) Theories of Explanation (Oxford University Press)

Railton, P., (1984) 'Alienation, Consequentialism, and the Demands of Morality',

Philosophy and Public Affairs, 13:134-171

(1981) 'Probability. Explanation, and Information', Syuthese, 48:233-256 
Rasmussen, D., (1990) Universalism is. Commmmitarianism (The MIT Press)

Ril\%, J.. (2006) "The Problem wilh Particularism (Dancy"s Version)", Mind, 115:99-120)

Reed, T. M., and Brown, A. L., (1984) 'On the Rational Rejection of Utilitarianism and the Limitations of Moral Principles'. Iommal of Valne Lnquiry, 18:227-232

Roberts, R. C. (1991) 'Virtues and Rules'. Philosophy and Phenomenological Rescarch, 60:325-343

Robinson, L., (2006) 'Moral Holism, Moral Generalism, and Moral Dispositionalism', Mind. $115: 331-360$

Rorty, A. O., (ed.) (1980) Essutys on Aristotle's Ethic's (University of California Press)

Ross, W. D., (1930) The Right And The Good (Oxlord: Clarendon Press)

Roth, P., (1988) 'Narrative Explanation: The Case of History', History and Theory, $27: 1-13$

Ruben. D. H., (1990) Exp/aining Explamation (Routledge)

Salmon. W. C. (1989) Fonr Decales of Scientifir Explanation (University of Minnesota Press)

---- (1971a) 'Statistical Explanation' in Salmon (1971b) pp. 29-87

(ed.) (1971b) Statistical Explanation and Statistical Reletance (University of Pitusburgh Press)

Schrenk, M., (2007) The Metaphysics of Ceteris Parihus Law's (Ontos Verlag)

Schur\%, G., (2002) 'Ceteris Paril)us Laws: Classification and Deconstruction'. Erkenntmis, 57:351-372

----- (2001) 'Peitroski and Rey on Ceteris Paribus Laws', The British Jommal for the Philosophy of Science, 52:359-370

Scriven, M., (1962) 'Explanations, Predictions, and Laws', in Feigl and Maxwell (1962) Pp. 17()-230

----- (1959a) 'Explanation and Prediction in Evolutionary Theory', Scicnce' 130:477482

----- (1959b) 'Truisms as the ground for historical explanations' in Gardiner (1959) pp. $443-475$

Shafer-Landau, R., (ed.) (2007) Oxford Studies in Metathics: Vol. II (Oxford University Press) 
--.-- (1997) 'Moral Rules', Ethic:s, 107:584-611

Shiffer, S., (1991) 'Coleris Parilms Laws', Mind 100:1-17

Silverberg, A., (1996) 'Psychological Laws and Non-Monotonic Logic", Erkenmmis, $44: 199-224$

Singer, P.. (ed.) (1991) A Companion to Elhics (Blackwell Publishing)

Simnotl-Armstrong. W., (1999) 'Some Varieties of Particularism", Melaphilosophỵ, 30:1-12

Smilh. H. M., (1988) 'Making Moral Decisions', Nô̂s 22:89-108

Stangl, R., (forthcoming) 'A Dilemma for Particularist Virtuc Ethics", The Philosophrical Quarterly

Stratton-Lake, P., (ed.) (2002) Entrical Imtritionism: Re-elvahation (Oxford: Clatrendon Press)

---.- (2000) Kaml, Duty and Moral Worlh (Roulledge)

Strong, C., (1988) 'Justilication in Ethics', in Brody (1988) pp. 193-211

Sunstein, C. R., (2005) 'Moral Heuristics', Behenvioral and Brain Scrence, 28:531-573

Swanton, C., (2001) 'A Virtue Ethical Account of Right Action”, Eshic's, 1 12:32-52

Tännsjö, T., (1995) "In Defence of Theory in Ehics", Cancrdian Jommal of Philosophy, 25:571-.594

Taylor, C. C. W., (2006) Aristonle: Niromalleam Elhics Books II-IV (Clatendon Press)

Taylor, R., (1988) 'Ancient Wisdom and Modern Folly', Midu'est Studies in Philosophy, 13:54-63

Thomas, A., (2007) 'Praclical Reasoning and Normative Relevance: A Reply to McKeever and Ridge", Jommal of Moral Philosophy', 4:77-84

Toulmin, S., (1981) 'The Tyranny of Principles', The Hastings Center Report, 11:31-39)

Urmson, J. O., (1973) 'Aristotle's Doctrine of the Mean', reprinted in Rorty (1980) pp). $157-170$

van Fraassen. B. C., (1980) The Scientific Image (Oxford: Clarendon Press)

Väyrynen, P., (2006) 'Ethical Theorics and Moral Guidance', Utilitas, 18:291-309 
----- (2004) 'Particularism and Default Reasons', Ethical Theory and Moral Practice. 7:53-79

Velleman, D., (2003) 'Natrative Explanation' The Philosophlical Review', 112(1):1-25

Waide, J., (1988) 'Virtues and Principles', Philosophly' and Plénomenological Resecurch, 48:455-472

Weingartner, R. H., (1961) 'The Quarrel about Historical Explanation' The Jonrulal of Philosophy, 58:29-45

Wiggins, D., (1975) 'Deliberation and Practical Reason', reprinted in Rorty (1980) pp. $221-240$

Winch, P.. (1972) Ethic's and Action (Routledge \& Kegan Paul)

----- (1965) 'The Universalizability of Moral Judgments', in Winch (1972) pp. 151-170

Woodward. J.. (2003a) Making Things Happen (Oxford University Press)

----- (2003b) 'Scientific Explanation'. The' Stenford Encyclopedia of Plitosophy (Simmuer 2008 Edition), Edward N. Zaltal (ed.). URL = <http://plato.stanford.edu/archives/sum2003/entries/scientific-explanation/>.

---- (2002) 'There is No Sueh Thing as Ceteris Paribus Law', Erkennmuis 57: 303-328

Worrall, J., and Currie, G., (eds.) (1978) Imre Lakatos Philosophical Papers Vol. I (Cambridge: Cambridge University Press)

Zimmerman, M., J., (1996) The Concept of Moral Obligation (Cambridge University Press) 





